\title{
Absence Epilepsy and Panayiotopoulos Syndrome
}

Citation for published version (APA):

Fonseca Wald, E. L. A. (2020). Absence Epilepsy and Panayiotopoulos Syndrome: Neurocognition and Brain Development. [Doctoral Thesis, Maastricht University]. Drukkerij Walters. https://doi.org/10.26481/dis.20200306ef

Document status and date:

Published: 01/01/2020

DOI:

10.26481/dis.20200306ef

Document Version:

Publisher's PDF, also known as Version of record

\section{Please check the document version of this publication:}

- A submitted manuscript is the version of the article upon submission and before peer-review. There can be important differences between the submitted version and the official published version of record.

People interested in the research are advised to contact the author for the final version of the publication, or visit the DOI to the publisher's website.

- The final author version and the galley proof are versions of the publication after peer review.

- The final published version features the final layout of the paper including the volume, issue and page numbers.

Link to publication

\footnotetext{
General rights rights.

- You may freely distribute the URL identifying the publication in the public portal. please follow below link for the End User Agreement:

www.umlib.nl/taverne-license

Take down policy

If you believe that this document breaches copyright please contact us at:

repository@maastrichtuniversity.nl

providing details and we will investigate your claim.
}

Copyright and moral rights for the publications made accessible in the public portal are retained by the authors and/or other copyright owners and it is a condition of accessing publications that users recognise and abide by the legal requirements associated with these

- Users may download and print one copy of any publication from the public portal for the purpose of private study or research.

- You may not further distribute the material or use it for any profit-making activity or commercial gain

If the publication is distributed under the terms of Article $25 \mathrm{fa}$ of the Dutch Copyright Act, indicated by the "Taverne" license above, 
Absence Epilepsy and Panayiotopoulos Syndrome: Neurocognition and Brain Development

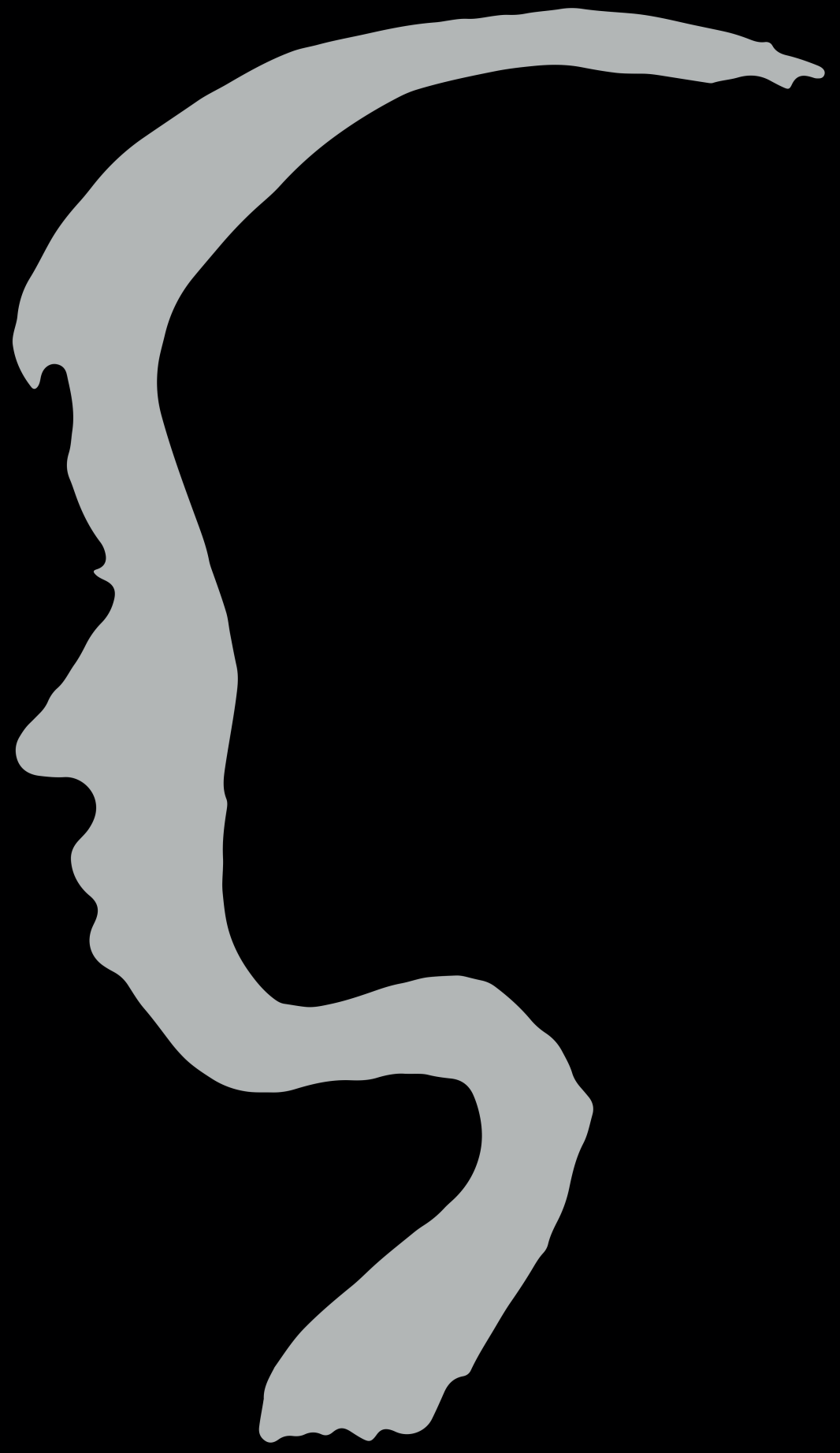

Eric Fonseca Wald 
Absence Epilepsy and Panayiotopoulos Syndrome:

Neurocognition and Brain Development

Eric Fonseca Wald 
(c) E.L.A. Fonseca Wald, Maastricht 2020

ISBN/EAN: 978-94-6380-719-7

Cover design: E.L.A. Fonseca Wald

Lay-out: E.L.A. Fonseca Wald

Print: Drukkerij Walters, Maastricht

The research described in this thesis was funded by:

Academic Centre for Epileptology (Maastricht University Medical Centre+ and Kempenhaeghe Epilepsy Centre) and Stichting Vooruit

The printing of this thesis was financially supported by Maastricht University and $\mathrm{SBOH}$, employer of GP trainees. 


\title{
Absence Epilepsy and Panayiotopoulos Syndrome: Neurocognition and Brain Development
}

\author{
PROEFSCHRIFT
}

ter verkrijging van de graad van doctor aan de Universiteit Maastricht, op gezag van Rector Magnificus, Prof. dr. Rianne M. Letschert, volgens het besluit van het College van Decanen, in het openbaar te verdedigen op vrijdag 6 maart 2020 om 10.00 uur

door

Eric Leonardo Agustin Fonseca Wald 


\section{Promotor}

Prof. dr. R.J. Vermeulen

\section{Copromotores}

Dr. M.H.J.A. Debeij-van Hall (Kempenhaeghe, Heeze)

Dr. J.G.M. Hendriksen (Kempenhaeghe, Heeze)

Dr. S. Klinkenberg

\section{Beoordelingscommissie}

Prof. dr. H.J.M. Majoie, voorzitter

Prof. dr. O.F. Brouwer (UMC Groningen)

Dr. V.H.J.M. van Kranen-Mastenbroek

Prof. dr. L. Lagae (KU Leuven)

Prof. dr. R.W.H.M. Ponds 




\section{Contents}

1 General introduction and outline of the thesis

2 Towards a better understanding of cognitive deficits in absence epilepsy: a systematic review and meta-analysis

3 Cognitive development in absence epilepsy during long-term follow-up

4 Lower myelin-water content of the frontal lobe in childhood absence epilepsy

5 Neurocognitive and behavioral profile in Panayiotopoulos Syndrome

6 General discussion

7 Summary 155

$8 \quad$ Nederlandse samenvatting

$9 \quad$ Valorization

Dankwoord

Curriculum Vitae 181

List of Publications 


$$
5
$$


General introduction 
Chapter 1 


\section{Introduction}

\section{Epilepsy}

Epilepsy consists of a wide range of disorders and occurs in all ages. In children, epilepsy is one of the most prevalent serious neurological disorders, with an incidence rate of $41-50$ per 100.000 in developed countries (1). It is currently viewed as a disorder of the brain characterized by an enduring predisposition to generate epileptic seizures and by the neurobiologic, cognitive, psychosocial, and social consequences of this condition (2).

Epileptic seizures are defined as a transient occurrence of signs and/or symptoms due to abnormal excessive or synchronous neuronal activity in the brain (2). Seizure semiology refers to the clinical signs and symptoms during an epileptic seizure. Broadly speaking, seizure or epilepsy types are currently classified as either generalized, i.e. originating from bilateral distributed networks, or focal, i.e. originating from neural networks limited to a part of one cerebral hemisphere (3, 4). In some this distinction is unknown and in others, both focal and generalized seizures may co-exist $(3,5)$. Furthermore, seizures are classified by the presence or absence of motor manifestations and in the case of focal seizures whether awareness is retained or impaired (3).

The most important tool in the diagnostic work-up is the electroencephalogram (EEG). An EEG is used to assess and locate epileptiform activity in the brain. Additional investigations such as video observation, imaging studies, metabolic and genetic testing may also be required to make a definitive diagnosis. Other investigations, such as a neuropsychological assessment may be needed to establish the degree of comorbidities.

Depending on the type(s) of seizures or epilepsy in a patient this may resemble an epilepsy syndrome, which is a complex of clinical features that define a unique epilepsy condition $(1,5)$. An epilepsy syndrome often includes features as the age of occurrence, seizure triggers, treatment options, remission rates, diurnal variation, co-morbidities and sometimes prognosis (5). 


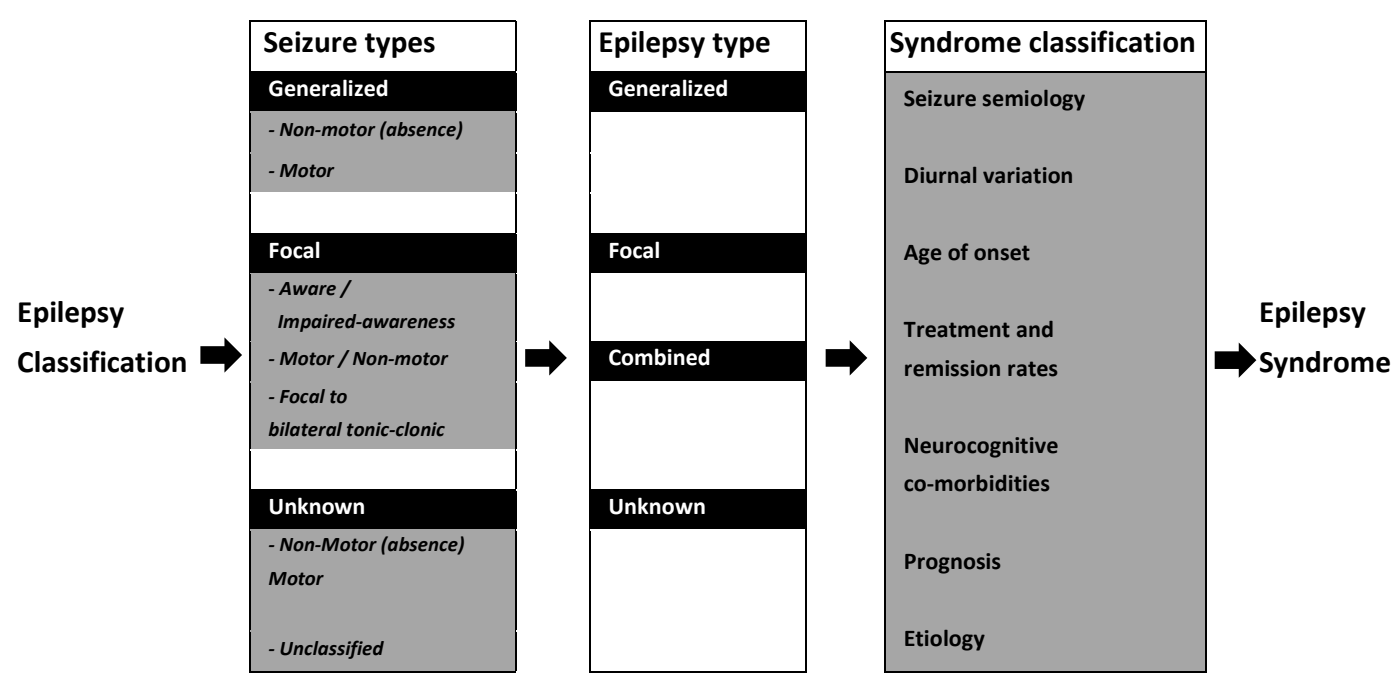

Figure 1. Framework for classification of epilepsy.

Adapted from Fisher et al. (2017) \& Scheffer et al. (2017)

Benign epilepsy syndromes are characterized by epileptic seizures that require no treatment or are easily treated in the majority of cases and remit without sequelae, as opposed to epileptic encephalopathy which is characterized by a progressive disturbance in cerebral function (1). Epileptic encephalopathy is mostly reserved for very severe epilepsy syndromes, however, encephalopathic effects above and beyond what is expected from the underlying pathology alone might occur in other types of epilepsy as Berg et al. stated (6). Idiopathic epilepsy syndromes are thought to have a hereditary predisposition, although no assignable cause or underlying structural brain lesion is present, as is the case in symptomatic epilepsy syndromes (1).

This thesis will focus on school-aged children with absence epilepsy or a Panayiotopoulos syndrome. An introduction to these two syndromes is presented below. 


\section{Absence epilepsy}

Absence seizures occur in different epilepsy syndromes; however, it's the defining seizure type in childhood absence epilepsy (CAE) and juvenile absence epilepsy (JAE). Typical absence seizures should be differentiated from atypical absence seizures and from absence-like seizures in focal epilepsies in the frontal lobe or temporal lobe as these require a different work-up and have a different prognosis. Atypical absence seizures have a slow onset or termination of the seizure, may have significant changes in tone and are characterized by an atypical, slow, generalized spike-wave complexes on the EEG (3). Atypical absence seizures are mostly associated with other severe epilepsy syndromes in children such as Lennox-Gastaut Syndrome. This thesis will focus on children with typical absence seizures as occur in childhood absence epilepsy (CAE) and juvenile absence epilepsy (JAE).

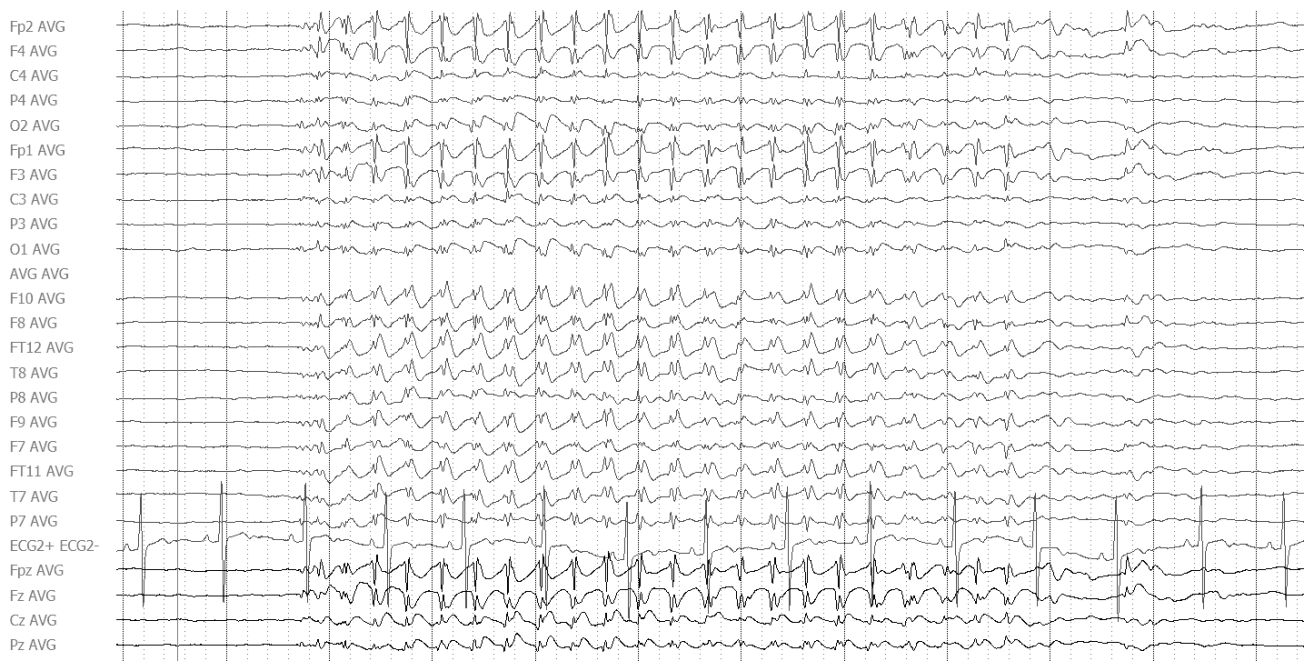

Figure 2. Twenty-four channel electroencephalogram (EEG) illustrating characteristic generalized bilateral three per second $(3 \mathrm{~Hz})$ spike-and-wave complexes. 
CAE and JAE account for $10-17 \%$ of all pediatric epilepsies $(7,8)$. A similar percentage of approximately $13 \%$ was found in the Dutch Study of Epilepsy in Childhood cohort (9). CAE and JAE are idiopathic generalized epilepsy syndromes characterized by reoccurring typical absence seizures (generalized non-motor seizures) in children which appear otherwise healthy (10-12). A typical absence seizure is a sudden interruption of ongoing activities, often with a blank stare, while unresponsive for a few seconds to half a minute. Activities are subsequently continued, without recollection of the time during the seizure and without post-ictal symptoms. Facial or limb automatisms, eye movements (eyeopening, eye blinking, mild eyelid myoclonias) are also often observed (13). In a large majority of children absence seizures can be triggered by voluntary hyperventilation (14). Typical epileptiform discharges on EEG are generalized bilateral 2.5-4 Hz spike-and-wave complexes $(3,15)$.

A clear delineation of the clinical spectrum between CAE and JAE is challenging (15-17). CAE presents most often between 4 and 10 years of age, whereas JAE usually starts between 10 and 17 years of age. Furthermore, compared to JAE in CAE absence seizures occur daily (up to tens per day), whereas the frequency of tonic-clonic seizures is relatively rare and the majority will not be chronically dependent on anti-epileptic drugs into adulthood (15-18).

Children with absence epilepsy are mostly treated with anti-epileptic drugs (AEDs) such as Ethosuximide, Valproate or Lamotrigine among others. The efficacy of these three AEDs was compared in a large double-blind randomized controlled trial, which showed that Valproate and Ethosuximide were more efficacious than Lamotrigine, although Valproate was associated with more adverse attentional side effects in CAE (19-21). Nevertheless, about 30\% do not achieve seizure control within one year on monotherapy (19). In the case of generalized tonic-clonic seizures Valproate would be the treatment of choice, which due to a higher occurrence in JAE is sometimes preferred among neurologists. 


\section{Panayiotopoulos syndrome}

Panayiotopoulos Syndrome (PS) is characterized by focal autonomic seizures which occur in an otherwise normally developing child (22-24). The incidence has been estimated at 0.8 per 100.000 children aged $<16$ years old (25). It presents in children aged 1 to 14 years old, with the majority being between 3 and 6 years old (26).

Seizures are often prolonged, infrequent (in some, limited to one episode) and occur mostly during sleep (22, 27-30). Autonomic status epilepticus may present in up to $20 \%$ of children $(22,24,31,32)$. Ictal autonomic manifestations consist of a wide spectrum of symptoms, such as nausea, vomiting, pallor, a deviation of head and eyes, generalized seizures, syncope, and stomach ache among others. As a result, Panayiotopoulos syndrome in some children may be challenging to diagnose and could easily be confused with other clinical disorders, potentially delaying correct treatment $(22,33)$.

The interictal electroencephalogram (EEG) is characterized by multifocal (high amplitude) spikes or sharp and slow-waves, with a preferential occipital/posterior location in $70 \%$ of patients $(22,29,34,35)$. PS was first described as a childhood occipital epilepsy under various names but was later substituted by the eponym Panayiotopoulos syndrome as occipital epileptiform activity is not always present and many autonomic symptoms do not suggest an occipital origin (35). Magnetoencephalography has confirmed spike localization along the Rolandic as well as the parieto-occipital and calcarine fissure.

Treatment with anti-epileptic drugs may not be necessary in case of very infrequent seizures. If treatment is indicated anti-epileptic drugs, such as oxcarbazepine, carbamazepine, valproate, levetiracetam, lamotrigine, and clobazam may be used. In the majority of children with PS, remission occurs 1 to 2 years after onset (36). 


\section{Neurocognitive function}

It has long been recognized that epilepsy is associated with neurodevelopmental and cognitive co-morbidities (37-39). This is reflected by a relatively high prevalence of cognitive deficits, educational underachievement and behavioral problems in epilepsy $(6,40)$. Nevertheless, the intricate relationship between epilepsy and neurocognitive co-morbidities is not fully understood and probably is multifactorial.

Epileptiform activity, ictal or interictal, may have an acute or lasting effect on brain structure and function $(6,38,41)$. However, reports on cognitive deficits in epilepsy in newly diagnosed drug-naïve children may suggest that processes during epileptogenesis or other underlying (genetic) mechanisms may also play a role $(6,42)$. In addition, some anti-epileptic drugs may also have a bearing on cognitive performance $(20,43)$. Furthermore, these factors may be particularly harmful during brain development and maturation (6).

More subtle neurodevelopmental and neurocognitive co-morbidities in benign epilepsy syndromes, such as absence epilepsy and Panayiotopoulos syndrome, are far less researched. Therefore, in these syndromes research focusing on the extent of neurocognitive co-morbidities and the course over time in addition to identifying alterations in brain development is warranted. 


\section{General aim of the thesis}

The aim of this thesis is to investigate neurocognition in absence epilepsy and Panayiotopoulos syndrome, by studying cognitive abilities and development over time, and exploring potential associated factors. From a neurodevelopment perspective the myelin content in the brain of children with childhood absence epilepsy will be assessed. 


\section{Outline of the thesis}

Cognitive functioning in absence epilepsy has historically been regarded within the normal range $(44,45)$. Nevertheless, reports on cognitive deficits in absence epilepsy have been accumulating. Therefore, in chapter 2, we systematically reviewed the current literature on cognitive performance in absence epilepsy.

Longitudinal data on the neurocognitive development based on individual children with absence epilepsy is scarce and most data are derived from crosssectional cohort studies. Persistence of cognitive weaknesses may hamper normal neurocognitive development, potentially leading to problems later in life. Therefore, the focus in chapter 3 was to report on cognitive development using two consecutive cognitive measurements in children with AE. Our aim was to determine the change in cognitive performance on a group and individual level by using reliable change methodology.

In chapter 4 we present the results of an ongoing prospective longitudinal cohort study on brain and neurocognitive development in children with absence epilepsy. The presented study is an MRI study focusing on cerebral myelin in children with CAE compared to controls by using myelin-water-fraction imaging, a novel imaging technique in epilepsy research. Due to the frontal involvement during generalized spike-wave complexes and the frequent attentional deficits in CAE, we hypothesize an altered myelin content in frontal areas. Furthermore, we explored the relationship of myelin content with neurocognitive performance.

Current research also points towards possible cognitive deficits in Panayiotopoulos syndrome, however, data is very limited. Therefore, chapter 5 focuses on cognitive performance in Panayiotopoulos syndrome, as current data on cognitive performance is lacking. Secondly, we report on behavioral problems in Panayiotopoulos syndromes, as this is entirely underreported in the literature.

In chapter 6 we will broadly summarize and discuss the obtained results in view of previous work. 


\section{References}

1. Guerrini R. Epilepsy in children. Lancet. 2006;367(9509):499-524.

2. Fisher RS, van Emde Boas W, Blume W, Elger C, Genton P, Lee P, et al. Epileptic seizures and epilepsy: definitions proposed by the International League Against Epilepsy (ILAE) and the International Bureau for Epilepsy (IBE). Epilepsia. 2005;46(4):470-2.

3. Fisher RS, Cross JH, French JA, Higurashi N, Hirsch E, Jansen FE, et al. Operational classification of seizure types by the International League Against Epilepsy: Position Paper of the ILAE Commission for Classification and Terminology. Epilepsia. 2017;58(4):522-30. Stafstrom CE, Carmant L. Seizures and Epilepsy: An Overview for Neuroscientists. Cold Spring Harbor perspectives in medicine. 2015;5(6). Scheffer IE, Berkovic S, Capovilla G, Connolly MB, French J, Guilhoto L, et al. ILAE classification of the epilepsies: Position paper of the ILAE Commission for Classification and Terminology. Epilepsia. 2017;58(4):512-21.

6. Berg AT. Epilepsy, cognition, and behavior: The clinical picture. Epilepsia. 2011;52 Suppl 1:712.

Berg AT, Shinnar S, Levy SR, Testa FM, Smith-Rapaport S, Beckerman B. How well can epilepsy syndromes be identified at diagnosis? A reassessment 2 years after initial diagnosis. Epilepsia. 2000;41(10):1269-75.

8. Jallon P, Loiseau P, Loiseau J. Newly diagnosed unprovoked epileptic seizures: presentation at diagnosis in CAROLE study. Coordination Active du Reseau Observatoire Longitudinal de l' Epilepsie. Epilepsia. 2001;42(4):464-75.

Geerts A, Arts WF, Stroink H, Peeters E, Brouwer O, Peters B, et al. Course and outcome of childhood epilepsy: a 15-year follow-up of the Dutch Study of Epilepsy in Childhood. Epilepsia. 2010;51(7):1189-97.

10. Li Q, Cao W, Liao X, Chen Z, Yang T, Gong Q, et al. Altered resting state functional network connectivity in children absence epilepsy. Journal of the neurological sciences. 2015;354(12):79-85.

Curwood EK, Pedersen M, Carney PW, Berg AT, Abbott DF, Jackson GD. Abnormal cortical thickness connectivity persists in childhood absence epilepsy. Annals of clinical and translational neurology. 2015;2(5):456-64.

12. Xue K, Luo C, Zhang D, Yang T, Li J, Gong D, et al. Diffusion tensor tractography reveals disrupted structural connectivity in childhood absence epilepsy. Epilepsy research. 2014;108(1):125-38.

Kessler SK, Shinnar S, Cnaan A, Dlugos D, Conry J, Hirtz DG, et al. Pretreatment seizure semiology in childhood absence epilepsy. Neurology. 2017;89(7):673-9.

14. Salvati KA, Beenhakker MP. Out of thin air: Hyperventilation-triggered seizures. Brain Res. 2017.

15. Hughes JR. Absence seizures: a review of recent reports with new concepts. Epilepsy \& behavior : E\&B. 2009;15(4):404-12.

16. Tenney JR, Glauser TA. The current state of absence epilepsy: can we have your attention? Epilepsy currents / American Epilepsy Society. 2013;13(3):135-40.

17. Trinka E, Baumgartner S, Unterberger I, Unterrainer J, Luef G, Haberlandt E, et al. Longterm prognosis for childhood and juvenile absence epilepsy. J Neurol. 2004;251(10):1235-41.

18. Callenbach PM, Bouma PA, Geerts AT, Arts WF, Stroink H, Peeters EA, et al. Long-term outcome of childhood absence epilepsy: Dutch Study of Epilepsy in Childhood. Epilepsy research. 2009;83(2-3):249-56.

19. Glauser TA, Cnaan A, Shinnar S, Hirtz DG, Dlugos D, Masur D, et al. Ethosuximide, valproic acid, and lamotrigine in childhood absence epilepsy: initial monotherapy outcomes at 12 months. Epilepsia. 2013;54(1):141-55.

20. Glauser TA, Cnaan A, Shinnar S, Hirtz DG, Dlugos D, Masur D, et al. Ethosuximide, valproic acid, and lamotrigine in childhood absence epilepsy. The New England journal of medicine. 2010;362(9):790-9.

21. Masur D, Shinnar S, Cnaan A, Shinnar RC, Clark P, Wang J, et al. Pretreatment cognitive deficits and treatment effects on attention in childhood absence epilepsy. Neurology. 2013;81(18):1572-80. 
22. Yalcin AD, Ertasoglu Toydemir H. Panayiotopoulos Syndrome with a special emphasis of ictal semiologic features. Epilepsy research. 2017;131:37-43.

23. Caraballo R, Cersosimo R, Fejerman N. Panayiotopoulos syndrome: a prospective study of 192 patients. Epilepsia. 2007;48(6):1054-61.

24. Panayiotopoulos CP. Autonomic seizures and autonomic status epilepticus peculiar to childhood: diagnosis and management. Epilepsy \& behavior : E\&B. 2004;5(3):286-95.

25. Weir E, Gibbs J, Appleton R. Panayiotopoulos syndrome and benign partial epilepsy with centro-temporal spikes: A comparative incidence study. Seizure. 2018;57:66-9.

26. Oguni H. Treatment of benign focal epilepsies in children: when and how should be treated? Brain \& development. 2011;33(3):207-12.

27. Michael M, Tsatsou K, Ferrie CD. Panayiotopoulos syndrome: an important childhood autonomic epilepsy to be differentiated from occipital epilepsy and acute non-epileptic disorders. Brain \& development. 2010;32(1):4-9.

28. Degerliyurt A, Teber S, Bektas O, Senkon G. Panayiotopoulos syndrome: a case series from Turkey. Epilepsy \& behavior : E\&B. 2014;36:24-32.

29. Specchio N, Trivisano M, Di Ciommo V, Cappelletti S, Masciarelli G, Volkov J, et al. Panayiotopoulos syndrome: a clinical, EEG, and neuropsychological study of 93 consecutive patients. Epilepsia. 2010;51(10):2098-107.

30. Schmitt B. Sleep and epilepsy syndromes. Neuropediatrics. 2015;46(3):171-80.

31. Specchio N, Trivisano M, Claps D, Battaglia D, Fusco L, Vigevano F. Documentation of autonomic seizures and autonomic status epilepticus with ictal EEG in Panayiotopoulos syndrome. Epilepsy \& behavior : E\&B. 2010;19(3):383-93.

32. Ferrie CD, Caraballo R, Covanis A, Demirbilek V, Dervent A, Fejerman N, et al. Autonomic status epilepticus in Panayiotopoulos syndrome and other childhood and adult epilepsies: a consensus view. Epilepsia. 2007;48(6):1165-72.

33. Carbonari G, Tonti G, Di Pisa V, Franzoni E, Cordelli DM. Pediatric epilepsies misdiagnosed as gastrointestinal disorders. Epilepsy \& behavior : E\&B. 2018;83:137-9.

34. Ferrie C, Caraballo R, Covanis A, Demirbilek V, Dervent A, Kivity S, et al. Panayiotopoulos syndrome: a consensus view. Developmental medicine and child neurology. 2006;48(3):23640.

35. Martinovic Z. The new ILAE report on classification and evidence-based commentary on Panayiotopoulos syndrome and autonomic status epilepticus. Epilepsia. 2007;48(6):1215-6.

36. Covanis A. Panayiotopoulos syndrome: a benign childhood autonomic epilepsy frequently imitating encephalitis, syncope, migraine, sleep disorder, or gastroenteritis. Pediatrics. 2006;118(4):e1237-43.

37. Hermann B, Seidenberg M, Jones J. The neurobehavioural comorbidities of epilepsy: can a natural history be developed? The Lancet Neurology. 2008;7(2):151-6o.

38. Tran LH, Zupanc ML. Neurocognitive Comorbidities in Pediatric Epilepsy: Lessons in the Laboratory and Clinical Profile. Seminars in pediatric neurology. 2017;24(4):276-81.

39. Helmstaedter C, Witt JA. Epilepsy and cognition - A bidirectional relationship? Seizure. 2017;49:83-9.

40. Fastenau PS, Jianzhao S, Dunn DW, Austin JK. Academic underachievement among children with epilepsy: proportion exceeding psychometric criteria for learning disability and associated risk factors. Journal of learning disabilities. 2008;41(3):195-207.

41. Aldenkamp A, Arends J. The relative influence of epileptic EEG discharges, short nonconvulsive seizures, and type of epilepsy on cognitive function. Epilepsia. 2004;45(1):5463.

42. Witt JA, Helmstaedter C. Cognition in epilepsy: current clinical issues of interest. Current opinion in neurology. 2017;30(2):174-9.

43. Ijff DM, Aldenkamp AP. Cognitive side-effects of antiepileptic drugs in children. Handbook of clinical neurology. 2013;111:707-18.

44. Adie WJ. Pyknolepsy; A form of Epilepsy in Children, with a good Prognosis. Proceedings of the Royal Society of Medicine. 1924;17(Neurol Sect):19-25.

45. Currier RD, Kooi KA, Saidman LJ. Prognosis of "Pure" Petit Mal; a follow-up study. Neurology. 1963;13:959-67. 
General introduction \& Outline of the thesis 


$$
5
$$




\section{Towards a better understanding of cognitive deficits in absence epilepsy: a systematic review and meta-analysis}

Eric L.A. Fonseca Wald Jos G.M. Hendriksen

Gerald S. Drenthen Sander M.J. v. Kuijk Albert P. Aldenkamp Johan S.H. Vles

R. Jeroen Vermeulen Mariette H.J.A. Debeij-van Hall

Sylvia Klinkenberg

Neuropsychology review. 2019;29(4):421-49. 


\begin{abstract}
Cognition in absence epilepsy (AE) is generally considered undisturbed. However, reports on cognitive deficits in $\mathrm{AE}$ in recent years have suggested otherwise. This review systematically assesses current literature on cognitive performance in children with AE.
\end{abstract}

A systematic literature search was performed in Pubmed, Embase, Cochrane and Web of Science. All studies reporting on cognitive performance in children with AE were considered. In total 33 studies were eligible for inclusion. Neuropsychological tests were classified into the following domains: intelligence; executive function; attention; language; motor \& sensory-perceptual examinations; visuoperceptual/visuospatial/visuoconstructional function; memory and learning; achievement. Random-effect meta-analyses were conducted by estimating the pooled mean and/or pooling the mean difference in case-control studies.

Full-scale IQ in children with AE was estimated at 96.78 (95\%CI:94.46-99.10) across all available studies and in case-control studies IQ was on average 8.03 (95\%CI:-10.45- -5.61) lower. Verbal IQ was estimated at 97.98 (95\%CI:95.80-10o.16) for all available studies and 9.01 (95\%CI:12.11- -5.90) points lower in case-control studies. Performance IQ was estimated at 97.23 (93.24-101.22) for all available studies and 5.32 (95\%CI:-8.27- -2.36) points lower in case-control studies. Lower performance was most often reported in executive function (cognitive flexibility, planning, and verbal fluency) and attention (sustained, selective and divided attention). Reports on school difficulties, neurodevelopmental problems, and attentional problems were high.

In conclusion, in contrast to common beliefs, lower than average neurocognitive performance was noted in multiple cognitive domains, which may influence academic and psychosocial development. 


\section{Introduction}

Typical absence seizures as occurring in childhood absence epilepsy (CAE) and juvenile absence epilepsy (JAE) are characterized by demarcated brief episodes of unconsciousness with generalized $\sim 3-\mathrm{Hz}$ spike-and-wave complexes, visible on an electroencephalogram (EEG), in otherwise healthy children (1-4). A clear delineation of the clinical spectrum between CAE and JAE is challenging $(2,5,6)$. CAE occurs mostly between 4 and 10 years of age whereas JAE occurs between 10 and 17 years of age. Furthermore, JAE is characterized by less frequent absence seizures, a higher incidence of tonic-clonic seizures and a higher drug dependency during adulthood.

Despite absence epilepsy (AE) being defined a "benign" disorder, a high rate of initial treatment failure, associated therapeutic side effects, development of generalized tonic-clonic seizures and psychosocial co-morbidities in more recent reports emphasize its real burden (7-13).

Starting from early descriptions, cognitive performance in AE has been considered to be normal $(14,15)$. However, in a large randomized clinical trial intelligence was lower than normal values, but still within normal range (8). Nevertheless, $36 \%$ of drug-naïve patients presented with attentional deficits. Moreover, subsequent allocation to monotherapy with Valproate was associated with more attentional dysfunction, than allocation to monotherapy with either Ethosuximide or Lamotrigine $(7,9,16)$. Nevertheless, attentional deficits persisted independent of the allocated anti-epileptic drug treatment or seizure control after 1-year of follow-up $(7,8,16)$. These are intriguing findings, as apart from therapeutic side effects and (inter)ictal activity other underlying mechanisms may also affect cognition in AE (17-20).

The number of studies reporting on cognitive performance in $\mathrm{AE}$ has been growing steadily and warrants a formal review $(8,11,21-52)$. A previous metaanalysis in idiopathic generalized epilepsy found significant impairments in general cognitive ability and across a wide variety of other cognitive domains (53). Sub-analyses were available for CAE, however, only four studies were included. Therefore, our review is aimed specifically to address all studies on cognitive performance in AE. Although, the different syndromes in idiopathic generalized epilepsy may constitute a biological continuum, and therefore resemble in their 
neuropsychological profile, specific cognitive deficits may still exist. Knowledge on cognitive deficits in AE may help clinician's establish better neuropsychological batteries and direct precautionary measures, as cognitive deficits may go unnoticed by their surroundings (8). Therefore, this review systematically assesses current literature on cognitive performance in children with AE.

\section{Methods}

This review adheres to the Preferred Reporting Items for Systematic Reviews and Meta-analysis guidelines (PRISMA) (54). The methods and procedures for this review are available in the paper with additional information provided in the supplemental materials. The review was not registered prior to conducting this review.

\section{Selection eligibility}

Selection criteria were defined according to PICOS: Participants = Children with $\mathrm{AE}$, either defined as 3-4 $\mathrm{Hz}$ spike-wave complexes or a syndromic classification of $\mathrm{CAE}$ and/or JAE; Intervention/diagnostic = neuropsychological tests (batteries) or reports on school performance; Comparison $=$ normative values (for example reports using standardized scores as these represents scores relative to the normative sample of the test) or a control group; Outcome = neuropsychological function based reported as a median/average score or prevalence of impairment based on cut-off values or a direct comparison of test scores with a control group; Design = Observational studies (cohort studies/case-control studies) or clinical trials (depending of the design of the clinical trial these data are also regarded as observational data, for example baseline neuropsychological results).

\section{Systematic literature search}

The search strategy consisted of indexed terms and free text words on absence epilepsy in combination with terms on observational research and clinical trials (the search in Pubmed is provided as a Supplemental file). The following electronic databases were searched: Pubmed (until 29-09-2017), EMBASE (until 23-03-2017), Cochrane (until 05-04-2017) and Web of Science (all databases) (until o6-04-2017). Furthermore, references of included articles were hand searched to 
find additional relevant articles. In case multiple publications were available on the same study sample or if reports reported overlapping results, only the most recent data were used. Only studies written in English, Dutch or Spanish were considered. Firstly, titles and/or abstracts identified by the search were first screened by EFW to remove any unrelated hits. Secondly, the remaining abstracts were screened by EFW and another author (GSD or SK or MD or JH) based on the predefined selection criteria. The second researcher was blinded for journal, authors, title, date of publication and publication language. Any discrepancies were resolved by consensus or by screening the full-text subsequently. Eligibility assessment of full-text articles was performed by EFW and one of the neurologists (MD or SK). Any discrepancies were resolved by consensus or by consulting a third author.

\section{Data extraction}

The following data were extracted: year of publication, country, study design, inclusion/exclusion criteria, number of included patients, number of patients per cognitive assessment, age at onset, age at the time of the study, anti-epileptic drug use and neuropsychological tests results.

Neuropsychological test results were classified to cognitive domains according to Baron and secondly according to the authors of the study or consensus within our team (55). We distinguished the following cognitive domains: intelligence; executive function; attention, language; motor and sensory-perceptual examinations; visuoperceptual/visuospatial/visuoconstructional function; learning and memory. Additionally, we included results on: achievement tests, parent/teacher (by proxy) reports on attention or attentional deficiency disorders; reported prevalence's of school difficulties; neuropsychological and/or neurodevelopmental problems.

\section{Risk of bias in individual studies}

Risk of bias was evaluated using a modified version of the Newcastle Ottawa Scale made suitable for this review (available in the Supplementary Materials). Two authors (EFW \& SK) independently rated each study, and any disagreement was resolved by consensus. For the interpretation of the total scores we used the following cut-off values as used previously in a systematic review (56). Scores $>7$ were considered a low risk of bias; 5 to 7 , a moderate risk; and $<5$, a high risk. For 
the meta-analysis sensitivity analyses were carried out by excluding studies with a score lower than seven.

\section{Meta-analyses}

Statistical analyses were conducted in R using the "meta" package (version 4.8-2) and "metaphor" package (version 1.9-9) (57, 58). Single-arm meta-analyses (a weighted pooling of the reported means including studies without a control group) were performed by estimating the weighted mean using a random effect model. For this, we used the reported mean and calculated the standard error (SE) for each study. In case a z-score with a 95\% confidence interval was reported we calculated the standard score and its standard deviation. The estimated mean was considered significantly different from normal if the $95 \%$ confidence interval did not include the normative mean of the neuropsychological test. In addition, a random-effects meta-analysis on the mean difference between cases and controls was performed in absence of normative values and/or as a sensitivity analysis. Studies that did not report usable data for pooling of results were discarded for the meta-analyses but were included in this systematic review. Pooling of results was conducted per neuropsychological test if methodology and reporting of the results allowed a direct comparison between studies. P-values of $\leq$ 0.05 were considered to infer statistical significance. The presence of small study effect and/or publication bias was assessed by visually inspecting funnel plots for asymmetry. In case of potential outliers, a sensitivity analysis was performed by recalculating the effect size after removal of these studies. Tau-squared $\left(T^{2}\right)$ was used to estimate the true variance of the true effect sizes (59). In addition, $\mathrm{I}^{2}$ is reported for descriptive purposes. Due to the limited amount of studies in the meta-analyses we were not able to perform subsequent meta-regressions to examine the impact of moderator variables $(60,61)$. 


\section{Results}

\section{Selection of studies}

The study selection process is depicted in figure 1. A total of 3833 individual articles across all electronic databases were screened. Additionally, nine references from selected articles were screened for eligibility. A total of 506 abstracts were selected for further reading, after which 351 were selected for fulltext screening. In the end, 33 articles were included in this systematic review.

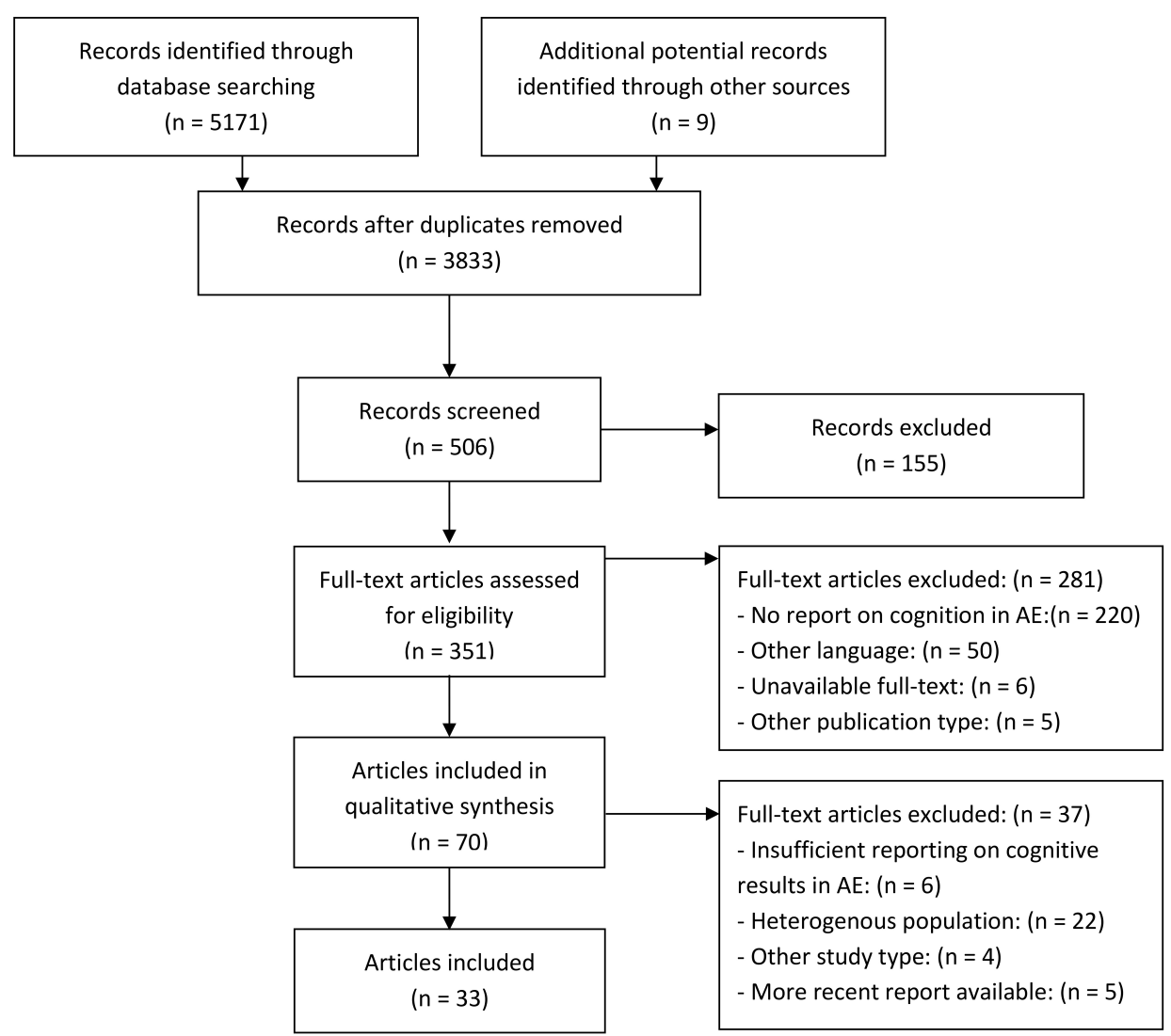

Figure 1. Flowchart (adapted from Moher 2009) 


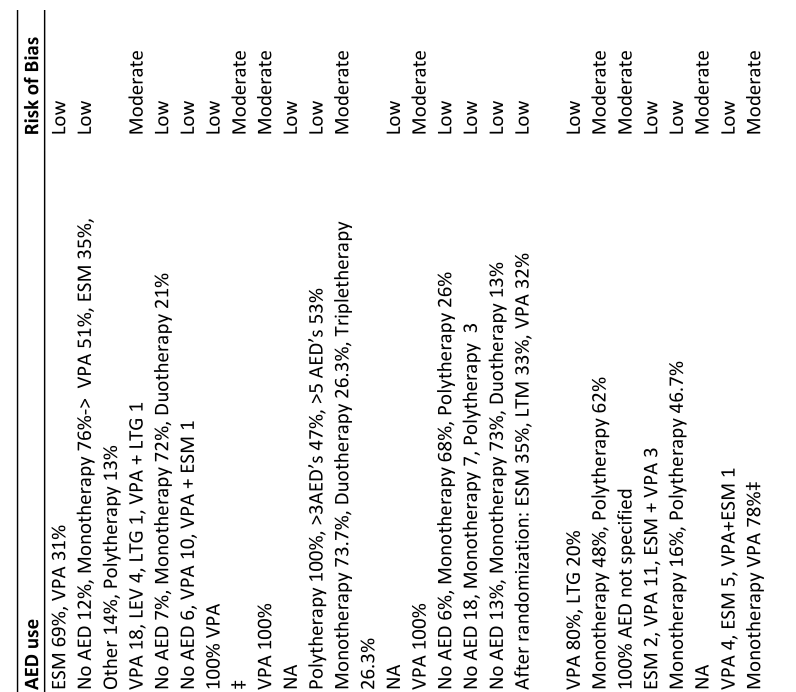

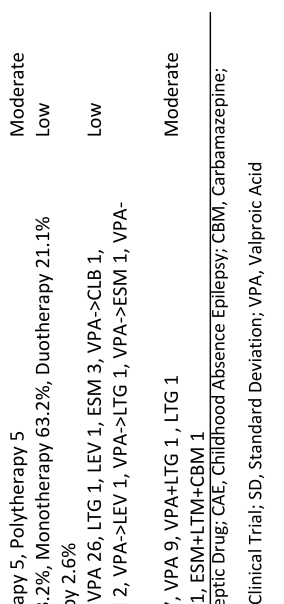

일

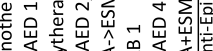

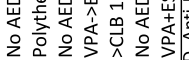

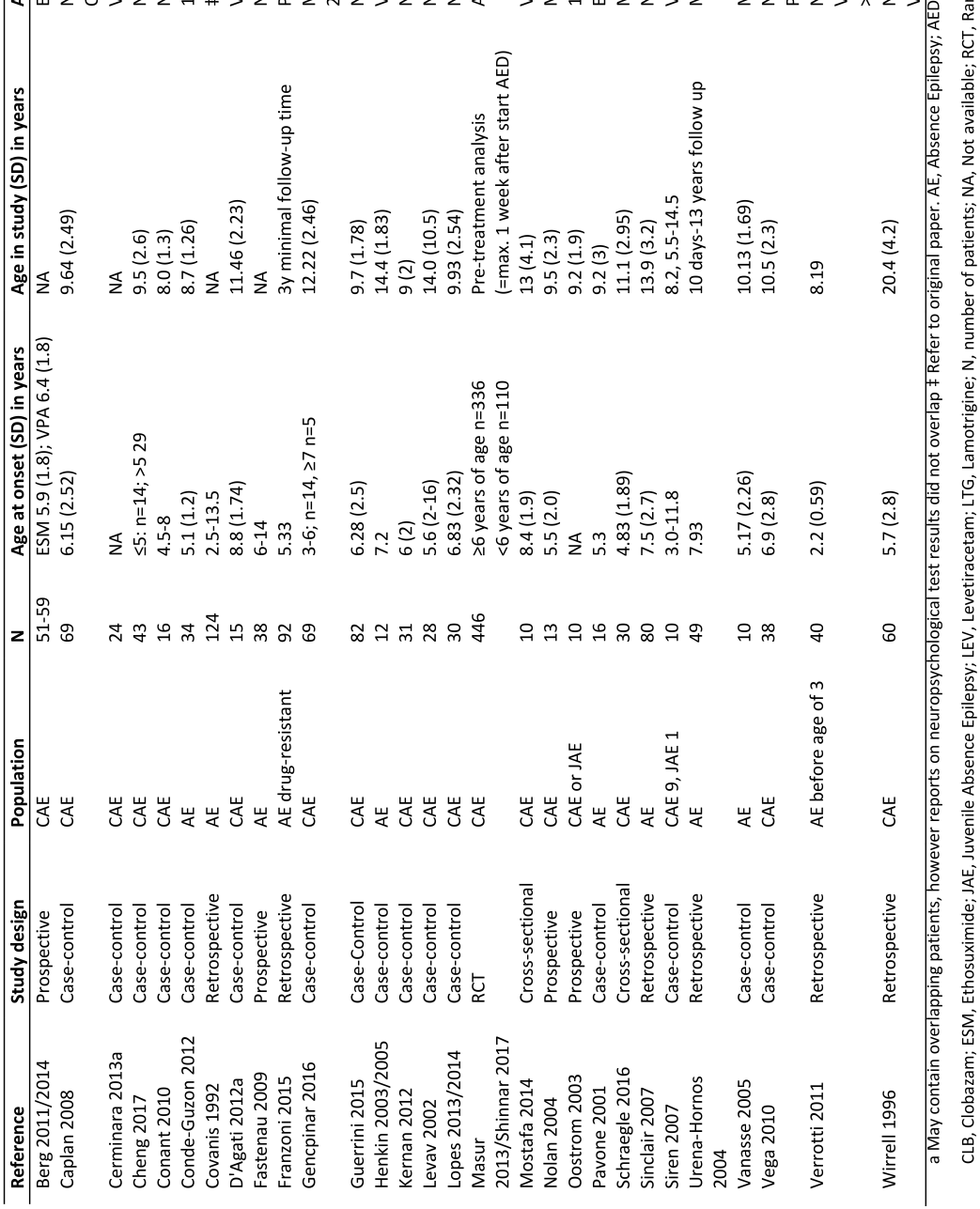




\section{Study characteristics}

Study characteristics of the 33 included articles are listed in Table 1. Eight articles reported on overlapping cohorts, but were included as each article provided complementary data in that cohort $(8,21,22,33,34,37,38,44)$. In total, data were available for 29 samples. In total, 17 cohorts reported only on CAE (8, 11, 21-25, 28, $31,32,35-41,43,44,46,47,50,52)$ and in 12 cohorts reports were available in children with AE or a combination of CAE with JAE (26, 27, 29, 30, 33, 34, 41, 42, $45-49,51)$. No studies were available reporting on JAE exclusively. Study sample sizes varied from 10 to 446 , with a mean of 54 participants. The time of cognitive assessment differed from early assessment close to the time of diagnosis to years after diagnosis. Overall Valproic Acid (VPA) seems the most used anti-epileptic drug in the studies. However, some studies only reported the amount of antiepileptic drug (AED) use (monotherapy, polytherapy) without stating the number of patients on particular AEDs.

Based on our assessment for the risk of bias eighteen studies had a low risk of bias and eleven studies had a moderate risk of bias. No studies were classified to have a high risk of bias. The highest risk of bias was due to inadequate selection and/or description of the non-exposed cohort and a small sample size.

\section{Intelligence}

Table 2 displays the neuropsychological results of the included study per cognitive domain. Wechsler Intelligence Test for Children (WISC-III) was the psychological test most often used to assess general intelligence. Of 11 studies reporting on fullscale IQ, nine studies were suitable for pooling of results $(8,11,26,28,31,35,38$, 40, 42). The estimated mean full-scale IQ from the single-arm random-effects meta-analysis was 96.78 (95\% CI: 94.46-99.10; $T^{2}=7.57: I^{2}=64.2 \%$ ) for absence patients, which is significantly different from the normative mean of 100 (Figure 2). The mean full-scale IQ based on a sensitivity analysis excluding studies with a moderate risk of bias was 97.43 (95\% CI: 94.43; 100.43; $T^{2}=10.84 ; I^{2}=75.9 \%$ ). The estimated mean difference in IQ points compared to a control group in seven available case-control studies was -8.03 (95\% CI: $\left.-10.45^{-}-5.61 ; T^{2}=0 ; I^{2}=0 \%\right)$. The mean difference in IQ points in a sensitivity analysis excluding studies with a moderate risk of bias was -8.52 (95\% CI:-11.31 - $\left.-5.73 ; T^{2}=0\right)$. The estimated mean full-scale IQ of the control group was 105.09 ( $95 \%$ CI: 101.63-108.56; $T^{2}=17.40 ; I^{2}=$ $82 \%$ ), which is significantly higher than the normative mean of 100 . 
Out of seven studies reporting on verbal IQ, four could be included in the metaanalysis with an estimated mean of 97.98 (95\% CI: 95.80-10o.16; $T^{2}=0.28 ; I^{2}=$ $5.5 \%)$ and an estimated mean difference of -9.01 (95\% CI: $-12.11--5.90 ; T^{2}=1.31 ; I^{2}=$ 12.85\%) compared to controls (Figure 2).

Out of seven studies reporting on performance IQ, four were suitable for metaanalytic comparison with an estimated mean of 97.23 (95\% CI: 93.24-101.22; $T^{2}$ $=15.86 ; I^{2}=78.7 \%$ ) and an estimated mean difference of -5.32 (95\% CI: -8.27- -2.36; $T^{2}=0 ; I^{2}=0 \%$ ) compared to controls (Figure 2).

The estimated mean for the Verbal Comprehension Index was 94.43 (95\% CI: 91.11-97.75; $\left.T^{2}=7.39 ; I^{2}=70.2 \%\right)$, the estimated mean for the Processing Speed Index was Processing Speed Index was 96.30 (95\% CI: 93.74-98.86; $T^{2}=2.77 ; I^{2}=$ 41.9\%) and the estimated mean for the Perceptual Organization Index was 97.09 (95\% CI: 95.50-98.69; $T^{2}=0 ; I^{2}=0 \%$ ). One study, which used the WISC-IV, reported a mean Working Memory Index of 94.8 (SD 14.2). Sensitivity analyses by excluding outliers based on the funnel plots did not yield different conclusions. Results on the subtests of the Wechsler Intelligence tests are available in Table S1.

Non-verbal intelligence tests were used in three studies. In the study with by far the largest sample of Masur et al. $(n=316)$ non-verbal intelligence assessed with the TONI-3 test was significantly higher compared to the normative mean (8). Raven's Progressive Matrices was used by Oostrom et al. which reported no significant difference from normative values in a small sample $(n=10)$ of children with either CAE or JAE (41). A simplified version of the Raven's Progressive Matrices was used by Cheng et al. in children with CAE $(\mathrm{n}=43)$ which performed significantly worse compared to controls (24). 


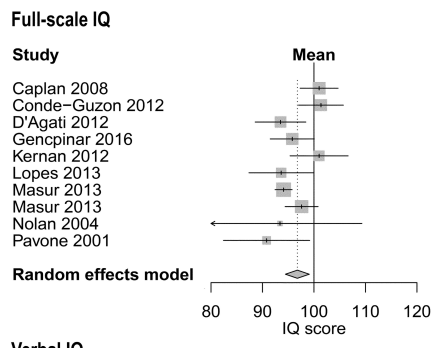

Verbal IQ

Study

Caplan 2008

Conde-Guzon 2012

D'Agati 2012

Lopes 2013

Random effects model

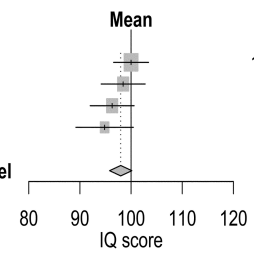

Performance IQ

Study

Caplan 2008

Conde-Guzon 2012

D'Agati 2012

Lopes 2013

Masur 2013

Random effects model

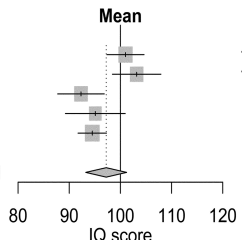

Trail Making Test A (Case-control)

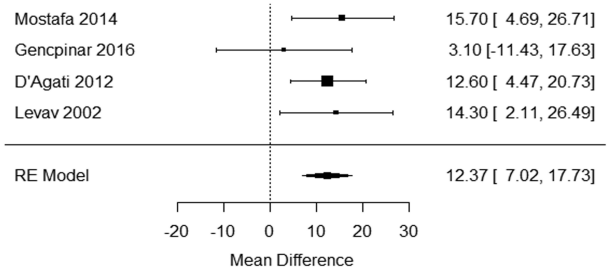

WRAT Arithmetic

Study

Conant 2010

Masur 2013

Random effects model
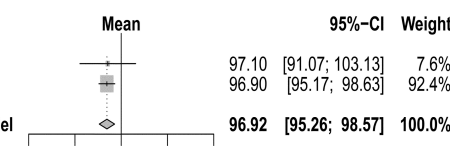

$97.10[91.07 \cdot 103.13] \quad 7.6 \%$ $96.90 \quad[95.17 ; 98.63] \quad 92.4 \%$ 96.92 [95.26; 98.57] $100.0 \%$

WRAT Spelling

$\begin{array}{lllll}80 & 90 & 100 & 110 & 120\end{array}$

Study

Conant 2010

Masur 2013

Random effects model

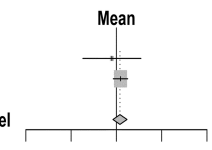

$\begin{array}{lllll}80 & 90 & 100 & 110 & 120\end{array}$

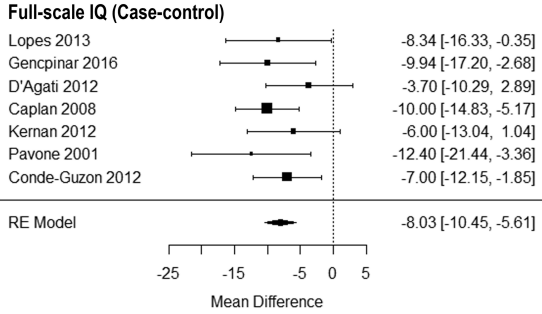

Verbal IQ (Case-control)

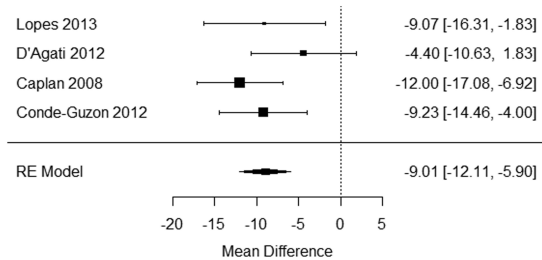

Performance IQ (Case-control)

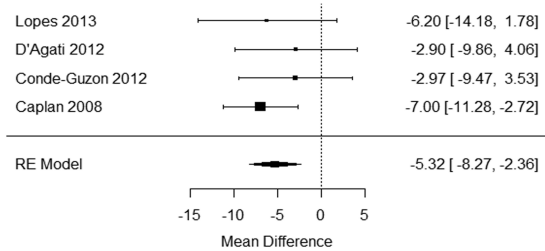

Trail Making Test $\mathrm{B}$ (Case-control)

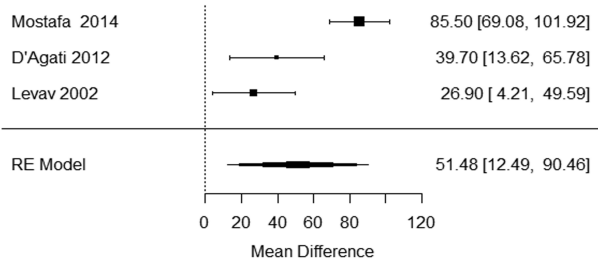

WRAT Reading

Study Mean 95\%-Cl Weight

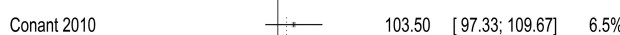

Masur $2013 \quad 101.80[100.17 ; 103.43] \quad 93.5 \%$

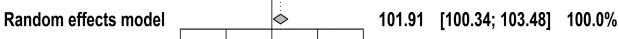

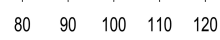

Beery Visual Motor Integration (VMI)

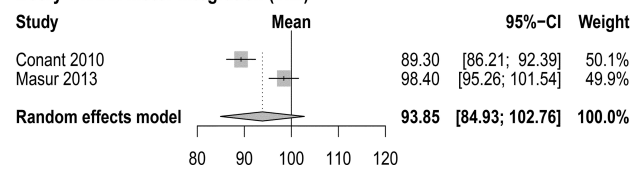

Figure 2. Forest plots of the single-arm meta-analyses (weighted average) and meta-analyses of the mean difference (difference in performance in case-control studies). For each study the mean is represented by a square (size is proportional to the study's weight) and the $95 \%$ confidence interval $(\mathrm{Cl})$ is represented by a horizontal line. The overall weighted mean is represented by a diamond shape. 


\section{Executive function}

A total of eight studies assessed executive function $(8,24,25,28,31,34-36)$ using different instruments. The performance of children with AE on the STROOP test did not significantly differ from controls (31, 35, 36). Significant worse performance was noted in multiple studies using the Wisconsin Card Sorting Test $(8,24,25,31,35,36)$, the Category Fluency Test $(25,28,34)$ and the Tower of London Test $(25,28)$. In two out of three studies lower function was noted on verbal fluency with the Controlled Oral Word Association Test $(25,28,34)$. The control group in the study of Conant et al. scored higher than the normative mean; while the children with AE scored approximately average. Pooling of results was not possible for these tests due to differences in administration of the neuropsychological test and/or outcome reporting.

\section{Attention}

A total of eight studies assessed attention $(8,23,24,28,31,36,39,46)$. A large randomized clinical trial in CAE showed impairments in attention in up to $1 / 3$ of patients with the Conner's Kiddie Continuous Performance Test in patients just started with anti-epileptic drug monotherapy ( $<1$ week) or before starting treatment (8). Errors of omission (missing relevant targets) were more common than errors of commission (responding to non-targets). During follow-up, attentional deficits persisted independent of anti-epileptic drug treatment or seizure control. The study of Levav et al. used the Rosvold Continuous Performance test and also reported diminished scores in visual sustained attention (36). However, in this study, the mean age of the control group used was 12 years older than the group with AE.

On the Trail Making Test A, the pooled estimated mean difference compared to controls was 12.37 seconds (95\% CI: 7.02-17.73; $T^{2}=0 ; I^{2}=0 \%$ ) longer for children with $\mathrm{AE}$ and on the Trail Making Test $\mathrm{B}$ an estimated mean difference was found of 51.48 seconds ( $95 \%$ CI: 12.49-90.46; $\left.T^{2}=1061.59 ; I^{2}=89.9 \%\right)$ (Figure 2$)(25,28$, $36,39)$.

Cerminara et al. found significantly lower scores in some measures of alertness, divided attention, impulsivity, and selective attention in CAE compared to controls (23). The divided and selective attention tasks were characterized by more errors of omission, whereas the impulsivity task was characterized by more commission errors. Reaction times had significantly more variability during the 
tonic arousal, phasic arousal and impulsivity task, but not in the divided or selective attention task. Focused attention did not differ from controls; however, Cheng et al. did find a significantly longer choice reaction time, which is similar to the focused attention task in the study performed by Cerminara et al. (24).

Mostafa et al. reported significantly lower mean scores compared to controls in an expressive attention and receptive attention task; however, it was not clear whether this was still statistically significant when corrected for the 6 years age difference with controls (39). Siren et al. used FEPSY auditory/visual reaction times and STIM tasks to assess attention and did not find a significant difference in this small sample $(\mathrm{n}=10)(46)$.

\section{Language}

A total of six studies assessed language $(8,11,24,26,33,49)$. Caplan et al. reported significantly lower scores on the Spoken Language Quotiënt (SLQ) using the Test of Language Development (TOLD) compared to a control group (11). Vanasse et al. used a metaphonological awareness task and reported significant worse phonemic segmentation compared to controls (49). None of the other variables in this test differed from controls.

Masur et al. and Vanasse et al. did not find a significant difference in receptive vocabulary using the Peabody Picture Vocabulary Test (PPVT) compared to normative values $(8,49)$. Vanasse et al. additionally used a denomination test to assess expressive language in a small sample of 10 subjects, but this did not yield a significant difference (49).

The study of Conde-Guzon and Cancho-Candela in typical AE patients reported significantly lower performance in phonemic hearing, articulation/repetition, denominating/narration and phonetic analysis (26). Comprehension and understanding of simple grammar did not differ significantly.

In a recent study by Cheng et al. semantic comprehension and word rhyming was not significantly worse compared to controls (24). Furthermore, Henkin et al. reported on auditory event-related potentials and found significant increased $\mathrm{N}_{2}$ amplitudes for phonetic and semantic processing, as well as, a significantly increased latency for semantic stimuli for $\mathrm{P}_{3}$ compared to controls (33). 


\section{Motor and Sensory-perceptual examinations}

Five studies have investigated motor function $(25,26,32,34,46)$. Siren et al. performed a finger-tapping test in the dominant and non-dominant hand but did not find significant differences compared to controls (46). Conant et al. also reported normal fine motor speed using a finger tapping test in the dominant and non-dominant hand (25). The control group in the study of Conant et al. scored higher than the normative mean; while children with AE scored approximately average. Conant et al. also assessed complex motor control and reported worse performance in AE compared to controls. Pooling of results with the finger tapping test was not possible due to differences in test protocols and reporting of results. Contrarily, Henkin et al. did find a significantly lower amount of taps per trial with finger-tapping in the right hand but not in the left-hand (34).

Furthermore, Guerrini et al. reported a higher prevalence of dysgraphia in AE (21\% vs. $8 \%$ for controls) and reported diminished overall performance in a handwriting fluency test compared to controls (32). Conde-Guzon and CanchoCandela used the LURIA-battery to assess motor and sensory functions compared to control subjects (26). They reported significantly lower performance in the manual subtest, but verbal regulation did not differ from normative values. Sensory functions such as rhythmic hearing and tactile subtests were significantly worse compared to controls, while kinesthesia and stereognosis did not differ from normative values.

\section{Visuoperceptual, visuospatial, and visuoconstructional function}

Two studies assessed visuomotor planning and integration. Of the studies using the Beery-VMI, the largest study from Masur et al. $(\mathrm{n}=106)$ reported a mean of 98.4 (SD 16.5), which is well within normal limits in children with CAE younger than 6 years of age (8). Conant et al. included a smaller subset of patients $(n=16)$ and reported a significantly lower score of 89.3 (SD 6.3) compared to controls (25). The single-arm random effect meta-analyses for the Beery-VMI was estimated at a mean of 93.85 (95\% CI: 84.93-102.76; $T^{2}=38.88 ; I^{2}=93.9 \%$ ), which is not significantly different from a normative mean of 100 (Figure 2).

On the contrary, Conant et al. found significant lower performance using the KABC-HM (imitation of hand movements) a test for visuomotor planning and integration (25). 
Five studies have investigated visuospatial skills. In total three studies used the Rey-Complex Figure Test (RCFT). Nolan found significant worse performance in the RCFT compared to normative data but did not include the average scores (40). Pavone et al. found lower performance in the RCFT compared to the control group, although still within normal clinical range (42). Henkin, et al did not find a significant difference in the RCFT with the control group (34). Cheng et al. reported that children with $\mathrm{CAE}$ did not perform worse in a $3 \mathrm{D}$ mental rotation test (2017), however, Conde-Guzon and Cancho-Candela did find significant worse performance in the visuospatial subtest of the LURIA-DNI neuropsychological battery $(24,26)$.

Two studies assessed visual search ability. Levav et al. used a Letter Cancellation test and reported a large difference in completing the test compared to controls, however, the age difference between patients with CAE and controls was $\sim 12$ years (36). In a study by Mostafa et al. total duration of a Visual Search Test was significantly worse compared to controls, however, controls were 6 years older on average (39).

\section{Learning and Memory}

Fourteen studies assessed memory function $(8,25,26,28,31,34-37,39,40,42,43$, 46). Pavone et al. used the Test Of Memory And Learning (TOMAL) and found significant impairments in the Nonverbal Memory Index Score, Delayed Recall Index and Kernan et al. found significant differences in the Memory for Stories Subtest Scores compared to control subjects $(35,42)$

Schraegle et al. reported intact verbal memory and list learning compared to normative data using the California Verbal Learning Test (auditory memory) (43). However, Kernan et al. (2012) and Henkin et al. (2005) did find significant memory impairment using this test compared to control subjects $(34,35)$. Kernan et al. reported a significant difference in the total mean score, whereas Henkin et al. reported significant differences in immediate recall, delayed recall, and retrieval.

Findings on the recall of the Rey-Osterrieth Complex Figure Test (visual memory) did not differ compared to controls, although Nolan et al. reported significant worse performance compared to normative data $(34,37,40)$. 
In the Randomized Clinical Trial of Masur et al. the Wide Range Assessment of Memory and Learning (WRAML) test showed a normal Verbal Memory Index, whereas the Visual Memory Index was abnormal (8). In addition, Conant et al. observed the largest differences between children with $\mathrm{AE}$ and controls in picture memory and story memory subtests of the WRAML test (25). Nolan et al. reported normal scores compared to normative data for all subtest of the WRAML test in a small study $(\mathrm{n}=13)(40)$.

The Serial Digit Learning Test used by Gencpinar et al. revealed a significant difference compared to controls (31). Number recall also seems diminished in the study of Mostafa et al., however controls were on average 6 years older (39).

Lopes et al. reported normal performance on LIST learning for words (37). Masur et al. reported a Sentence Repetition mean standard score of 9.2 which is significantly lower compared to a normative mean of 10 in children with CAE younger than 6 years of age (8). Conde-Guzon and Cancho-Candela reported impairments in immediate (short-term) memory and logical memory in typical absence epilepsy compared to controls (26).

The performance on several other memory tests (Corsi Block Tapping Test (28, 37), Visual Aural Digit Span Test (31), Rey Auditory Verbal Learning Test (36), Spatial Memory Test (39), Incidental Verbal Memory Test (39), STIM-tasks (46) and Doors and People (35) did not differ in performance from control subjects.

\section{Achievement}

Five studies used an achievement test (8, 24-26, 49). Masur et al. and Conant et al. reported on arithmetic, reading and spelling ability using the Wide Range Achievement Test-3 (8, 25). On arithmetic, the estimated mean was 96.92 (95\% CI: 95.26-98.57; $T^{2}=0 ; I^{2}=0 \%$ ) (Figure 2). On spelling, the estimated mean did not differ from normative data 100.79 (95\% CI: 99.23-102.35; $T^{2}=0 ; I^{2}=0 \%$ ). However, the estimated mean on reading was 101.91 (95\% CI: 100.34-103.48; $T^{2}=0$; $\left.I^{2}=0 \%\right)$ Vanasse et al. investigated reading ability in a small group $(\mathrm{n}=10)$ and found lower scores across a regular, irregular and non-word reading task, albeit only the regular word reading task was significantly different from the control group (49). The post-hoc administered Alouette reading task showed a mean reading deficit of $\mathbf{2 5 . 7}$ months (SD 14.28) in children with CAE. 
In children with CAE, 40-50\% had more than 1-year delay in school grade levels compared to $10 \%$ of the control group. Conde-Guzon and Cancho-Candela found significant worse performance in writing, reading, numerical structure and arithmetic abilities compared to controls using the LURIA-DNI battery (26).

\section{Reports on attention or attentional deficiencies (by proxy)}

Vega et al. reported attentional problems, especially forgetfulness and distractibility to be more prevalent in children with CAE compared to controls using the Behavior Assessment System for Children (50).

The prevalence of attentional problems in $38 \%$ of children with AE differed significantly compared to $16 \%$ in control subjects assessed with the Child Behavior Checklist (CBCL) in the study by Caplan et al. (11). However, Shinnar et al. reported a lower percentage of $15 \%$ clinically significant attentional problems in CAE compared to the study of Caplan et al. but used a higher cut-off value (44). Conant et al. and Shinnar et al. reported similar mean scores on attention, which in the study of Conant et al. were significantly higher than controls (25). Caplan et al. also reported a higher prevalence of $37 \%$ with a diagnosis of attentional deficit hyperactivity disorder (ADHD) versus $6 \%$ in control subjects in their population (11). Shinnar et al. estimated a $26 \%$ prevalence of ADHD in drug-naïve children with CAE (44).

\section{Prevalence of school difficulties}

Four studies reported on school performance (22, 27, 41, 48). Urena-Hornos et al. reported school problems in 12 out of 49 (24\%) children with AE using a telephonic follow-up assessment (48). Covanis et al. reported a low average school achievement in 65 out of 124 (52\%) CAE patients (27). Berg et al. reported that 13 out of $57(23 \%)$ CAE patients had already received special education prior to diagnosis of epilepsy (22). Oostrom et al. reported special educational assistance in 7 out of 10 children with either CAE or JAE (41).

\section{Miscellaneous data on neurodevelopmental problems}

Four studies assessed the prevalence of neuropsychological and/or neurodevelopmental problems (21, 29, 45, 52). In the study of Berg et al., neurodevelopmental disorders (Table 2) were present in 13 out of $51(26 \%)$ 


\section{Chapter 2}

patients (22). Fastenau et al. reported that $32 \%$ of 38 patients had at least one neuropsychological deficit in at least one domain (see table 2) (29). Sinclair et al. reported intellectual disability in $22 \%$ out of 119 children with CAE. Subgroup analysis showed intellectual disability in $16 \%$ of children with typical absences and $33 \%$ of children with $\mathrm{AE}$ and additional atypical features (45). Wirrell et al. reported cognitive difficulties at presentation in $24 \%$ out of 58 children with AE $(52)$. 


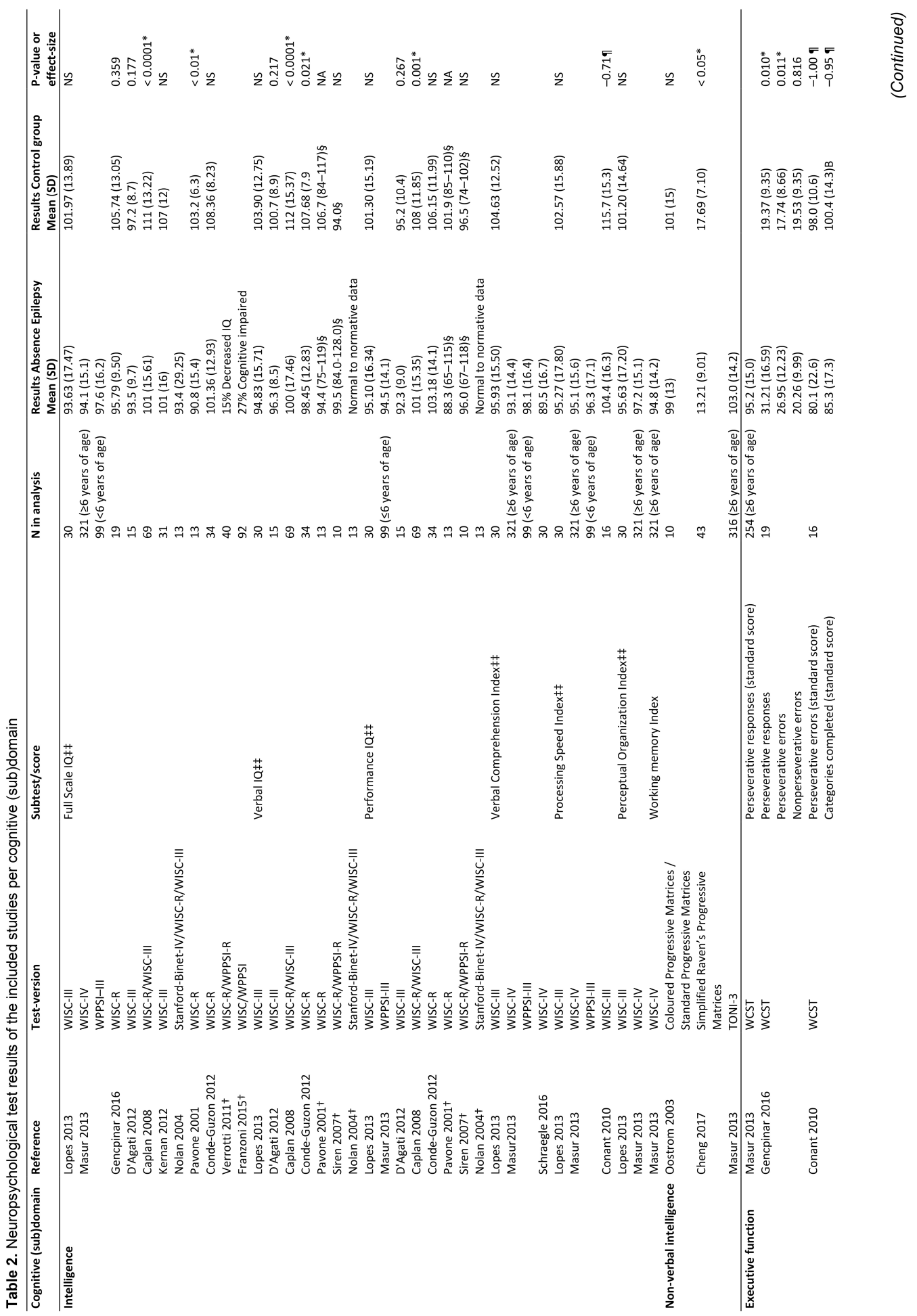




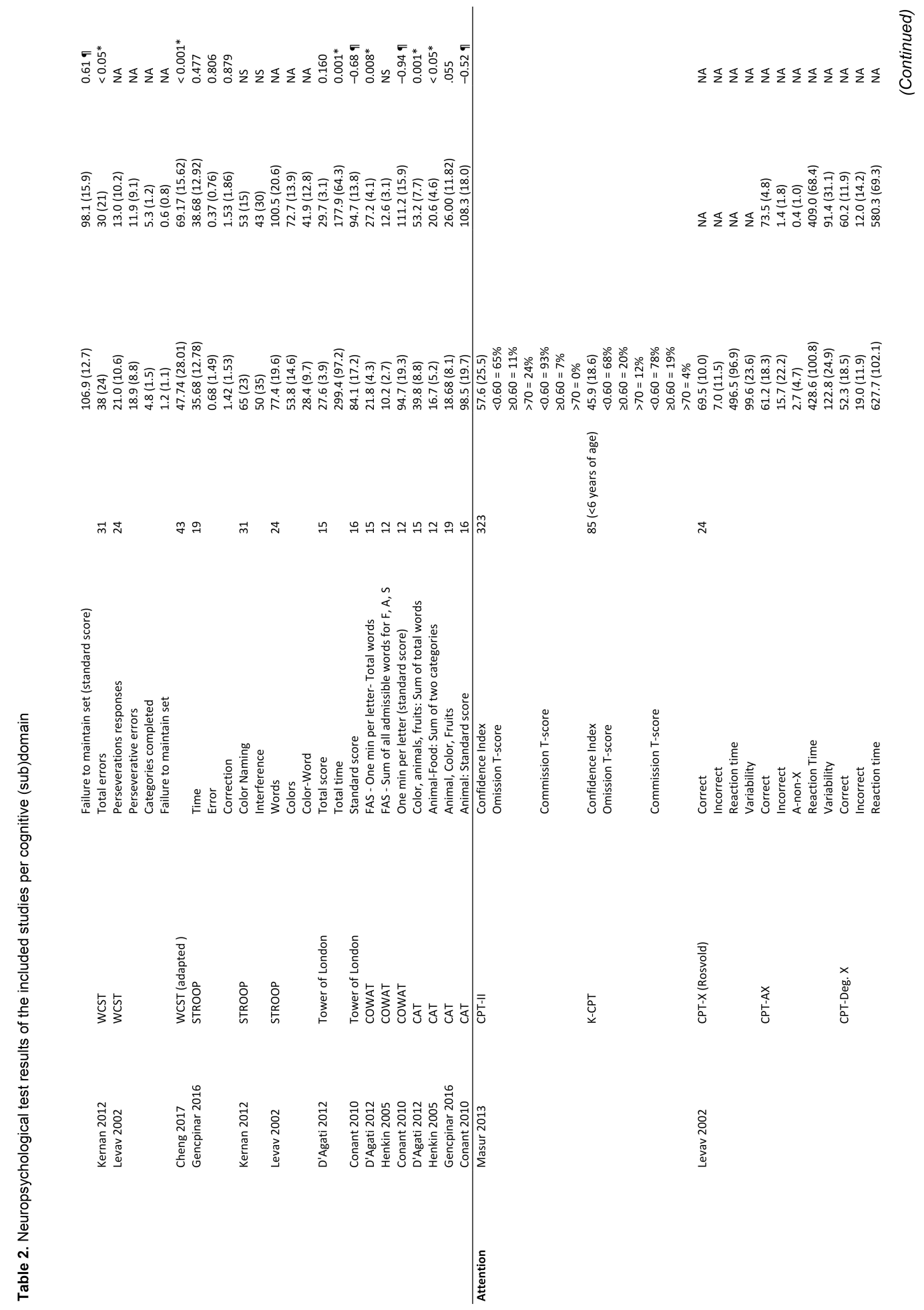




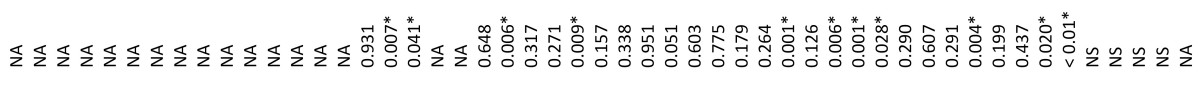

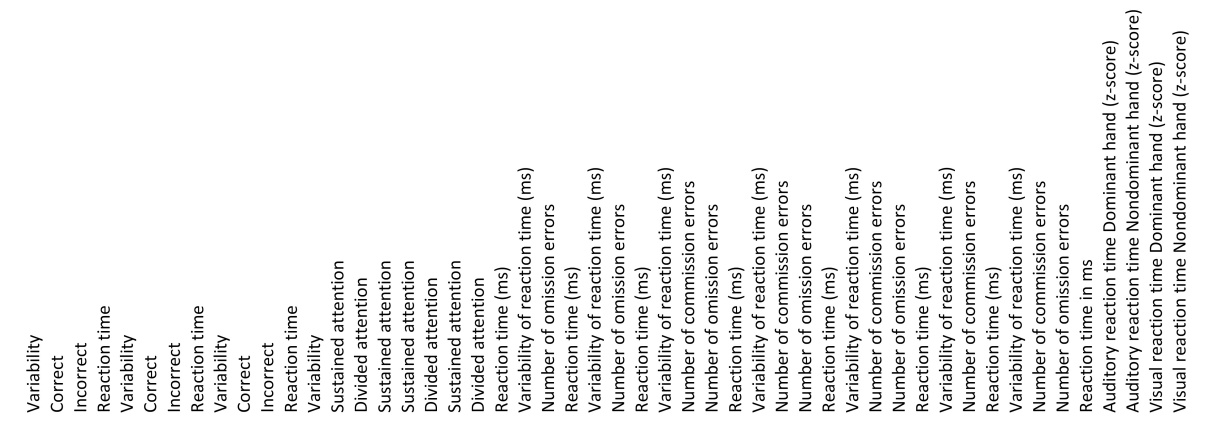




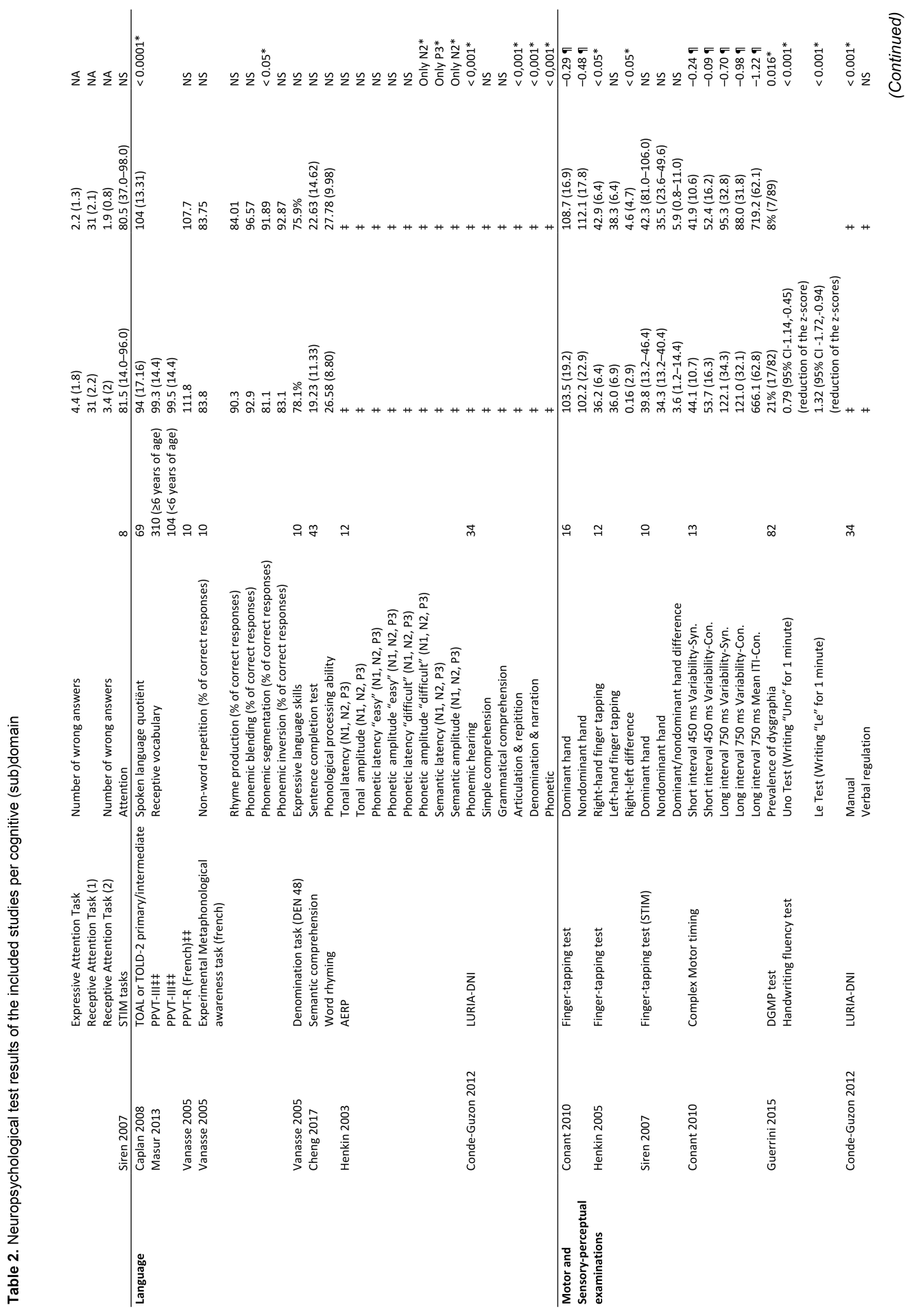




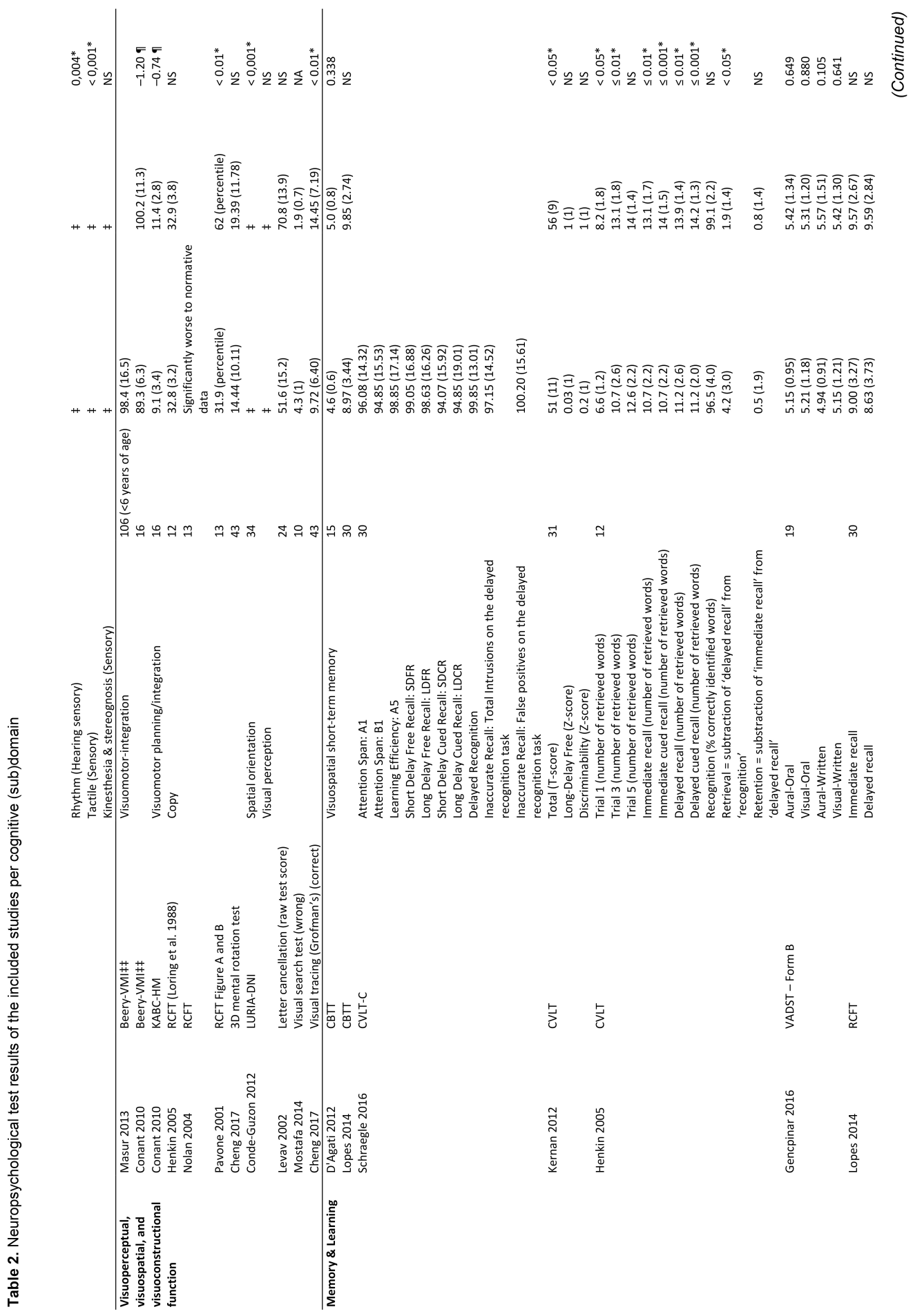




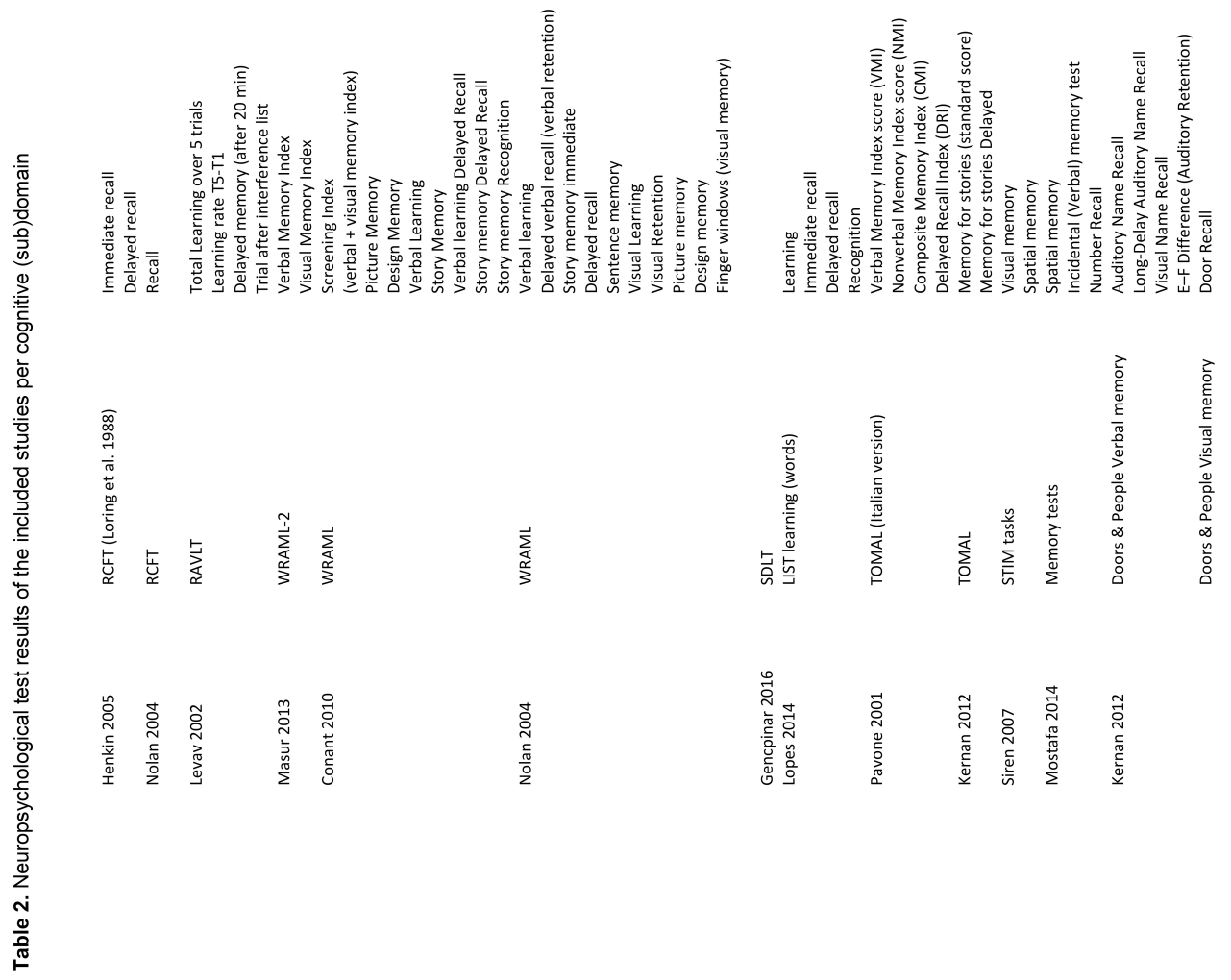


Towards a better understanding of cognitive deficits in absence epilepsy
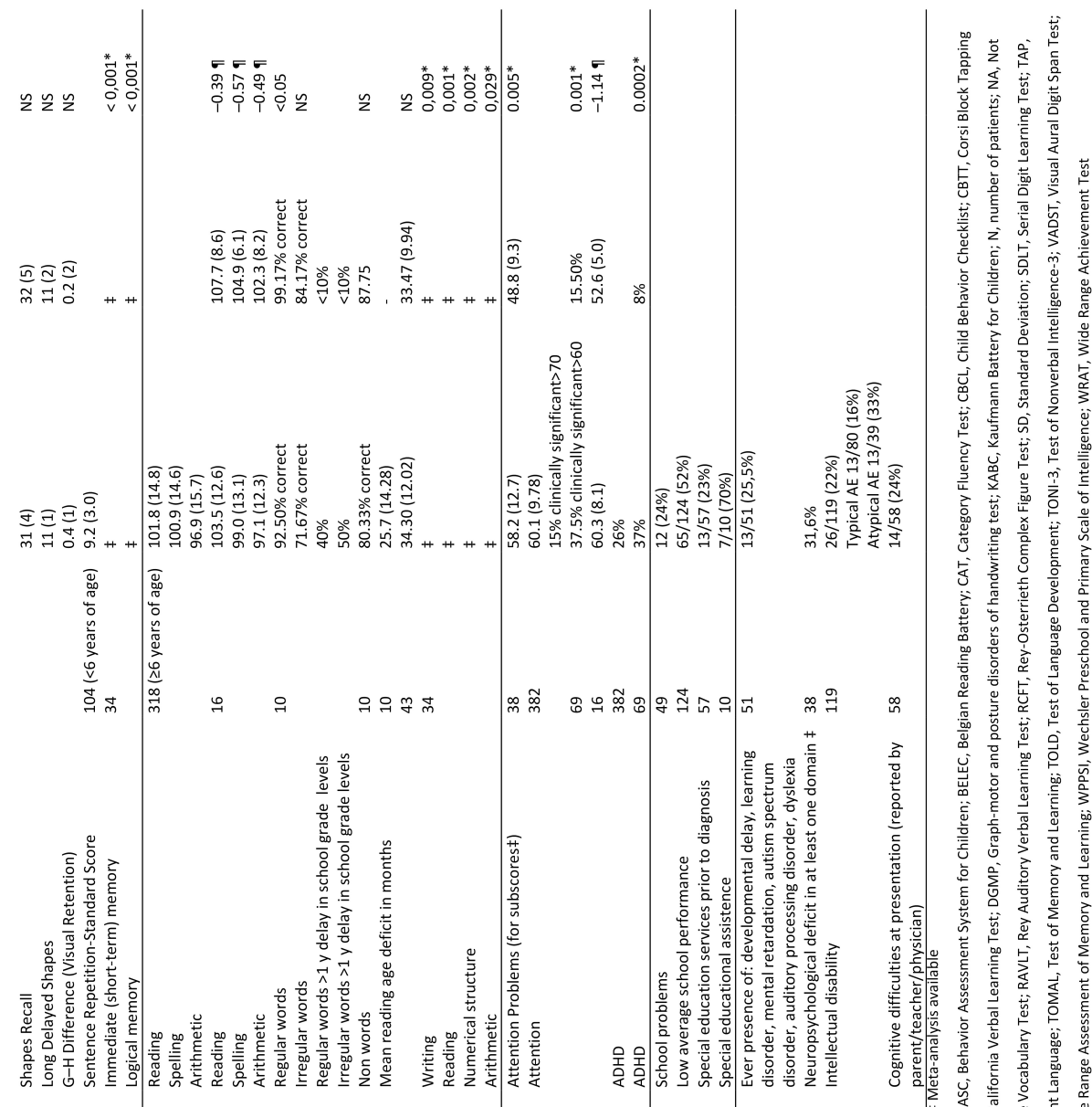

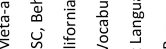




\section{Discussion}

The aim of this review was to systematically assess the literature on cognitive performance in $\mathrm{AE}$. Children with $\mathrm{AE}$ are regarded to have cognitive functioning within normal range $(14,15)$. Nevertheless, we found multiple studies reporting lower cognitive performance across a wide spread of cognitive domains. However, the exact degree of impaired cognitive functioning is difficult to estimate as the methodologies across studies vary and multiple neuropsychological tests have been used, which hampers comparisons between studies. Moreover, it is currently difficult to distinguish momentary effects on cognitive performance during the active stage of $\mathrm{AE}$ from long-lasting effects on cognitive functioning, as most studies reported on cognitive performance at different time-points after seizure onset. Some studies tested prior to introduction of anti-epileptic drug treatment, while others reported on a mixed population of children on or off anti-epileptic drug treatment and with or without ongoing seizures.

\section{Intelligence}

Full-scale IQ was estimated to be approximately three points lower on average compared to normative values. It is important to note that, although average performance in intelligence measures are statistically lower, the pooled averages still fall well within normal values. However, in case-control studies, the mean difference is larger with a difference of $\sim 8$ points in full-scale IQ, $\sim 9$ points in verbal IQ and $\sim 5$ points in performance IQ. There may be several explanations for these results. The mean IQ of the control subjects was significantly higher than normative values, which may simply resemble a higher average IQ in the studied population or geographical area. However, it may be due to exclusion of patients with a low IQ in several case-control studies (11, 28, 31, 34, 35, 38). Another explanation for a higher IQ in controls may be bias due to convenience sampling (e.g. children from academics), although this was not evident based on the methods used for the recruitment of control subjects in these studies. However, the estimated mean IQ in the single-arm meta-analysis in patients with AE is less subject to bias due to sampling error as a far larger proportion of the total population is being tested. Moreover, the estimated true variance $\left(T^{2}\right)$ for the single-arm meta-analyses was totally dependent on the three studies $(11,26,35)$ 
with the highest mean IQ scores in AE and controls. The estimated true variance $\left(T^{2}\right)$ was small for the pooled difference in case-control studies.

\section{Executive function}

Lower than average performance in executive functioning was noted in cognitive flexibility, planning and verbal fluency $(8,24,25,28,31,34-36)$. However, not all tests were indicative of lower executive functioning as results on the STROOP test did not differ.

\section{Attention}

There are clear indications for a lower performance in attention, such as sustained attention, selective attention and divided attention. From our meta-analysis, we can conclude that trail making $\mathrm{A}$ and $\mathrm{B}$ scores take significantly more time to perform by children with AE compared to controls, especially when attentional shifts (divided attention) are necessary. The estimated true variance $\left(T^{2}\right)$ for the trail making test B was high, however, this may be explained by differences in study design, as the study by Levav et al. reported in children $\geq 13$ years of age, which would probably require less seconds to finish the test than younger counterparts in the other two studies. Furthermore, in the study by Masur et al. sustained attention was mostly affected due to attentional lapses (errors of omission) rather than reflecting disinhibition (errors of commission) (8).

\section{Language}

Results on specific language tests are of particular interest, as verbal IQ was estimated to be lower in case-control studies, and a relatively low mean verbal comprehension index (in children $>6$ years of age) was reported in the study by Masur et al.(8). However, receptive vocabulary was not affected with the Peabody Picture Vocabulary Test in the study by Masur et al. (8). Two studies with a descent sample size may raise concerns regarding expressive language as found by Caplan et al. (although still within normal clinical range) and Conde-Guzon \& Cancho-Candela (11, 26). However, these two studies were characterized by relatively high verbal IQ's in controls. Therefore, data on language tests in AE remains inconclusive, but warrants further research. 


\section{Motor function}

Studies on simple motor tasks were inconclusive $(25,34,46)$. Complex motor tasks may be impaired but were only assessed in one study (25) and the control group was characterized by higher scores than the normative mean. Furthermore, one study found a higher prevalence of dysgraphia and diminished performance in handwriting fluency. These findings were associated with abnormal neurophysiological findings, which led the authors to conclude that these patients had a form of dystonic dysgraphia. Interestingly, 12 out of 17 patients with initial dysgraphia were re-tested 5-years later and showed resolution of dysgraphia and improved handwriting skills. In addition, Conde-Guzon and Cancho-Candela also reported worse performance in a writing test (26).

\section{Visuoperceptual, visuospatial, and visuoconstructional function}

Visual-motor integration from the Beery-VMI test did not differ from the normative mean in our meta-analysis, although only two studies were available. The lower mean score in the Beery-VMI in the study by Conant et al. may be due to a small study effect. Studies on visual search tests and visuospatial skills remain inconclusive $(24,26,34,36,39,40,42)$. Indeed, visual-spatial thinking ability in the meta-analysis of Loughman et al. in idiopathic generalized epilepsies did also not differ significantly in case-control studies (53).

\section{Learning and Memory}

Results on memory have yielded inconclusive results. The largest study on memory by Masur et al. suggests lower visual memory function, although still within normal clinical range (8). However, other studies on non-verbal memory tests have overall found average performance $(25,28,31,34,35,37,40,42,46)$. Furthermore, studies on verbal memory mostly showed normal performance ( 36 , $37,43)$. Nevertheless, some studies using subtests for memory for stories and with the California Verbal Learning Test did find lower performance compared to controls $(25,34,35)$. However, the observed difference with controls in the studies by Kernan et al. and Conant et al. might suggests a sample bias related to a higher functional level of the controls $(25,34)$. Only, one study found an overall lower than average performance in memory functioning, especially in short-term auditory, visual memory and logical memory, although this study was also 
potentially characterized by a better than average control group as reflected by the performance of the control group on the WISC-R (26). Sentence repetition was lower compared to the normative mean in the study by Masur et al. (8), although scores still fall within normal clinical range and may be related to attentional deficits.

\section{Achievement}

Arithmetic ability may be vulnerable based on our meta-analysis of the WRAT-3 test, although test scores fall within the normal clinical range. Nevertheless, arithmetic ability was also worse compared to controls in children with AE in the study by Conde-Guzon and Cancho-Candela . Evidence regarding reading ability, is contradictory, as the meta-analysis on the WRAT-3 test was not significantly lower, but other reading tests by Vanasse et al. and Conde-Guzon et al. did report worse performance compared to controls $(26,49)$.

\section{By proxy (parent-reported functioning)}

Studies using parental questionnaires also point towards attentional problems and a higher prevalence of attentional deficit hyperactivity disorder.

\section{Prevalence of school difficulties}

School difficulties seem more prevalent in patients with AE than in the normal population, as the three largest studies reported school difficulties in $23 \%$ to $52 \%$ $(22,27,48)$.

\section{Prevalence of neuropsychological and/or neurodevelopmental problems}

A prevalence of neuropsychological and/or neurodevelopmental problems were found in approximately $22 \%$ to $32 \%$ of the patients with CAE $(22,29,45,52)$. 


\section{General discussion}

Cognitive deficits in one area may be related to the performance in another cognitive domain. Masur et al. reported a direct sequential effect among attention, memory, executive function, and academic achievement (8). Therefore, the emergent pattern of clear attentional deficits in a proportion of children with absence epilepsy may influence performance in other cognitive domains. Nevertheless, the overall pattern suggests vulnerabilities in intelligence, attention and executive function. Less conclusive results were found for (expressive) language, motor function, visuo-perceptual functioning and learning \& memory. Ultimately, vulnerabilities in cognitive domains may impact neurocognitive development and lead to more academic difficulties.

How children with AE mature into adulthood is far less researched. The few studies that have investigated cognitive function during adulthood in patients with AE suggest that lower performance on neuropsychological tests may persist, but current studies are small in sample size. A study in $(\mathrm{n}=10)$ adults with CAE in remission reported a full-scale IQ of 92 (69-99), a performance IQ of 85 (66-117), with particularly low scores in the picture arrangement, block design and object assembly subtests of the WAIS-R (62). Language and executive function were also tested using specific tests, but did not differ with a control group. Recently Loughman et al. reported on cognitive function using the Woodcock-Johnson-III test of cognitive abilities in an adult population of genetic generalized epilepsy syndromes, including CAE $(\mathrm{n}=10)$ and JAE $(\mathrm{n}=21)$ patients (2017). This study reported lower scores on brief intellectual ability, crystallized intelligence, new learning/memory and speed of processing (63).

In conclusion, neurodevelopment may ultimately differ in $\mathrm{AE}$, as a study also found abnormal cortical thickness connectivity in various regions after in young adults with a history of CAE (64).

What the impact may be on their working careers and psychosocial well-being is another important question. In a telephone follow-up study, $25 \%$ of 52 retrospectively identified patients of 11 to 36 years old with CAE had a history of psycho-pedagogical help (65). Another study in patients focusing on long-term psychosocial outcome in juvenile myoclonic epilepsy (JME) with a mean age over 60 years used AE patients as an epilepsy matched-control group (66). To the 
surprise of the authors, a significantly lower amount of patients with a history of AE accomplished a university degree compared to controls. Nevertheless, the overall psychosocial outcome of this study was favorable. However, another study compared a group of patients with rheumatoid arthritis to patients with CAE and similar impact of "chronic disease" (67). Young adults with a history of CAE were more prone to working in jobs requiring minimum education, having more behavioral problems and psychiatric consultations. Therefore, the potential impact later on in life cannot be underestimated and deserves further scientific attention.

Cognitive findings may also be related to (inter)ictal activity, pharmacological effects or another underlying (genetic) vulnerability, but disentangling all factors may not be feasible. The use of valproate was associated with attentional dysfunction in the study by Masur et al. $(7-9,68)$. In addition, seizure duration of more than 20 seconds correlated well with attentional dysfunction and errors of omission (68). In the prospective cohort study of Caplan et al. verbal IQ was associated with duration of illness and AED treatment. Moreover, ADHD was associated with the duration of illness and seizure frequency (11). However, these associations have not been consistent across the literature.

Insights into possible underlying mechanisms are starting to be unraveled in recent years. Multiple studies using advanced magnetic resonance imaging (MRI) techniques in $\mathrm{AE}$ have for example found differences in brain regions or networks which are associated with executive function (64, 69-76), attention (70, 73, 74, 7678 ) and expressive language $(64,69,71,75,77,79,80)$.

\section{Limitations}

We opted to use single-arm meta-analyses and/or a meta-analysis of the difference between cases and controls. This was chosen as sampling error may be of greater influence in a relatively small sample of the normal population, than it would be to estimate the true mean in $\mathrm{AE}$, as a larger proportion of the group is likely to be included in a given geographical area. In addition, some studies did not match a control group specifically to children with AE as other types of epilepsy were also included. Therefore, residual confounding may still be present in those studies where there is a large age difference between patients with $\mathrm{AE}$ and controls. Some studies may have included patients with AE, which may have 
concomitant features, such as myoclonic jerks or atypical features. Also, some of the included studies focused on multiple epilepsy groups and therefore the findings of sub-analyses in patients with AE were often underpowered. Furthermore, some studies were relatively small in sample size and may be subject to a small-study effect. Importantly, multiple comparisons may have yielded falsepositive findings (type 1 errors) in the included studies. Furthermore, the Flynn effect, which is a tendency of IQ to rise by $\sim 3$ points per decade on average, may have a small but significant bearing on our results (81). Unfortunately, inconsistent reporting of neuropsychological test results across studies hindered comparison between studies and pooling of results. Granting that cognitive domains may overlap, assigning neuropsychological tests to a specific cognitive domain may lead to an oversimplified view.

\section{Future work}

Future work should focus on large (multi-center) long-term observational studies to assess cognitive development and to identify children with AE most at risk for neuropsychological co-morbidity. Importantly, this may clarify whether repeated neuropsychological tests could be helpful and how cognitive development differs from healthy peers. Emphasis should be made to characterize children with $\mathrm{AE}$ according to semiology, EEG characteristics, and epilepsy syndrome. Especially separate reporting in JAE is lacking. Early identification of children with concomitant cognitive dysfunctions may help health care workers to initiate additional supportive programs, as well as communicate vulnerabilities and discuss teaching strategies with their school. A broad neuropsychological test battery, focusing on executive functioning, attention and verbal abilities should be used. Ideally, this should be done before the start of anti-epileptic drugs and repeated at least once to track cognitive development. Given that cognitive dysfunctions may be case-specific, personalized supportive programs may be most useful, which may be discussed in a multidisciplinary team, consisting of at least a neurologist, neuropsychologists and a school expert. 


\section{Acknowledgements}

We would like to thank I. Gijselhart (librarian at Epilepsy Centre Kempenhaeghe)

for her assistance in building the search strategy and retrieving full-text articles.

\section{Compliance with Ethical Standards}

Funding: This research was made possible by collaborative funding by the MUMC+ and Epilepsy Centre Kempenhaeghe.

Conflict of Interest: The authors report that they do not have any conflict of interest. 


\section{References}

1. Guerrini R. Epilepsy in children. Lancet. 2006;367(9509):499-524.

2. Tenney JR, Glauser TA. The current state of absence epilepsy: can we have your attention? Epilepsy currents / American Epilepsy Society. 2013;13(3):135-40.

3. Myers T, Fecske E. The "staring" child. The Nurse practitioner. 2016;41(1):9-11.

4. Panayiotopoulos CP. Treatment of typical absence seizures and related epileptic syndromes. Paediatric drugs. 2001;3(5):379-403.

5. Hughes JR. Absence seizures: a review of recent reports with new concepts. Epilepsy \& behavior : E\&B. 2009;15(4):404-12.

6. Trinka E, Baumgartner S, Unterberger I, Unterrainer J, Luef G, Haberlandt E, et al. Longterm prognosis for childhood and juvenile absence epilepsy. J Neurol. 2004;251(10):1235-41.

7. Cnaan A, Shinnar S, Arya R, Adamson PC, Clark PO, Dlugos D, et al. Second monotherapy in childhood absence epilepsy. Neurology. 2017;88(2):182-90.

8. Masur D, Shinnar S, Cnaan A, Shinnar RC, Clark P, Wang J, et al. Pretreatment cognitive deficits and treatment effects on attention in childhood absence epilepsy. Neurology. 2013;81(18):1572-80.

9. Glauser TA, Cnaan A, Shinnar S, Hirtz DG, Dlugos D, Masur D, et al. Ethosuximide, valproic acid, and lamotrigine in childhood absence epilepsy. The New England journal of medicine. 2010;362(9):790-9.

10. IJff DM, van Veenendaal TM, Debeij-van Hall MH, Jansen JF, de Louw AJ, Majoie MH, et al. The Cognitive Profile of Ethosuximide in Children. Paediatric drugs. 2016;18(5):379-85.

11. Caplan R, Siddarth P, Stahl L, Lanphier E, Vona P, Gurbani S, et al. Childhood absence epilepsy: behavioral, cognitive, and linguistic comorbidities. Epilepsia. 2008;49(11):1838-46.

12. Loughman A, Bendrups NA, D'Souza WJ. A Systematic Review of Psychiatric and Psychosocial Comorbidities of Genetic Generalised Epilepsies (GGE). Neuropsychology review. 2016;26(4):364-75.

13. Bouma PA, Westendorp RG, van Dijk JG, Peters AC, Brouwer OF. The outcome of absence epilepsy: a meta-analysis. Neurology. 1996;47(3):802-8.

14. Adie WJ. Pyknolepsy; A form of Epilepsy in Children, with a good Prognosis. Proceedings of the Royal Society of Medicine. 1924;17(Neurol Sect):19-25.

15. Currier RD, Kooi KA, Saidman LJ. Prognosis of "Pure" Petit Mal; a follow-up study. Neurology. 1963;13:959-67.

16. Glauser TA, Cnaan A, Shinnar S, Hirtz DG, Dlugos D, Masur D, et al. Ethosuximide, valproic acid, and lamotrigine in childhood absence epilepsy: initial monotherapy outcomes at 12 months. Epilepsia. 2013;54(1):141-55.

17. Jafarian M, Karimzadeh F, Alipour F, Attari F, Lotfinia AA, Speckmann EJ, et al. Cognitive impairments and neuronal injury in different brain regions of a genetic rat model of absence epilepsy. Neuroscience. 2015;298:161-70.

18. Lenck-Santini PP, Scott RC. Mechanisms Responsible for Cognitive Impairment in Epilepsy. Cold Spring Harbor perspectives in medicine. 2015;5(10).

19. Nicolai J, Ebus S, Biemans DP, Arends J, Hendriksen J, Vles JS, et al. The cognitive effects of interictal epileptiform EEG discharges and short nonconvulsive epileptic seizures. Epilepsia. 2012;53(6):1051-9. 
20.

21.

22.

23.

24.

25.

26.

27.

28.

29.

30.

31.

32.

34.

35.

33. Henkin Y, Kishon-Rabin L, Pratt H, Kivity S, Sadeh M, Gadoth N. Linguistic processing in

Aldenkamp A, Arends J. The relative influence of epileptic EEG discharges, short nonconvulsive seizures, and type of epilepsy on cognitive function. Epilepsia. 2004;45(1):5463.

Berg AT, Caplan R, Hesdorffer DC. Psychiatric and neurodevelopmental disorders in childhood-onset epilepsy. Epilepsy \& Behavior. 2011;20(3):550-5.

Berg AT, Levy SR, Testa FM, Blumenfeld H. Long-term seizure remission in childhood absence epilepsy: might initial treatment matter? Epilepsia. 2014;55(4):551-7.

Cerminara C, D'Agati E, Casarelli L, Kaunzinger I, Lange KW, Pitzianti M, et al. Attention impairment in childhood absence epilepsy: an impulsivity problem? Epilepsy \& behavior : E\&B. 2013;27(2):337-41.

Cheng D, Yan X, Gao Z, Xu K, Zhou X, Chen Q. Common and Distinctive Patterns of Cognitive Dysfunction in Children With Benign Epilepsy Syndromes. Pediatric neurology. 2017;72:36-41.e1.

. Conant LL, Wilfong A, Inglese C, Schwarte A. Dysfunction of executive and related processes in childhood absence epilepsy. Epilepsy \& Behavior. 2010;18(4):414-23.

Conde-Guzon PA, Cancho-Candela R. Idiopathic generalized epilepsies with absence seizures with valproic acid treatment: neuropsychological disorders. Revista de neurologia. 2012;55(2):65-73.

Covanis A, Skiadas K, Loli N, Lada C, Theodorou V. Absence epilepsy: early prognostic signs. Seizure. 1992;1(4):281-9.

D'Agati E, Cerminara C, Casarelli L, Pitzianti M, Curatolo P. Attention and executive functions profile in childhood absence epilepsy. Brain \& development. 2012;34(10):812-7.

Fastenau PS, Johnson CS, Perkins SM, Byars AW, deGrauw TJ, Austin JK, et al. Neuropsychological status at seizure onset in children: risk factors for early cognitive deficits. Neurology. 2009;73(7):526-34.

Tranzoni E, Matricardi S, Di Pisa V, Capovilla G, Romeo A, Tozzi E, et al. Refractory absence seizures: An Italian multicenter retrospective study. European journal of paediatric neurology : EJPN : official journal of the European Paediatric Neurology Society. 2015;19(6):660-4.

Gencpinar P, Kalay Z, Turgut S, Bozkurt O, Duman O, Ozel D, et al. Evaluation of Executive Functions in Patients With Childhood Absence Epilepsy. Journal of child neurology. 2016;31(7):824-30.

32. Guerrini R, Melani F, Brancati C, Ferrari AR, Brovedani P, Biggeri A, et al. Dysgraphia as a Mild Expression of Dystonia in Children with Absence Epilepsy. PloS one. 2015;10(7):e0130883. idiopathic generalized epilepsy: an auditory event-related potential study. Epilepsia. 2003;44(9):1207-17.

Henkin Y, Sadeh M, Kivity S, Shabtai E, Kishon-Rabin L, Gadoth N. Cognitive function in idiopathic generalized epilepsy of childhood. Developmental medicine and child neurology. 2005;47(2):126-32.

Kernan CL, Asarnow R, Siddarth P, Gurbani S, Lanphier EK, Sankar R, et al. Neurocognitive profiles in children with epilepsy. Epilepsia. 2012;53(12):2156-63. 
36. Levav M, Mirsky AF, Herault J, Xiong L, Amir N, Andermann E. Familial association of neuropsychological traits in patients with generalized and partial seizure disorders. Journal of clinical and experimental neuropsychology. 2002;24(3):311-26.

37. Lopes AF, Monteiro JP, Fonseca MJ, Robalo C, Simoes MR. Memory functioning in children with epilepsy: frontal lobe epilepsy, childhood absence epilepsy, and benign epilepsy with centrotemporal spikes. Behavioural neurology. 2014;2014:218637.

38. Lopes AF, Simoes MR, Monteiro JP, Fonseca MJ, Martins C, Ventosa L, et al. Intellectual functioning in children with epilepsy: frontal lobe epilepsy, childhood absence epilepsy and benign epilepsy with centro-temporal spikes. Seizure. 2013;22(10):886-92.

39. Mostafa M, Talaat F, Shalaby N, El-Fayoumy N, Labib D. Cognitive impairment in idiopathic generalized epilepsies. Egyptian Journal of Neurology, Psychiatry and Neurosurgery. 2014;51(2):215-21.

40. Nolan MA, Redoblado MA, Lah S, Sabaz M, Lawson JA, Cunningham AM, et al. Memory function in childhood epilepsy syndromes. Journal of paediatrics and child health. 2004;40(12):20-7.

41. Oostrom KJ, Smeets-Schouten A, Kruitwagen C, Peters ACB, Jennekens-Schinkel A, DuSech. Not only a matter of epilepsy: Early problems of cognition and behavior in children with "epilepsy only" - A prospective, longitudinal, controlled study starting at diagnosis. Pediatrics. 2003;112(6):1338-44.

42. Pavone P, Bianchini R, Trifiletti RR, Incorpora G, Pavone A, Parano E. Neuropsychological assessment in children with absence epilepsy. Neurology. 2001;56(8):1047-51.

43. Schraegle WA, Nussbaum NL, Stefanatos AK. List-learning and verbal memory profiles in childhood epilepsy syndromes. Epilepsy \& behavior : E\&B. 2016;62:159-65.

44. Shinnar RC, Shinnar S, Cnaan A, Clark P, Dlugos D, Hirtz DG, et al. Pretreatment behavior and subsequent medication effects in childhood absence epilepsy. Neurology. 2017.

45. Sinclair DB, Unwala H. Absence epilepsy in childhood: electroencephalography (EEG) does not predict outcome. J Child Neurol. 2007;22(7):799-802.

46. Siren A, Kylliainen A, Tenhunen M, Hirvonen K, Riita T, Koivikko M. Beneficial effects of antiepileptic medication on absence seizures and cognitive functioning in children. Epilepsy \& behavior : E\&B. 2007;11(1):85-91.

47. Talero-Gutierrez C, Sanchez-Torres JM, Velez-van-Meerbeke A. Learning skills and academic performance in children and adolescents with absence epilepsy. Neurologia (Barcelona, Spain). 2015;30(2):71-6.

48. Urena-Hornos T, Rubio-Rubio R, Gros-Esteban D, Cabrerizo de Diago R, Pena-Segura JL, Lopez-Pison J. [Absence epilepsy. A review of our 14 years' experience]. Revista de neurologia. 2004;39(12):1113-9.

49. Vanasse CM, Beland R, Carmant L, Lassonde M. Impact of childhood epilepsy on reading and phonological processing abilities. Epilepsy \& behavior : E\&B. 2005;7(2):288-96.

50. Vega C, Vestal M, DeSalvo M, Berman R, Chung M, Blumenfeld H, et al. Differentiation of attention-related problems in childhood absence epilepsy. Epilepsy \& behavior : E\&B. 2010;19(1):82-5.

51. Verrotti A, Olivieri C, Agostinelli S, Coppola G, Parisi P, Grosso S, et al. Long term outcome in children affected by absence epilepsy with onset before the age of three years. Epilepsy \& behavior : E\&B. 2011;20(2):366-9. 
52. Wirrell EC, Camfield CS, Camfield PR, Gordon KE, Dooley JM. Long-term prognosis of typical childhood absence epilepsy: remission or progression to juvenile myoclonic epilepsy. Neurology. 1996;47(4):912-8.

53. Loughman A, Bowden SC, D'Souza W. Cognitive functioning in idiopathic generalised epilepsies: a systematic review and meta-analysis. Neuroscience and biobehavioral reviews. 2014;43:20-34.

54. Moher D, Liberati A, Tetzlaff J, Altman DG. Preferred reporting items for systematic reviews and meta-analyses: the PRISMA statement. Journal of clinical epidemiology. 2009;62(10):1006-12.

55. Baron IS. Neuropsychological evaluation of the child: Oxford University Press; 2004.

56. Marengoni A, Vetrano DL, Manes-Gravina E, Bernabei R, Onder G, Palmer K. The Relationship Between COPD and Frailty: A Systematic Review and Meta-Analysis of Observational Studies. Chest. 2018;154(1):21-40.

57. Viechtbauer W. Conducting meta-analyses in $\mathrm{R}$ with the metafor package. J Stat Softw. 2010;36(3):1-48.

58. Schwarzer G. Meta: An R package for meta-analysis. R news. 2007;7(3):40-5.

59. Borenstein M, Higgins JP, Hedges LV, Rothstein HR. Basics of meta-analysis: I(2) is not an absolute measure of heterogeneity. Research synthesis methods. 2017;8(1):5-18.

6o. Thompson SG, Higgins JP. How should meta-regression analyses be undertaken and interpreted? Statistics in medicine. 2002;21(11):1559-73.

61. Shuster JJ. Cochrane handbook for systematic reviews for interventions, Version 5.1. o, published 3/2011. Julian PT Higgins and Sally Green, Editors. Research synthesis methods. 2011;2(2):126-30.

62. Hommet C, Billard C, Motte J, Passage GD, Perrier D, Gillet P, et al. Cognitive function in adolescents and young adults in complete remission from benign childhood epilepsy with centro-temporal spikes. Epileptic disorders : international epilepsy journal with videotape. 2001;3(4):207-16.

63. Loughman A, Bowden SC, D'Souza WJ. A comprehensive assessment of cognitive function in the common genetic generalized epilepsy syndromes. European journal of neurology : the official journal of the European Federation of Neurological Societies. 2017;24(3):453-60.

64. Curwood EK, Pedersen M, Carney PW, Berg AT, Abbott DF, Jackson GD. Abnormal cortical thickness connectivity persists in childhood absence epilepsy. Annals of clinical and translational neurology. 2015;2(5):456-64.

65. Martinez-Ferrandez C, Martinez-Salcedo E, Casas-Fernandez C, Alarcon-Martinez H, Ibanez-Mico S, Domingo-Jimenez R. Long-term prognosis of childhood absence epilepsy. Neurologia (Barcelona, Spain). 2017.

66. Holtkamp M, Senf P, Kirschbaum A, Janz D. Psychosocial long-term outcome in juvenile myoclonic epilepsy. Epilepsia. 2014;55(11):1732-8.

67. Camfield CS, Camfield PR. Long-term social outcomes for children with epilepsy. Epilepsia. 2007;48:3-5.

68. Dlugos D, Shinnar S, Cnaan A, Hu F, Moshe S, Mizrahi E, et al. Pretreatment EEG in childhood absence epilepsy: associations with attention and treatment outcome. Neurology. 2013;81(2):150-6. 
69. Bai X, Guo J, Killory B, Vestal M, Berman R, Negishi M, et al. Resting functional connectivity between the hemispheres in childhood absence epilepsy. Neurology. 2011;76(23):1960-7.

7o. Berman R, Negishi M, Vestal M, Spann M, Chung MH, Bai X, et al. Simultaneous EEG, fMRI, and behavior in typical childhood absence seizures. Epilepsia. 2010;51(10):2011-22.

71. Caplan R, Levitt J, Siddarth P, Wu KN, Gurbani S, Sankar R, et al. Frontal and temporal volumes in Childhood Absence Epilepsy. Epilepsia. 2009;50(11):2466-72.

72. Carney PW, Masterton RA, Flanagan D, Berkovic SF, Jackson GD. The frontal lobe in absence epilepsy: EEG-fMRI findings. Neurology. 2012;78(15):1157-65.

73. Li Q, Cao W, Liao X, Chen Z, Yang T, Gong Q, et al. Altered resting state functional network connectivity in children absence epilepsy. Journal of the neurological sciences. 2015;354(12): $79-85$.

74. Luo C, Yang T, Tu S, Deng J, Liu D, Li Q, et al. Altered intrinsic functional connectivity of the salience network in childhood absence epilepsy. Journal of the neurological sciences. 2014;339(1-2):189-95.

75. Tosun D, Siddarth P, Toga AW, Hermann B, Caplan R. Effects of childhood absence epilepsy on associations between regional cortical morphometry and aging and cognitive abilities. Human brain mapping. 2011;32(4):580-91.

76. Zhang Z, Liao W, Wang Z, Xu Q, Yang F, Mantini D, et al. Epileptic discharges specifically affect intrinsic connectivity networks during absence seizures. Journal of the neurological sciences. 2014;336(1-2):138-45.

77. Luo C, Li Q, Lai Y, Xia Y, Qin Y, Liao W, et al. Altered functional connectivity in default mode network in absence epilepsy: a resting-state fMRI study. Human brain mapping. 2011;32(3):438-49.

78. Killory BD, Bai X, Negishi M, Vega C, Spann MN, Vestal M, et al. Impaired attention and network connectivity in childhood absence epilepsy. NeuroImage. 2011;56(4):2209-17.

79. Holmes MD, Brown M, Tucker DM. Are "generalized" seizures truly generalized? Evidence of localized mesial frontal and frontopolar discharges in absence. Epilepsia. 2004;45(12):156879 .

8o. Tucker DM, Brown M, Luu P, Holmes MD. Discharges in ventromedial frontal cortex during absence spells. Epilepsy \& Behavior. 2007;11(4):546-57.

81. Trahan LH, Stuebing KK, Fletcher JM, Hiscock M. The Flynn effect: a meta-analysis. Psychological bulletin. 2014;140(5):1332-6o. 


\section{Supplementary materials}

\section{Examplary Search in Pubmed}

((((((()(("epilepsy, absence"[MeSH]) OR "absence epilepsy") OR "absence seizure") OR "absence seizures") OR "absence epilepsies") OR "pykno-epilepsy") OR "juvenile absence") OR "childhood absence") OR "petit mal") OR "pyknolepsy") ) AND $(((()(((()((()((()(($ prevalence) $)$ OR long-term) OR casecontrol) OR retrospective) OR modifier*) OR risk) OR prognos*) OR "prognosis"[MeSH]) OR predict*) OR "Epidemiologic studies"[MeSH]) OR cohort) OR longitudinal) OR "follow up") OR "followup") OR "follow-up") OR course) OR incidence[TW]) OR "incidence"[MeSH]) OR protect*) OR "epidemiologic factors"[MeSH]) OR "clinical study"[Publication Type]) OR "clinical study") OR "trial") 


\section{Newcastle-Ottawa Quality Assessment Form for Cohort Studies}

Note: A maximum of one star for each numbered item within the Selection and Outcome categories. A maximum of two stars can be given for Comparability.

\section{Selection}

1) Representativeness of the exposed cohort

Star a) Truly representative

Star b) Somewhat representative

c) Selected group

d) No description of the derivation of the cohort

2) Selection of the non-exposed cohort

Star a) Drawn from the same community as the exposed cohort

b) Drawn from a different source

c) No description of the derivation of the non-exposed cohort

3) Ascertainment of exposure

Star a) Secure record

b) Inadequately described

4) Demonstration that outcome of interest was not present at start of study

Star a) Yes (one star)

b) No

\section{Comparability (maximum of two stars)}

1) Comparability of cohorts on the basis of the design or analysis controlled for confounders

Star a) The study controls for age and/or sex

Star b) Study controls for other factors (list)

c) Cohorts are not comparable on the basis of the design or analysis controlled for

confounders

\section{Outcome}

1) Assessment of outcome

Star a) Independent blind assessment

Star b) Validated test

c) Inadequate description of non-validated test and/or no blind assessment in non-

validated tests

2) Sample size

Star a) Justified and satisfactory

b) Small

3) Statistical analyses

Star a) Appropriate statistical analysis, reporting of all planned analyses

Star b) Only minor problems in statistical analysis

c) Inappropriate statistical analysis, selective reporting 


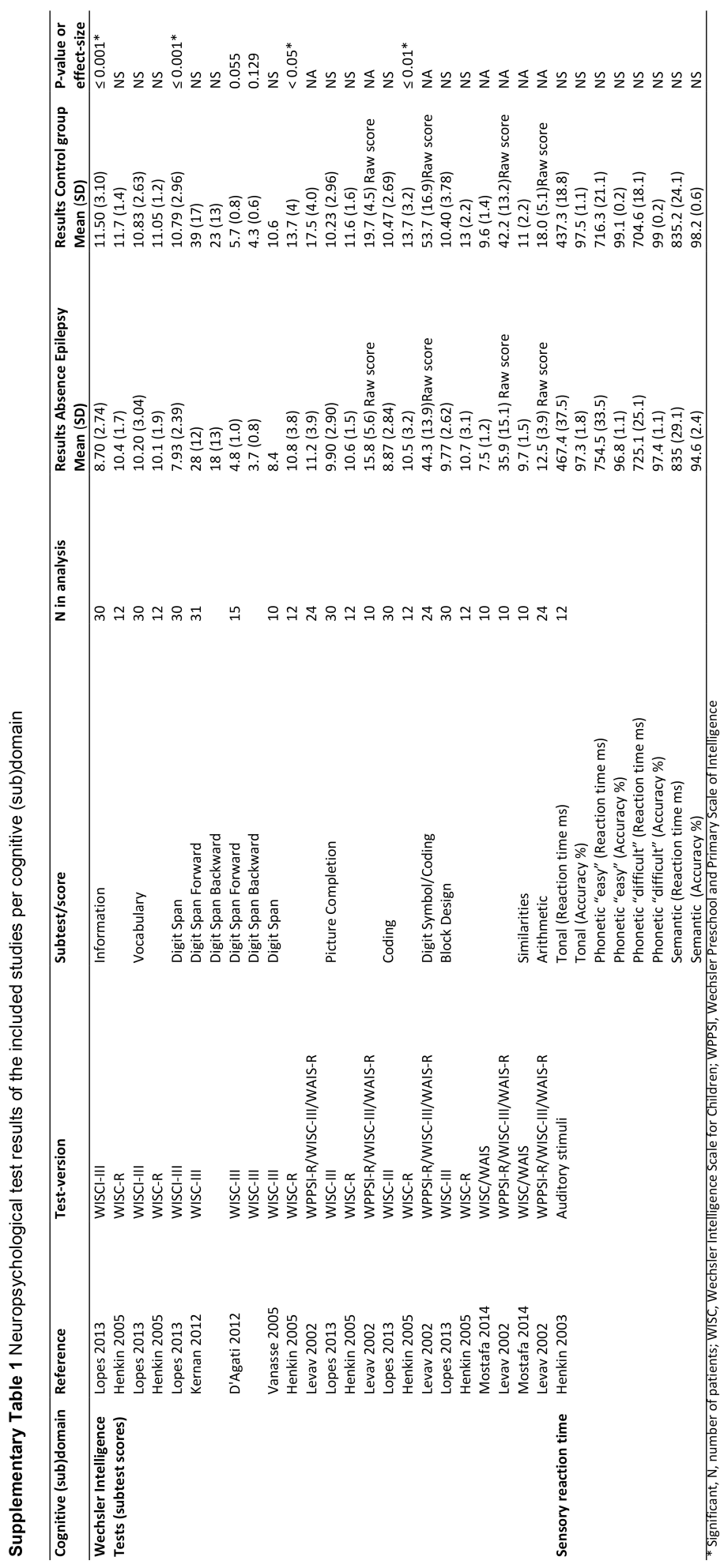




\section{Funnel-plots of the included meta-analyses}

Full-scale IQ

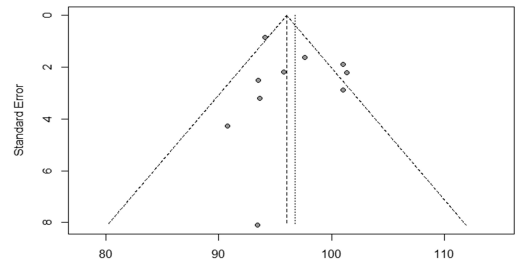

Verbal IQ

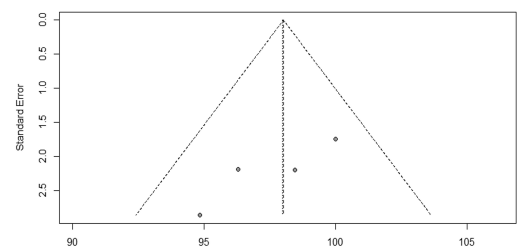

Performance IQ

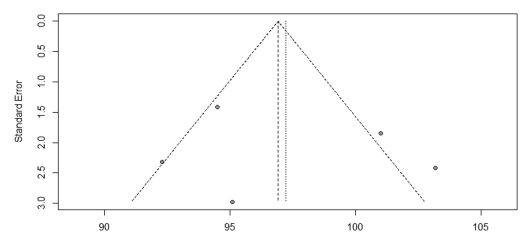

Trail Making Test A (Case-control)

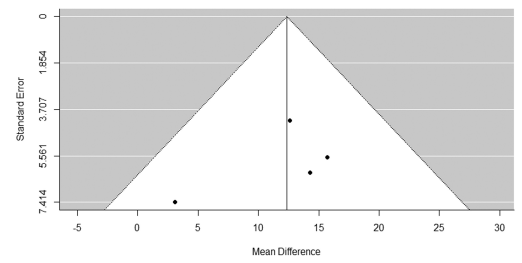

WRAT Arithmetic
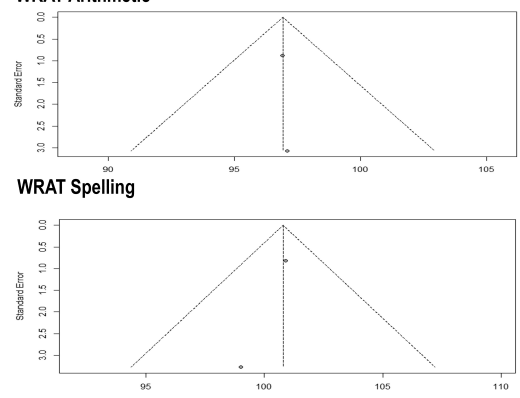

Full-scale IQ (Case-control)

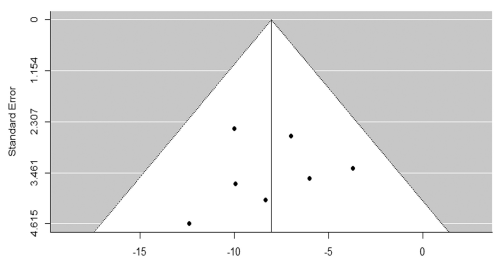

Verbal IQ (Case-control)

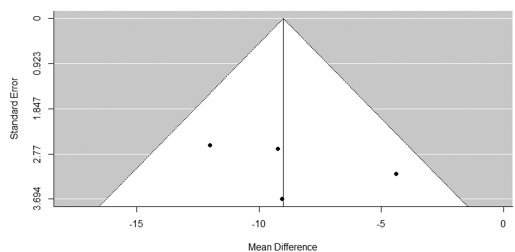

Performance IQ (Case-control)

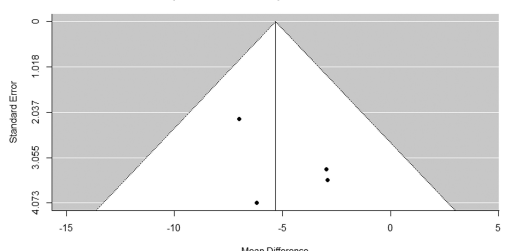

Trail Making Test B (Case-control)

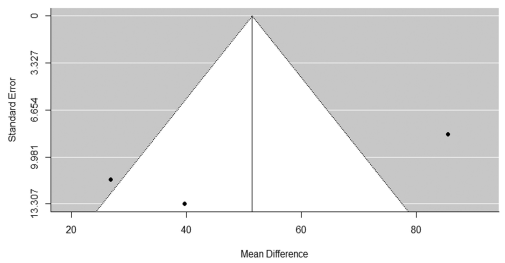

WRAT Reading

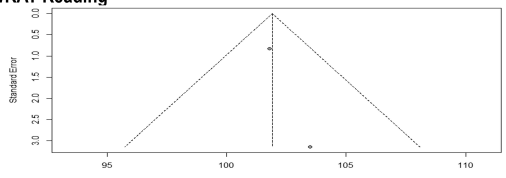

Beery Visual Motor Integration (VMI)

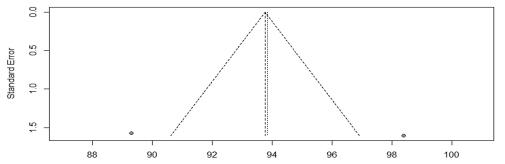


Towards a better understanding of cognitive deficits in absence epilepsy 


$$
5
$$




\section{Cognitive development in absence epilepsy during long-term follow-up}

Eric L.A. Fonseca Wald

Sylvia Klinkenberg

Twan P.C. Voncken

Saskia C.M. Ebus

Albert P. Aldenkamp Johan S.H. Vles

R. Jeroen Vermeulen Jos G.M. Hendriksen Mariette H.J.A. Debeij-van Hall

Child neuropsychology. 2019:1-19. 


\begin{abstract}
Absence epilepsy (AE) has been associated with lower than average cognitive functioning, which are clinically relevant in some and may predispose to problems later in life. This study aimed to assess cognitive development during long-term follow-up in children with AE.
\end{abstract}

Thirty-one children with AE, who had undergone two neuropsychological assessments between 2010-2017 were analyzed retrospectively. Cognitive measurements were $1.7 \pm 0.95$ years apart. The difference in neurocognitive test scores was assessed on a group-level and on an individual-level using reliable change methodology.

Results show that sustained attention was lower at the first measurement compared to the normative mean. Sustained attention improved during follow-up and 7 out of 14 children showed improvement after correction for practice effects. Receptive vocabulary showed a decline over time, but did not differ from the normative mean. Significant lower mean group-scores were present for performance-IQ, perceptual organization, processing speed, simple reaction times, and visual-motor-integration, while being stable over time in the majority of children. Cognitive development was not associated with seizure freedom. Mild-to-severe academic underachievement was present in $65 \%$ and comorbidities that might affect learning in $38 \%$.

This study in children with AE showed improvement in sustained attention during long-term follow-up while other cognitive weaknesses persisted over time, regardless of seizure freedom. 


\section{Introduction}

Absence epilepsy, one of the most common epilepsy syndromes in children, is characterized clinically by frequent episodes of brief unconsciousness and neurophysiologically by generalized $\sim 3-\mathrm{Hz}$ spike-and-wave complexes on the electroencephalogram (EEG) (1). Absence seizures are the hallmark of both childhood absence epilepsy (CAE) and juvenile absence epilepsy (JAE). Although classified as two different syndromes, overlap exists and the clinical separation may be challenging (2-5). CAE presents most often between 4 and 10 years of age, whereas JAE usually starts between 10 and 17 years of age. Furthermore, in CAE absence seizures occur more frequently, whereas the frequency of tonic-clonic seizures and chronic drug dependency is lower compared to JAE $(3,6,7)$.

Starting from early descriptions, children with AE have been considered to have a normal cognitive functioning $(8,9)$. In the last two decades, however, numerous studies have reported cognitive weaknesses in children with $\mathrm{AE}$ in various cognitive domains such as intelligence, executive functioning, attention, and language (10-17).

Nevertheless, data on the course of cognitive functioning in children with AE are still scarce as most studies only report cross-sectional data. A longitudinal study on cognitive development in a heterogeneous group of children with epilepsy $($ CAE $n=2)$ found that performance IQ was initially lower than verbal IQ, however this discrepancy decreased over time during the course of the epilepsy (18). To date, only two studies investigated cognitive performance in AE over time. Both studies used a limited follow-up period between 10 to 12 months. Siren et al. measured cognitive performance before and 10 months after the introduction of medication in a small sample $(n=6-10)$ of children with AE (19). No significant change was found in verbal-IQ, performance-IQ, auditory/visual reaction times and spatial memory. Significant improvements were noted in visual memory, finemotor fluency, and attention; however, the control group did also improve in finemotor fluency and attention. Furthermore, the authors speculated that the lack of improvement in verbal-IQ compared to the improvement observed in the control group may indicate an attenuation of the practice or maturation effect. The second study a large randomized clinical trial reported attentional deficits in onethird of drug-naïve patients at the time of diagnosis. These attentional deficits 
persisted after one-year follow-up despite successful treatment or the randomly allocated treatment (11, 20-22). Based on behavioral questionnaires from the same trial, attentional problems seem to improve during one year of follow-up (23). Nevertheless, follow-up data within other cognitive domains were not available. We hypothesized that cognitive deficits in children with AE would show an improvement over time during adequate treatment.

Additional data on neurocognitive development and follow-up in children with $\mathrm{AE}$ is needed, especially since the benign nature of this syndrome has been questioned (17). Persistence of cognitive weaknesses may hamper normal neurocognitive development, potentially leading to problems later in life. Moreover, only limited data on neurocognitive development in AE are currently available and are either based on the average change in test scores or a change in the prevalence of cognitive deficits in a sample. No data exists on individual changes in cognitive development. This is especially important as average changes do not reflect individual changes per se and individual changes are only reliable if they exceed the measurement error of the test (24).

The primary aim of the current study is to report on the long-term follow-up of cognitive development using two consecutive cognitive measurements in children with AE. This is done by retrospectively analyzing cognitive development on a group-level and on an individual level.

\section{Methods}

\section{Inclusion}

Children with a clinical diagnosis of AE referred between 2010 and 2017 to Kempenhaeghe Epilepsy Centre, a tertiary epilepsy centre, were included based on the following criteria: 1) Patients with absences seizures with an onset between 218 years of age and an EEG showing ictal $3 \mathrm{~Hz}(2.5-4.5 \mathrm{~Hz})$ generalized rhythmic (poly)spike-and-wave complexes or in adolescence faster irregular $3.5-6 \mathrm{~Hz}$ generalized spike-and-wave and polyspike-and-waves (a diagnosis according to ILAE statements for CAE and JAE (25-27); 2) A clinical follow-up duration of at least 1-year with a minimum of two neuropsychological assessments. It was not a requirement for the patient to be drug-naïve at the first assessment. All included 
children and/or parents had given permission for the use of medical charts for research purposes. This research protocol was approved by the local medical ethics committee.

\section{Clinical, neuropsychological and educational achievement assessment}

All children underwent at least two multidisciplinary assessments as part of regular clinical care, which included a medical assessment, an ambulatory $24 \mathrm{~h}-$ EEG, a neuropsychological/behavioural assessment and an academic assessment. A description of the neuropsychological and educational-achievement tests used is presented in Table 1. Neuropsychological tests were classified to cognitive domains using Baron's distinction of different neurocognitive domains in child neuropsychology (28). The following neurocognitive domains were systematically assessed: intelligence, attention, visual-perceptual function, language and memory/learning.

All medical charts were carefully inspected and clinical data such as the age of onset, semiology, drug-history, (24h)-(video)-EEG findings, and school performances were collected in an online data management system (Castor Electronic Data Capture, CIWIT bv, The Netherlands). EEG reports were all scored by a clinical neurophysiologist. Presence of school and behavioral problems were derived from reports of a neuropsychologist and academic evaluations by a school-specialist and defined according to Massa et al. 2001 (Table 2) (29). Educational underachievement was defined as: absent; mild, reported by teachers but allowing normal schooling; moderate, requiring individualized help (1-year delay); severe, requiring special educational measures ( $\geq 2$-year delay). Behavioral problems were defined as: absent; mild, reported by parents but causing minor harm to others; moderate, requiring psychotherapeutic or pharmacologic interventions; severe, provoking major difficulties despite adequate management.

\section{Statistical Analysis}

Neurocognitive development on a group-level

Mean scores for each neurocognitive test were compared to the normative mean using a one-sample t-test. The mean difference between the two measurements was calculated as an absolute difference and calculated as the difference per year 
to account for differences in follow-up time and tested using a one-sample t-test. A p-value of 0.05 was considered to indicate statistical significance.

\section{Neurocognitive development per individual}

Average changes in neurocognitive domains on a group level do not equal the amount of significant change in neurocognitive performance on an individual level per se. Different methods have been described to assess individual change, such as the reliable change methodology and regression-based methods (30). A widely adopted method is the reliable change index (RCI) methodology, initially described by Jacobsen \& Truax (31), which is preferred over regression-based methods for assessing reliable change in studies without a large sample size (30). The RCI determines whether a change in function exceeds the probable range of measurement error (24). The RCI requires a calculation of the standard error of the difference (SEdiff). Subsequently, the amount of change in test scores is divided by the SEdiff. Therefore, the magnitude of change is expressed relative to the SEdiff. If the RCI exceeds the critical value (for example \pm 1.64 or \pm 1.94 ) it is considered a reliable change. With this method the probability (area under the curve) of the change happening due to chance can be calculated. This would not be possible by calculating cut-off values for reliable change for each test (by multiplying the SEdiff of the test by the critical value). This is important as the use of multiple tests increases the likelihood of finding reliable changes due to chance (30). For this study, we considered a critical value of $\pm 1.64(90 \% \mathrm{CI})$ as a reliable change, as used by Brooks et al. (32). Based on this critical value $\sim 5 \%$ of reliably improved and $\sim 5 \%$ of reliably declined scores is expected in a non-clinical population.

An important factor to take in to account when calculating reliable change is the presence of practice effects with serial neurocognitive assessments. The interval between measurements in this study of at least one year or more reduces the magnitude of practice effects, although a residual practice effect cannot be entirely discarded. Therefore, the RCI calculations were corrected for the average change in test scores between the first and second measurement as has been used by others $(24,32,33)$. However, this method does not account for the range of practice effects, as some may improve and others may worsen (30). It has been proposed that correction for practice effects is only required if at least $>75 \%$ of the sample shows an improvement, but this cut-off may still be arbitrary (34). Instead, 
we did not correct for practice effects if the overall difference in cognitive mean scores was negative. In some instances, we opted to report RCIs with and without correction for practice effects. Most studies on test-retest scores have been performed in healthy subjects over a relatively short period of time (2-6 weeks). Little is known on test-retest results over a long period of time in healthy subjects and whether this resembles test-retest scores in clinical samples. Therefore, we preferably used reliability coefficients based on internal consistency (e.g. Cronbach's alpha), rather than test-retest coefficients. Although no consensus exists on this matter, the use of internal consistency has been recommended for clinical samples $(35,36)$. If available, reliability coefficients corresponding to a specific age group were used (as these constitute large tables, we refer to the test manuals for reference). Furthermore, when calculating the RCI, the normative SD was used, as the difference was based on standardized scores (corrected for age). For each measurement, a standard error of measurement was calculated by multiplying the standard deviation with the square root of minus 1 the reliability coefficient.

Formulas used to calculate the Reliable Change Index $R C I=\frac{\text { Change in test scores over time }}{S E d i f f}=\frac{2 \text { nd score }-1 \text { st score }}{\sqrt{(S D \sqrt{1-r 1})^{2}+(S D \sqrt{1-r 2})^{2}}}$

$R C I_{(\text {corrected for practice effects })}=\frac{\left(2 n d \text { score }-\left(\overline{x_{2}}-\overline{x_{1}}\right)\right)-1 \text { st score }}{\sqrt{(S D \sqrt{1-r 1})^{2}+(S D \sqrt{1-r 2})^{2}}}$

Abbreviations: $S D$, normative standard deviation of the test; 11 ; correlation coefficient (internal consistency or test-retest coefficient) for the $1^{\text {st }}$ measurement derived from test manuals; $r 2$, correlation coefficient (internal consistency or test-retest coefficient) for the second measurement derived from test manuals; $R C l$, reliable change index; $\bar{x} 1$, sample mean at first measurement; $\bar{x} 2$, sample mean at the second measurement.

\section{Explorative correlations with cognitive development}

Bivariate correlations with the average change in test scores were computed for the following clinical parameters: age of onset; total duration of epilepsy; seizure freedom at second neurocognitive assessment; the difference in drug-load 
between measurements. The following EEG parameters were considered: the longest observed duration of generalized spike-and-wave discharges recorded by EEG in seconds (longest GSW discharge); presence of a focal onset with rapid generalization in one or more of the generalized discharges (defined as one second of focal discharge before generalization) (Focal onset); presence of ictal and/or inter-ictal polyspikes; the index per hour of generalized spike-and-wave discharges $(\geq 3 \mathrm{sec}$ ) counted in two random hours and the first hour after awakening (seizure frequency). For normally distributed data the Pearson's chisquare test for correlation was used and for not normally distributed data the Spearman rank test was used. A p-value of 0.05 was considered to indicate statistical significance. All analyses were performed using SPSS (version 23, IBM, USA).

Table 1 Description of neurocognitive and educational achievement tests

\begin{tabular}{|c|c|c|}
\hline Cognitive domain & Test & Description \\
\hline Intelligence & $\begin{array}{l}\text { WISC-III-NL (Kort et al., 2005; } \\
\text { Wechsler, 1992) }\end{array}$ & $\begin{array}{l}\text { An intelligence test for children aged 6;0 to } 17 \text { years, consisting of } 13 \text { subtests. Intellectual ability in } \\
\text { this study was expressed in Full-scale IQ, Verbal IQ, Performance IQ, Perceptual Organization Index, } \\
\text { Verbal Comprehension Index and Processing Speed Index. }\end{array}$ \\
\hline \multirow[t]{5}{*}{ Attention } & Bourdon-Vos (Vos, 1988) & $\begin{array}{l}\text { A cancellation test requiring sustained attention and vigilance for visual stimuli, for children aged } 6 \text { to } \\
17 \text { years. The test consists of a page with } 33 \text { lines with } 24 \text { dotted characters, in which a specific figure } \\
\text { (target stimulus) has to be crossed out as quickly and accurate as possible. }\end{array}$ \\
\hline & Iron Psyche (FePsy 2.0)(Alpherts \& & Computerized neuropsychological battery for children from $+/-7$ years of age. \\
\hline & Aldenkamp, 1995) & 1) Reaction times for simple auditory or visual stimuli are measured. \\
\hline & $\begin{array}{l}\text { 1) Auditory/visual reaction time } \\
\text { 2) Binary choice task }\end{array}$ & $\begin{array}{l}\text { 2) The binary choice task consists of } 60 \text { visual stimuli, in which a colored dot appears and the button } \\
\text { on the same side (left or right) has to be pressed. }\end{array}$ \\
\hline & 3) CVST & $\begin{array}{l}\text { A visual searching task, measuring visual (complex) information processing and perceptual-mental } \\
\text { strategies. It consists of } 24 \text { screens of } 24 \text { checkerboards, in which the identical figure to the one in the } \\
\text { middle has to be found as quickly as possible. Adapted from Goldstein's visual searching task. }\end{array}$ \\
\hline $\begin{array}{l}\text { Visual-perceptual } \\
\text { function }\end{array}$ & Beery-VMI (Beery \& Beery, 2006) & $\begin{array}{l}\text { Visual-motor integration tests, for children from } 2 \text { years of age. It consists of a developmental } \\
\text { sequence of } 27 \text { geometric forms to be copied with paper and pencil. }\end{array}$ \\
\hline Language & PPVT-III-NL (Dunn \& Dunn, 1997) & $\begin{array}{l}\text { A receptive vocabulary and verbal ability test in children from } 2 ; 03 \text { years old. The test is administered } \\
\text { verbally and no reading is required. It consists of pages with four pictures of which the picture } \\
\text { corresponding to the spoken word by the examiner has to be identified. }\end{array}$ \\
\hline Memory \& Learning & $\begin{array}{l}\text { R-AVLT(Kalverboer \& Deelman, } \\
\text { 1986) }\end{array}$ & $\begin{array}{l}\text { Rey auditory verbal learning task: An auditory-verbal memory test, for children from } 6 \text { years of age, } \\
\text { consisting of } 5 \text { rounds of immediate recall of } 15 \text { spoken words. After } 20 \text { minutes it is followed by a } \\
\text { round of delayed recall. }\end{array}$ \\
\hline \multicolumn{3}{|c|}{ Educational Achievement } \\
\hline & $\begin{array}{l}\text { Speeded reading test (De Vos, 2000, } \\
\text { 2002) }\end{array}$ & $\begin{array}{l}\text { Word and sentence reading speed. The outcome is measured in months ahead or behind compared to } \\
\text { the current amount of months of teaching instruction in school. }\end{array}$ \\
\hline & $\begin{array}{l}\text { Speeded arithmetic test (De Vos, } \\
\text { 2004) }\end{array}$ & $\begin{array}{l}\text { Arithmetic speed. The outcome is measured in months ahead or behind compared to to the current } \\
\text { amount of months of teaching instruction in school. }\end{array}$ \\
\hline
\end{tabular}




\section{Results}

\section{Population}

Clinical characteristics of the included children are presented in Table 2. Twentyseven children were classified as CAE and four children as JAE, based on clinical presentation and EEG criteria. In total, 31 children (from a sample of 55 children) met the inclusion criteria, with a mean age of onset of $6.6 \pm 2.2$ years old and a mean duration of follow-up of $3.7 \pm 1.6$ years. Six children had generalized discharges of more than 20 seconds in their EEG, but not longer than 30 seconds. Eleven children had a focal onset, mostly frontal with rapid generalization. Ten had polyspikes of which nine had generalized ictal polyspike-and-wave complexes and seven had interictal polyspikes. In six children polytherapy was needed. At the time of the first measurement, only two children were seizure free. At the second measurement ten children were seizure-free while performing the WISCIII, six while performing the Bourdon-Vos, nine while performing the Fepsy, eight while performing the PPVT-III and ten while performing the Beery-VMI. At the time of data gathering (Feb 2018) 23 children were seizure free of which 10 were without anti-epileptic drugs (AED).

\section{Cognitive comorbidities and academic development}

At the beginning of the follow-up in our centre one patient was already diagnosed with attention deficit hyperactivity disorder $\mathrm{AD}(\mathrm{H}) \mathrm{D}$. During follow-up, an additional six children were diagnosed with $\mathrm{AD}(\mathrm{H}) \mathrm{D}$, one with autism spectrum disorder, one with developmental coordination disorder (DCD), eight with dyslexia and one with dyscalculia. Furthermore, during follow-up, one patient had endured an absence status epilepticus and another patient with JAE developed generalized tonic-clonic seizures.

Using the scoring system by Massa et al., twenty (65\%) children had mild-tosevere educational underachievement and seven (23\%) children had mild-tosevere behavioral problems (29). 


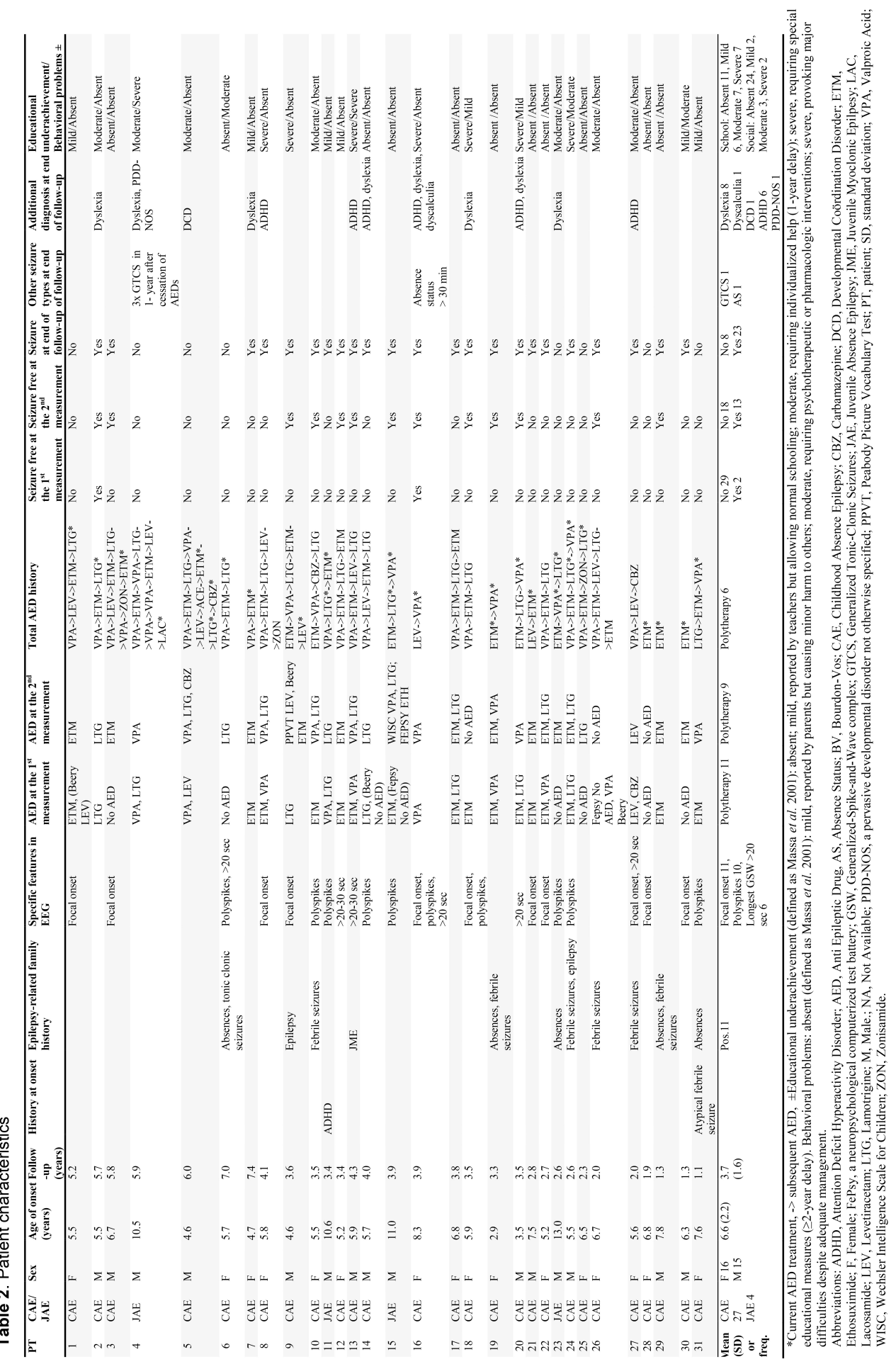




\section{Neurocognitive performance at the first and second measurement}

Results on neurocognitive performance for both measurements are shown in Table 3. Mean intelligence scores (WISC-III) were within the normal clinical range (mean $=94.33)$. Performance IQ and perceptual organization index were significantly lower compared to a normative value of 100 for both measurements. Full-scale IQ, verbal IQ, and verbal comprehension index were not significantly different from a normative value of 100. Furthermore, processing speed was not significantly lower at the first measurement but was significantly lower at the second measurement. Sustained visual attention (Bourdon-Vos cancelation task) was significantly lower compared to the normative mean for speed at the first measurement, whereas accuracy did not differ significantly. The average z-score for speed and accuracy (combination score) was significantly lower for the first measurement, but not the second measurement. Both auditory and visual simple reaction times (FEPSY) of the dominant hand were significantly lower than the normative z-score. More complex attention processes like the binary choice reaction or computerized visual searching task did not differ significantly compared to the norm. Visual-motor-integration was significantly lower compared to the normative mean. The average scores of the Peabody Picture Vocabulary Test (receptive vocabulary) and the Rey-Auditory Verbal Learning Test (immediate and delayed recall for verbal memory) did not differ significantly compared to the norm for both measurements. Speeded reading and arithmetic performance were not significantly delayed at both measurements.

\section{Neurocognitive development on a group level}

Results on the average difference per year between both measurements are shown in Table 3. On average the first and second neuropsychological assessment was 1.7 \pm 0.95 years apart. Sustained attention (combination score) improved significantly between the first and second measurement (Table 3). Receptive vocabulary declined significantly between the first and second measurement, but on average was still within the normal clinical range. Other neurocognitive results (standardized for age) did not differ significantly between the first and second measurement. Excluding the four patients with JAE from the analysis did not yield different results. 
Table 3 Neuropsychological results of children with two consecutive cognitive assessments

\begin{tabular}{|c|c|c|c|c|c|c|}
\hline \multirow[t]{2}{*}{ Cognitive domain } & \multirow[t]{2}{*}{ Test } & \multirow[t]{2}{*}{$\mathbf{N}$} & \multicolumn{2}{|c|}{$\begin{array}{l}\text { Cognitive performance compared to } \\
\text { normative values }\end{array}$} & \multicolumn{2}{|l|}{ Cognitive development } \\
\hline & & & $1^{\text {st }}$ measurement & $2^{\text {nd }}$ measurement & Mean difference per year & P-value \\
\hline \multirow[t]{7}{*}{ Intelligence } & WISC-III\& & & & & & \\
\hline & Full-scale IQ & 18 & $94.33(11.81)$ & $95.17(13.07)$ & $1.25(-1.00-3.52)$ & 0.26 \\
\hline & Performance IQ & & $91.94(10.21)^{*}$ & $92.22(14.82)^{*}$ & $0.86(-1.35-3.07)$ & 0.55 \\
\hline & Verbal IQ & & $98.11(14.23)$ & $98.78(14.49)$ & $1.30(-3.17-5.78)$ & 0.43 \\
\hline & Perceptual Organization Index & & $92.44(10.47)^{*}$ & $94.00(15.54)^{*}$ & $1.91(-2.30-6.13)$ & 0.35 \\
\hline & Verbal Comprehension Index & & $98.11(13.61)$ & $100.78(15.99)$ & $2.43(-0.33-5.20)$ & 0.08 \\
\hline & Processing speed & 19 & $94.16(13.83)$ & $90.84(11.77)^{*}$ & $-1.41(-4.89-2.07)$ & 0.41 \\
\hline \multirow[t]{10}{*}{ Attention } & Bourdon Vos $\hat{\dagger}$ & & & & & \\
\hline & Speed & 14 & $-0.95(0.91)^{*}$ & $-0.21(1.24)$ & $0.38(-0.03-0.79)$ & 0.07 \\
\hline & Accuracy & & $-0.64(1.34)$ & $0.14(1.10)$ & $0.35(-0.12-0.83)$ & 0.14 \\
\hline & Combination Score & & $-0.80(0.66)^{*}$ & $-0.04(0.80)$ & $0.37(0.10-0.64)$ & $0.01^{*}$ \\
\hline & $\begin{array}{l}\text { FePsy } 2.0 * \\
\quad \text { Reaction Time }\end{array}$ & & & & & \\
\hline & Auditory dominant hand & 19 & $-1.96(2.87)^{*}$ & $-1.39(1.63)^{*}$ & $0.20(-0.87-1.26)$ & 0.70 \\
\hline & Visual dominant hand & 18 & $-2.62(2.37)^{*}$ & $-2.27(2.58)^{*}$ & $-0.23(-2.06-1.61)$ & 0.80 \\
\hline & Binary Choice Reaction & 17 & $0.00(1.36)$ & $0.47(1.09)$ & $0.78(-0.15-1.72)$ & 0.10 \\
\hline & $\begin{array}{l}\text { Computerized Visual Searching Task } \\
\text { Time }\end{array}$ & 9 & $-0.41(0.97)$ & $0.08(1.17)$ & $-0.05(-1.63-1.53)$ & 0.95 \\
\hline & False & & $0.22(0.85)$ & $-0.39(0.92)$ & $-0.76(-2.28-0.77)$ & 0.29 \\
\hline \multirow{4}{*}{$\begin{array}{l}\text { Visual-perceptual } \\
\text { function } \\
\text { Language }\end{array}$} & Beery $\S$ & & & & & \\
\hline & Visual-Motor-Integration & 22 & $93.16(11.88)^{*}$ & $91.33(12.48)^{*}$ & $-0.19(-2.73-2.34)$ & 0.88 \\
\hline & PPVT-III§ & & & & & \\
\hline & Receptive vocabulary & 11 & $105.45(11.0)$ & $97.18(9.56)$ & $-3.92(-7.23--0.61)$ & $0.03^{*}$ \\
\hline \multirow{3}{*}{$\begin{array}{l}\text { Memory \& } \\
\text { Learning }\end{array}$} & R-ALVT $\dagger$ & & & & & \\
\hline & Immediate Recall & 17 & $0.06(1.23)$ & $0.14(1.19)$ & $-0.06(-0.39-0.28)$ & 0.73 \\
\hline & Delayed Recall & & $-0.33(1.42)$ & $-0.03(1.47)$ & $0.20(-0.28-0.69)$ & 0.39 \\
\hline \multirow{4}{*}{$\begin{array}{l}\text { Educational } \\
\text { achievement }\end{array}$} & Speeded Reading/Arithmetic test & & & & & \\
\hline & Words (Months behind/ahead) & 8 & $0.88(15.04)$ & $2.38(17.61)$ & $1.99(-6.27-10.25)$ & 0.59 \\
\hline & Sentences (Months behind/ahead) & 7 & $-1.71(12.68)$ & $2.43(12.92)$ & $3.63(-3.89-11.15)$ & 0.28 \\
\hline & Arithmetic (Months behind/ahead) & 13 & $-3.54(9.70)$ & $-5.15(10.00)$ & $-1.72(-3.56-0.11)$ & 0.06 \\
\hline
\end{tabular}

Cognitive performance per measurement is compared with normative values. The mean difference per year is compared to zero.

Abbreviations: IQ, Intelligence Quotient; N, Number of children with at least two measurements; PPVT, Peabody Picture Vocabulary Test; SD, Standard Deviation; WISC, Wechsler Intelligence Scale for Children

$* \mathrm{p}<0.05 ; \uparrow \mathrm{Z}$-score; $\S$ Standard score; $\uparrow$ A combination score for sustained attention was calculated by averaging the z-scores for speed and accuracy.

\section{Neurocognitive development on an individual level}

Table 4 shows the reliable change scores per individual as well as the number of reliably changed children per test. In most tests, the majority of children did not undergo a reliable change, except for sustained attention, simple reaction times and the computerized visual searching task. Sustained attention (combination score) showed the highest frequency of reliable change, with an improvement in seven out of fourteen children after correction for practice effects. As the average difference in improvement between measurements in sustained attention scores was a reliable improvement by itself, correcting for this effect in children who performed normal on both tests, would wrongly designate these children as reliably worsened. Therefore, corrected RCI's are only shown for those children who showed an improvement in Table 4, as well as, the uncorrected RCI's for all children. Two children with JAE showed a reliable decline in sustained attention, while another child with JAE showed a reliable improvement in sustained attention.

Auditory reaction times improved in five and worsened in six out of nineteen. Visual reaction times improved in four and worsened in five out of eighteen. 
Performance in the computerized visual searching task improved in three and worsened in two out of nine. Receptive vocabulary worsened in four out of eleven.

\section{Explorative correlations of clinical and baseline EEG parameters with cognitive function}

Explorative correlations are presented in Table 5. Performance IQ, processing speed, sustained attention and receptive vocabulary were considered for explorative correlations as these showed the largest differences between measurements 1 and 2 on a group-level. Baseline EEG-parameters did not correlate significantly with the difference between cognitive measurements for seizure frequency, longest generalized spike-wave complex, the presence of polyspikes, or a focal onset. Clinical parameters did not correlate significantly with the difference between cognitive measurements for the age of onset, the total duration of epilepsy or seizure freedom at the time of the second neurocognitive assessment. The difference in drug-load between measurements did correlate positively with the difference in sustained attention scores. However, on closer inspection, this correlation was based on three patients who were taking less AED's during the second measurement, but the specific change in AED regimes was different for all these patients (see Table 2, patient 4, 11, 20). 


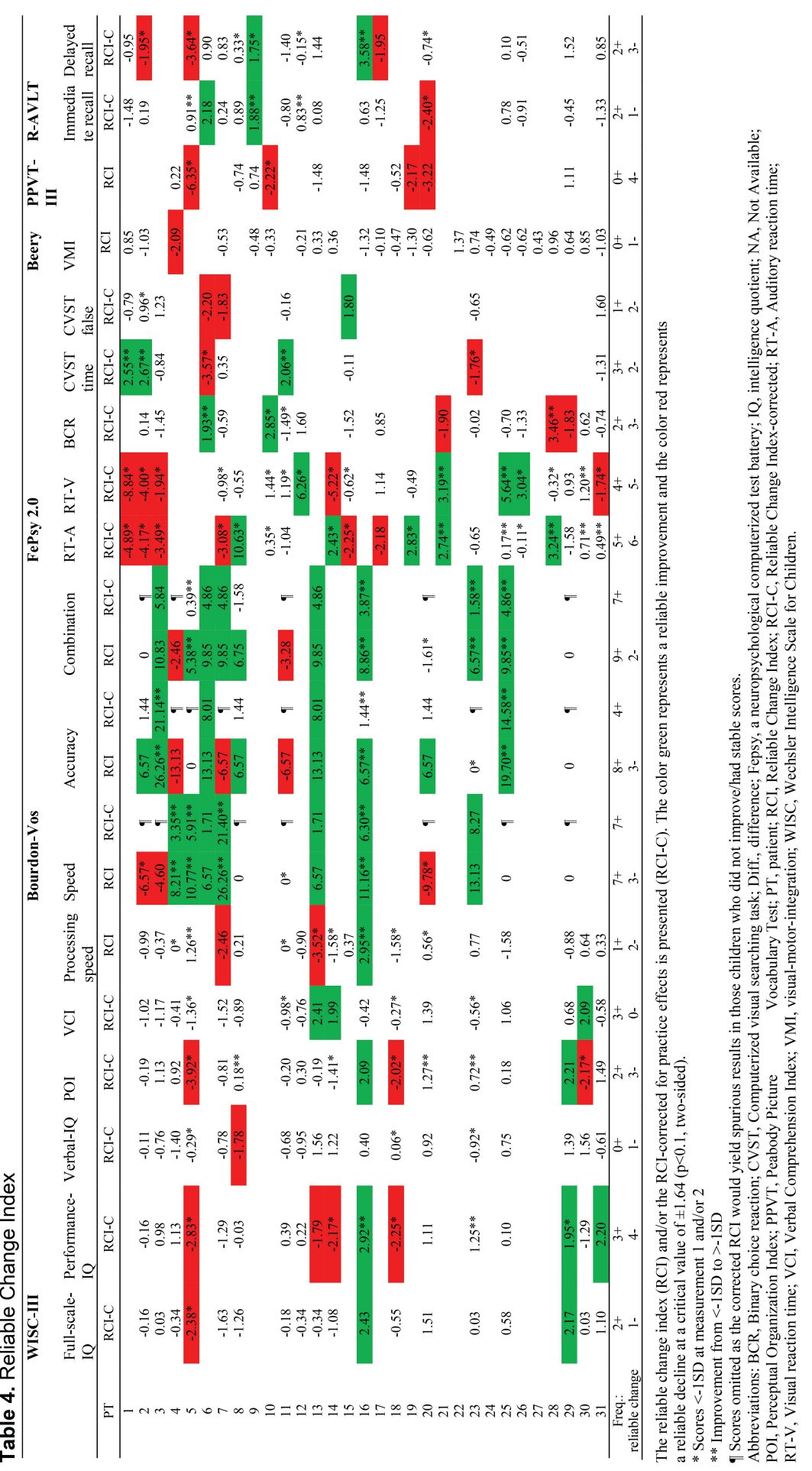


Table 5. Explorative correlations with cognitive development

\begin{tabular}{|c|c|c|c|c|c|c|c|c|c|}
\hline $\begin{array}{l}\text { Change in test } \\
\text { score } 1 \text { and } 2\end{array}$ & & $\begin{array}{l}\text { Age of onset } \\
\text { (years) }\end{array}$ & $\begin{array}{l}\text { Duration of } \\
\text { epilepsy (years) }\end{array}$ & $\begin{array}{l}\text { The difference in } \\
\text { number of AEDs }\end{array}$ & $\begin{array}{l}\text { Polyspikes } \\
\text { (no vs yes) }\end{array}$ & $\begin{array}{l}\text { Focal onset } \\
\text { (no vs yes) }\end{array}$ & $\begin{array}{l}\text { The longest } \\
\text { duration of } \\
\text { GSWD }\end{array}$ & $\begin{array}{l}\text { Seizure } \\
\text { frequency }\end{array}$ & $\begin{array}{l}\text { Seizure } \\
\text { freedom at } \\
\text { 2nd test }\end{array}$ \\
\hline \multirow[t]{3}{*}{ Performance-IQ } & $r$ & .41 & -.23 & -.01 & .15 & -.07 & .10 & .01 & .07 \\
\hline & p-value & .09 & .35 & .98 & .55 & .78 & .71 & .99 & .79 \\
\hline & $\mathrm{N}$ & 18 & 18 & 18 & 12 vs 6 & 13 vs 5 & 16 & 10 & 9 vs 9 \\
\hline \multirow[t]{3}{*}{ Processing speed } & $\mathrm{r}$ & .33 & -.14 & -.01 & .26 & .41 & .33 & -.12 & .08 \\
\hline & p-value & .17 & .58 & .98 & .28 & .08 & .19 & .73 & .76 \\
\hline & $\mathrm{N}$ & 19 & 19 & 19 & 12 vs 7 & 14 vs 5 & 17 & 11 & 9 vs 10 \\
\hline \multirow[t]{3}{*}{ Sustained attention } & $\mathrm{r}$ & -.13 & .02 & .63 & .23 & .36 & .37 & .31 & -.07 \\
\hline & p-value & .66 & .94 & .02 & .43 & .20 & .21 & .55 & .83 \\
\hline & $\mathrm{N}$ & 14 & 14 & $\begin{array}{l}14 \text { (only three } \\
-1, \text { all with } \\
\text { different AEDs) }\end{array}$ & 10 vs 4 & 11 vs 3 & 13 & 6 & 7 vs 6 \\
\hline \multirow{3}{*}{$\begin{array}{l}\text { Receptive } \\
\text { vocabulary }\end{array}$} & $r$ & .54 & -.23 & -.05 & -.29 & .28 & -.54 & -.72 & -.05 \\
\hline & p-value & .08 & .49 & .89 & .39 & .41 & .11 & .07 & .88 \\
\hline & $\mathrm{N}$ & 11 & 11 & 11 & 8 vs 3 & 7 vs 4 & 10 & 7 & 3 vs 8 \\
\hline
\end{tabular}

\section{Discussion}

Our aim was to assess cognitive development in children with AE over time, as data on the course of cognitive performance in children with $\mathrm{AE}$ is scarce. These data demonstrate that children with AE improve in sustained attention over time, as reflected by significant improvement as a group and a reliable improvement in up to half of the patients. Receptive vocabulary showed a decline over time, but cognitive performance was still within normal clinical range. In line with previous cross-sectional research $(11,15,37)$, lower than average scores for performance-IQ, perceptual organization, processing speed, attention, simple reaction times, and visual-motor-integration were found, which in this study were shown to persist over time, despite some children improving or worsening in specific cognitive domains. Furthermore, although cognitive scores were statistically lower compared to normative data, average scores still fall well within the average clinical range and are only clinically relevant in some. Furthermore, a high frequency of mild-to-severe academic difficulties and co-morbidities that might affect learning were present.

Attentional weaknesses in children with AE have been reported in the past; however, uncertainty exists whether this reflects a momentary observation or 
whether attention improves over time. We observed a substantial improvement in the performance of sustained attention during long-term follow-up in about half of the children. Although an improvement of sustained attention in the study of Siren et al. was seen over a 10-month period, this was also seen in the control group. However, as their study did not use age-corrected norms, the observed improvement in both groups may be attributable to an age-effect as the authors stated. Baseline data of a large randomized clinical trial (RCT) found attentional deficits were present in up to one-third of patients with CAE and were directly related to performance in memory, executive function and achievement tests (11). On the contrary, improvement in sustained attention in this study did not coincide with similar improvement in other cognitive domains. Furthermore, although attentional deficits in this RCT were associated with the use of Valproate, the overall prevalence of attentional deficits from baseline up to 12 months of follow-up remained roughly the same, while some improved and some worsened $(11,20,21)$. However, in line with our results, modest improvements in attention were reported in a by proxy questionnaire in the same RCT after one year (23). Based on the data in our study with a longer follow-up time, it seems that an improvement in attention becomes apparent after a follow-up time of more than 12 months and occurs in both children with and without seizure freedom.

In this study some children experienced a worsening in cognitive function in specific cognitive domains, especially in receptive vocabulary and auditory-verbal delayed recall. Performance-IQ, and reaction times also had a relatively high frequency of decline, although the frequency of improvement was similar. Despite a decline in receptive vocabulary in some, performance was within normal clinical range in most children. Receptive vocabulary (PPVT-III) in the study by Masur et al. was also normal in recently diagnosed drug-naïve children with CAE compared to the normative mean (11), while Jackson et al. reported a lower performance in receptive vocabulary in children with $\mathrm{AE}$ at 8 months follow-up compared to controls (38). Although in the latter study, verbal-IQ was also significantly lower than controls, which is in contrast with our study.

Persistence of lower than average performance during follow-up in our study is in line with the sparse literature on cognitive functioning in adults who suffered from AE during their childhood. A small study by Hommet et al. in adults with 
CAE in remission reported a full-scale IQ of 92 (69-99), a performance IQ of 85 (66-117), with particularly low scores in the picture arrangement, block design and object assembly subtests of the WAIS-R (39). Language and executive functioning, however, did not differ with a control group. Recently, Loughman et al. reported lower scores on brief intellectual ability, crystallized intelligence, new learning/memory and speed of processing in an adult population of genetic generalized epilepsy comprising of CAE and JAE patients (40). Abarrategui et al. reported lower scores in visual-spatial working memory, processing speed (coding), cognitive flexibility, abstract visual-spatial, verbal reasoning and acquired knowledge in patients with CAE and JAE persisting into adulthood.

The persistence of other cognitive weaknesses even after cessation of seizures, in combination with the emerging evidence of cognitive weaknesses in adults with a history of $\mathrm{AE}$, is in contrast with the allegedly benign nature of the syndrome. Moreover, in line with previous research, the presence of mild-to-severe academic difficulties in $65 \%$ and related co-morbidities in $42 \%$ in this study is high and adds to the clinical relevance $(17,41-44)$. Therefore, it is recommended that children with $\mathrm{AE}$ are monitored for cognitive deficits and educational underachievement. Long-term prospective cohort studies with repeated measures on cognition and educational achievement are warranted.

Cognitive development was not associated with seizure freedom, the duration of epilepsy or EEG variables and may suggest that underlying mechanisms other than the ictal activity per se are responsible for the association between cognitive weaknesses and absence epilepsy. Siren et al. concluded that the improvements in cognition were due to attaining seizure freedom. However, as the majority (1o out of 11) were seizure free, a direct relationship was difficult to test in that study (19). Furthermore, drug-load was not correlated with neurocognitive development in this study and correlations with specific AED use were not possible due to insufficient power. Nevertheless, anti-epileptic drug (AED) treatment may have had an impact on neurocognitive performance and development. Ethosuximide has been associated with lower performance on simple reaction times but does not seem to affect measures on intelligence, processing speed, sustained attention with the Bourdon-Vos, visual-motor-integration or verbal memory (45). Valproate has been associated with additional numbers of attentional deficits on the Continuous Performance Task compared to monotherapy with Ethosuximide or 
Lamotrigine (20-22). In this study, some children showed an improvement in sustained attention despite the use of Valproic acid. A previous systematic review concluded that Lamotrigine is not associated with reduced cognitive function (46), but may increase attentional performance slightly. In this study, a reliable improvement in sustained attention was noted in all children in who Lamotrigine was added after the first measurement. It should be noted that the use of various AEDs may have had a bearing on our results.

This study was performed in a tertiary epilepsy centre, in which the AE patients were closely monitored regarding clinical, cognitive, and EEG aspects during follow-up. Importantly, a large proportion of the AE patients were difficult to treat in this population, however, previously it has been shown that about half of CAE patients fail treatment on the first and second monotherapy (3, 20-22). Furthermore, as this study focused on cognitive development, only children with two neuropsychological assessments were included. Due to the retrospective setup, the time points of the cognitive assessments and total follow-up time varies between patients. Lack of significant correlations may be related to the relatively small sample size in this study. This was taken into account by correcting for the time between cognitive assessments and using age-corrected norms.

\section{Conclusion}

This study in children with AE demonstrates that weaknesses in sustained attention improved during long-term follow-up. Despite some children showing an improvement or worsening in specific cognitive domains, cognitive functioning, in general, was stable over time. Nevertheless, average functioning in performance-IQ, perceptual organization index, processing speed, simple reaction times, and visual-motor-integration was lower compared to normative values, although still within normal clinical range, while cognitive weaknesses were only present in a proportion of the children. Receptive vocabulary did show a decline over time, but cognitive performance was within normal clinical range. Seizure freedom was not correlated with any aspect of cognitive development as assessed in this study. Furthermore, a high prevalence of mild-to-severe academic difficulties and additional co-morbidities that might affect learning was present in our sample. 


\section{Acknowledgments}

We would like to thank the members of our multidisciplinary team in

Kempenhaeghe who were involved in the care of these patients. 


\section{References}

1.

2.

Berg AT, Shinnar S, Levy SR, Testa FM, Smith-Rapaport S, Beckerman B. How well can epilepsy syndromes be identified at diagnosis? A reassessment 2 years after initial diagnosis. Epilepsia. 2000;41(10):1269-75.

Guerrini R. Epilepsy in children. Lancet. 2006;367(9509):499-524.

Tenney JR, Glauser TA. The current state of absence epilepsy: can we have your attention? Epilepsy currents / American Epilepsy Society. 2013;13(3):135-40.

Myers T, Fecske E. The "staring" child. The Nurse practitioner. 2016;41(1):9-11.

Panayiotopoulos CP. Treatment of typical absence seizures and related epileptic syndromes. Paediatric drugs. 2001;3(5):379-403.

Hughes JR. Absence seizures: a review of recent reports with new concepts. Epilepsy \& behavior : E\&B. 2009;15(4):404-12.

Trinka E, Baumgartner S, Unterberger I, Unterrainer J, Luef G, Haberlandt E, et al. Longterm prognosis for childhood and juvenile absence epilepsy. J Neurol. 2004;251(10):1235-41.

Adie WJ. Pyknolepsy; A form of Epilepsy in Children, with a good Prognosis. Proceedings of the Royal Society of Medicine. 1924;17(Neurol Sect):19-25.

Currier RD, Kooi KA, Saidman LJ. Prognosis of "Pure" Petit Mal; a follow-up study. Neurology. 1963;13:959-67.

Cheng D, Yan X, Gao Z, Xu K, Zhou X, Chen Q. Common and Distinctive Patterns of Cognitive Dysfunction in Children With Benign Epilepsy Syndromes. Pediatric neurology. 2017;72:36-41.e1.

Masur D, Shinnar S, Cnaan A, Shinnar RC, Clark P, Wang J, et al. Pretreatment cognitive deficits and treatment effects on attention in childhood absence epilepsy. Neurology. 2013;81(18):1572-80.

Kernan CL, Asarnow R, Siddarth P, Gurbani S, Lanphier EK, Sankar R, et al. Neurocognitive profiles in children with epilepsy. Epilepsia. 2012;53(12):2156-63.

Levav M, Mirsky AF, Herault J, Xiong L, Amir N, Andermann E. Familial association of neuropsychological traits in patients with generalized and partial seizure disorders. Journal of clinical and experimental neuropsychology. 2002;24(3):311-26.

Cerminara C, D'Agati E, Casarelli L, Kaunzinger I, Lange KW, Pitzianti M, et al. Attention impairment in childhood absence epilepsy: an impulsivity problem? Epilepsy \& behavior : E\&B. 2013;27(2):337-41.

D'Agati E, Cerminara C, Casarelli L, Pitzianti M, Curatolo P. Attention and executive functions profile in childhood absence epilepsy. Brain \& development. 2012;34(10):812-7.

Verrotti A, Matricardi S, Rinaldi VE, Prezioso G, Coppola G. Neuropsychological impairment in childhood absence epilepsy: Review of the literature. Journal of the neurological sciences. 2015;359(1-2):59-66.

Caplan R, Siddarth P, Stahl L, Lanphier E, Vona P, Gurbani S, et al. Childhood absence epilepsy: behavioral, cognitive, and linguistic comorbidities. Epilepsia. 2008;49(11):1838-46.

van Iterson L, Zijlstra BJ, Augustijn PB, van der Leij A, de Jong PF. Duration of epilepsy and cognitive development in children: a longitudinal study. Neuropsychology. 2014;28(2):212-21. Siren A, Kylliainen A, Tenhunen M, Hirvonen K, Riita T, Koivikko M. Beneficial effects of antiepileptic medication on absence seizures and cognitive functioning in children. Epilepsy \& behavior : E\&B. 2007;11(1):85-91. 
2o. Cnaan A, Shinnar S, Arya R, Adamson PC, Clark PO, Dlugos D, et al. Second monotherapy in childhood absence epilepsy. Neurology. 2017;88(2):182-90.

21. Glauser TA, Cnaan A, Shinnar S, Hirtz DG, Dlugos D, Masur D, et al. Ethosuximide, valproic acid, and lamotrigine in childhood absence epilepsy: initial monotherapy outcomes at 12 months. Epilepsia. 2013;54(1):141-55.

22. Glauser TA, Cnaan A, Shinnar S, Hirtz DG, Dlugos D, Masur D, et al. Ethosuximide, valproic acid, and lamotrigine in childhood absence epilepsy. The New England journal of medicine. 2010;362(9):790-9.

23. Shinnar RC, Shinnar S, Cnaan A, Clark P, Dlugos D, Hirtz DG, et al. Pretreatment behavior and subsequent medication effects in childhood absence epilepsy. Neurology. 2017.

24. Iverson GL. Interpreting change on repeated neuropsychological assessments of children. Pediatric forensic neuropsychology. 2012:89-112.

25. Berg AT, Berkovic SF, Brodie MJ, Buchhalter J, Cross JH, van Emde Boas W, et al. Revised terminology and concepts for organization of seizures and epilepsies: report of the ILAE Commission on Classification and Terminology, 2005-2009. Epilepsia. 2010;51(4):676-85.

26. Scheffer IE, Berkovic S, Capovilla G, Connolly MB, French J, Guilhoto L, et al. ILAE classification of the epilepsies: Position paper of the ILAE Commission for Classification and Terminology. Epilepsia. 2017;58(4):512-21.

27. Fisher RS, Cross JH, French JA, Higurashi N, Hirsch E, Jansen FE, et al. Operational classification of seizure types by the International League Against Epilepsy: Position Paper of the ILAE Commission for Classification and Terminology. Epilepsia. 2017;58(4):522-30.

28. Baron IS. Neuropsychological evaluation of the child: Oxford University Press; 2004.

29. Massa R, de Saint-Martin A, Carcangiu R, Rudolf G, Seegmuller C, Kleitz C, et al. EEG criteria predictive of complicated evolution in idiopathic rolandic epilepsy. Neurology. 2001;57(6):1071-9.

30. Iverson GL, Lovell MR, Collins MW. Interpreting change on ImPACT following sport concussion. The Clinical neuropsychologist. 2003;17(4):460-7.

31. Jacobson NS, Truax P. Clinical significance: a statistical approach to defining meaningful change in psychotherapy research. Journal of consulting and clinical psychology. 1991;59(1):12-9.

32. Brooks BL, Holdnack JA, Iverson GL. To Change is Human: "Abnormal" Reliable Change Memory Scores are Common in Healthy Adults and Older Adults. Archives of clinical neuropsychology : the official journal of the National Academy of Neuropsychologists. 2016.

33. Chelune GJ, Naugle RI, Lüders H, Sedlak J, Awad IA. Individual change after epilepsy surgery: Practice effects and base-rate information. Neuropsychology. 1993;7(1):41-52.

34. Iverson GL. Interpreting change on the WAIS-III/WMS-III in clinical samples. Archives of Clinical Neuropsychology. 2001;16(2):183-91.

35. Tingey R, Lambert M, Burlingame G, Hansen N. Clinically significant change: practical indicators for evaluating psychotherapy outcome. Psychotherapy research : journal of the Society for Psychotherapy Research. 1996;6(2):144-53.

36. Martinovich Z, Saunders S, Howard K. Some comments on "assessing clinical significance". Psychotherapy research : journal of the Society for Psychotherapy Research. 1996;6(2):124-32.

37. Conant LL, Wilfong A, Inglese C, Schwarte A. Dysfunction of executive and related processes in childhood absence epilepsy. Epilepsy \& Behavior. 2010;18(4):414-23. 
38. Jackson DC, Jones JE, Hsu DA, Stafstrom CE, Lin JJ, Almane D, et al. Language function in childhood idiopathic epilepsy syndromes. Brain and language. 2018.

39. Hommet C, Billard C, Motte J, Passage GD, Perrier D, Gillet P, et al. Cognitive function in adolescents and young adults in complete remission from benign childhood epilepsy with centro-temporal spikes. Epileptic disorders : international epilepsy journal with videotape. 2001;3(4):207-16.

40. Loughman A, Bowden SC, D'Souza WJ. A comprehensive assessment of cognitive function in the common genetic generalized epilepsy syndromes. European journal of neurology : the official journal of the European Federation of Neurological Societies. 2017;24(3):453-60.

41. Berg AT, Levy SR, Testa FM, Blumenfeld H. Long-term seizure remission in childhood absence epilepsy: might initial treatment matter? Epilepsia. 2014;55(4):551-7.

42. Covanis A, Skiadas K, Loli N, Lada C, Theodorou V. Absence epilepsy: early prognostic signs. Seizure. 1992;1(4):281-9.

43. Oostrom KJ, Smeets-Schouten A, Kruitwagen C, Peters ACB, Jennekens-Schinkel A, DuSech. Not only a matter of epilepsy: Early problems of cognition and behavior in children with "epilepsy only" - A prospective, longitudinal, controlled study starting at diagnosis. Pediatrics. 2003;112(6):1338-44.

44. Urena-Hornos T, Rubio-Rubio R, Gros-Esteban D, Cabrerizo de Diago R, Pena-Segura JL, Lopez-Pison J. [Absence epilepsy. A review of our 14 years' experience]. Revista de neurologia. 2004;39(12):1113-9.

45. IJff DM, van Veenendaal TM, Debeij-van Hall MH, Jansen JF, de Louw AJ, Majoie MH, et al. The Cognitive Profile of Ethosuximide in Children. Paediatric drugs. 2016;18(5):379-85.

46. Aldenkamp AP, Baker G. A Systematic Review of the Effects of Lamotrigine on Cognitive Function and Quality of Life. Epilepsy \& behavior : E\&B. 2001;2(2):85-91.

47. Wechsler D. Wechsler Intelligence Scale for Children - Third Edition UK London: The Psychological Corporation. 1992.

48. Kort W, Schittekatte M, Dekker PH, Verhaeghe P, Compaan EL, Bosman M, et al. WISC-III NL. Handleiding en verantwoording. Londen: The Psychological Corporation. 2005.

49. Vos PG. Bourdon-Vos test handleiding. Swets test Services. 1988.

50. Alpherts WCJ, Aldenkamp AP. FePsy: 'The Iron Psyche'. Heemstede: Instituut voor epilepsiebestrijding. 1995 .

51. Beery KE, Beery NA. The Beery-Buktenica development test of visual-motor integration, administration, scoring and teaching manual, 5th ed. Minneapolis: NCS Pearson. 2006.

52. Dunn LM, Dunn LM. Peabody Picture Vocabulary Test, Third Edition. Circle Pines, MN: American Guidance Service. 1997.

53. Kalverboer AF, Deelman BG. De 15-woorden tests A en B: een voorlopige handleiding (15WT/VWT). Groningen: Academisch Ziekenhuis Groningen, afd. Neuropsychologie. 1986.

54. De Vos T. Tempo-Test-Lezen (woorden). 2nd ed. Lisse: Swets \& Zeitlinger. 2002.

55. De Vos T. Tempo-Test-Lezen (zinnen). 2nd ed. Lisse: Swets \& Zeitlinger. 2000.

56. De Vos T. Handleiding tempo-test-rekenen. Amsterdam: Harcourt Assessment bv. 2004. 
Cognitive development in Absence Epilepsy during long-term follow-up 


$$
5
$$




\section{Lower myelin-water content of the frontal lobe in childhood absence epilepsy}

Eric L.A. Fonseca Wald*

Gerald S. Drenthen*

Walter H. Backes

Mariette H.J.A. Debeij-van Hall Jos G.M. Hendriksen Albert P. Aldenkamp

R. Jeroen Vermeulen Sylvia Klinkenberg Jacobus F.A. Jansen

*Authors share first authorship

Epilepsia 2019;00:1-8 


\section{Abstract}

The frontal lobe in childhood absence epilepsy (CAE) might be affected due to the suggested involvement of the frontal lobe during absence seizures and reports on attentional deficits. Previously, subtle white matter abnormalities have been reported in CAE. However, the impact of one of the most characteristic components of the white matter, the myelin content, remains underdetermined. Therefore, this study investigated whether the myelin content in frontal areas is adversely affected in CAE compared to controls.

Seventeen children with childhood absence epilepsy (mean age \pm standard deviation [SD], $9.2 \pm 2.1$ years) and 15 age- and sex-matched controls (mean age $\pm \mathrm{SD}, 9.8 \pm 1.8$ years) underwent neuropsychological assessment and a magnetic resonance imaging (MRI) examination. T2 relaxometry scans were used to distin-guish myelin-water from tissue water and to determine the myelin-water fraction (MWF) in the frontal, temporal, parietal, occipital, and insular lobes. A linear re-gression model including age and sex as covariates was used to investigate group differences. Furthermore, the relationship of MWF with cognitive performance and epilepsy characteristics was determined.

The frontal lobe revealed a significantly lower myelin-water content in children with CAE compared to controls over the developmental age range of 6-12 years $(5.7 \pm 1.0 \%$ vs $6.6 \pm 1.1 \%, P=0.02)$. This association was not found for any of the other four lobes $(\mathrm{P}>\mathrm{0.10})$. No significant relation was found between myelinwater content and cognitive performance or epilepsy characteristics.

The lower frontal myelin-water content of children with CAE in comparison with healthy controls probably reflects an altered neurodevelopmental aspect in CAE, of which the underlying mechanisms still need to be unraveled. 


\section{Introduction}

Childhood absence epilepsy (CAE) is characterized by seizures of brief losses of awareness occurring multiple times per day in otherwise normally developing school-aged children. Ictal activity on an electroencephalography (EEG) shows approximately $3 \mathrm{~Hz}$ generalized spike-and-wave discharges (GSWDs). The generation or propagation of these GSWDs was previously suggested to have a frontal involvement, although the precise identification of brain regions involved is an ongoing debate $(1,2)$. Magnetic resonance imaging (MRI) of the brain is normally omitted from the standard clinical workup, as specific structural brain abnormalities are not regarded to be part of this generalized epilepsy syndrome. Nevertheless, cognitive (3) and neuroimaging (4-7) studies in children with absence epilepsy have raised concerns about the true neurocognitive impact of this allegedly benign syndrome. A higher incidence of academic difficulties and neurocognitive deficits, mainly attentional deficits, for which the frontal lobe plays an important role, has been observed in CAE (8-16). Furthermore, a study employing diffusion-weighted MRI reported altered structural connectivity in children with CAE, which was suggested to imply abnormal myelination (17). However, although diffusion-weighted MRI can provide markers sensitive to myelin content, these markers are not specific to the myelin content only (18).

The process of myelination is most active during the first 2 years of life but continues through adulthood (19). Myelin is wrapped around the axons causing efficient action potential conduction and increased conductance velocity in axons, which is essential for information transmission through neural circuits (20). Abnormal and exceptional synchronization of neural activity (eg, epileptic seizures) may be related to the myelination process and thus neurodevelopment in children with CAE. Currently, quantitative data on in vivo myelin content and its change during brain development are lacking in CAE imaging studies.

The myelin content can be quantified through MRI of myelin-water. Myelin-water quantification is based on the quantification of water between the bilayers of the myelin sheath using T2 relaxometry. Because water is an important component of myelin, making up to $40 \%$ of the total myelin volume, myelin-water imaging can be regarded as a specific marker of myelin content (21). Water trapped between the bilayers of the myelin has a faster $\mathrm{T}_{2}$ relaxation rate compared to more freely 
moving water in the intracellular and extracellular spaces. Myelin content can be quantified using the fraction of myelin-water signal to the total water signal, the so-called myelin-water fraction (MWF).

In this study, myelination was investigated in children with CAE and controls, by applying MWF imaging. Due to the frontal involvement during seizures in children with CAE, we hypothesize altered myelin content in frontal areas.

The primary aim of the current study is to assess differences in myelin-water content between children with CAE and controls, and the secondary aim is to explore the relationship of myelin-water content with the duration of CAE and neurocognitive performance.

\section{Methods}

\section{Inclusion}

Children with CAE were prospectively recruited via pediatricians and pediatric neurologists within the adherence areas of Kempenhaeghe Epilepsy Centre, a tertiary epilepsy centre. Children with a clinical diagnosis of CAE were included based on the following criteria: (a) primarily presenting with daily occurring episodes of brief loss of consciousness in an otherwise normal child and an EEG showing ictal $3 \mathrm{~Hz}(2.5-4.5 \mathrm{~Hz})$ generalized rhythmic spike-and-wave complexes with a discharge duration of at least 3 seconds on a present or former EEG (in accordance with International League Against Epilepsy [ILAE] statements for CAE22, 23); (b) early absence epilepsy, defined as a confirmed diagnosis or seizure onset within 2 years; And (c) 6 to 12 years of age. Healthy age- and sex-matched controls were recruited via advertisements. To be included, controls needed to follow regular school without major problems. All caregivers and children age 12 years old gave written permission prior to inclusion in the study. This research protocol was approved by the medical ethics committee azM/UM NL55455.068.15/METC152055 and is listed at clinicaltrials.gov under NCTo2954107. 


\section{Clinical and neuropsychological assessment}

Clinical characteristics including age at onset, seizure semiology, duration of epilepsy, drug history, and EEG reports were collected in an online data management system (Castor Electronic Data Capture, CIWIT bv). All children underwent a multidisciplinary assessment, which included a medical assessment, a 24 hour video-EEG, and a neuropsychological assessment. Six subtests of the Wechsler Intelligence Scale for Children third edition (WISC-III) (similarities, vocabulary, picture completion, coding, block design, and symbol search) were used to assess general intelligence and processing speed $(24,25)$. The BourdonVos, a paper and pencil cancellation test, was used to test for sustained visual attention and vigilance (26). Based on age-dependent normative data, the WISCIII and Bourdon-Vos were expressed as standard scores.

\section{MRI Acquisition}

All subjects were scanned on a 3.0T unit (Philips Achieva) using a 32-element phased-array coil. To minimize moving during the MRI, children were carefully prepared beforehand using a combination of video and written information. In addition, parents were instructed to practice lying still with the child at home and to be present with them in the magnet room during the scanning. First, for anatomic reference and segmentation, T1-weighted three-dimensional (3D) turbo field echo images were acquired (repetition time $[\mathrm{TR}]=8.36 \mathrm{msec}$, echo time $[\mathrm{TE}]=3.84 \mathrm{msec}$, flip angle $[\mathrm{FA}]=8$ degrees, cubic voxel size $=1 \mathrm{~mm}$ ). For MWF estimation, whole cerebrum 2D multislice gradient and spin echo (GRASE) images were acquired $(\mathrm{TR}=3000 \mathrm{msec}, 32$ echoes with $9.3 \mathrm{msec}$ echo spacing, range 9.3$297.6 \mathrm{msec}$, echo-planar imaging (EPI) factor $=3$, Turbo factor $=32,24$ slices, $1 \mathrm{~mm}$ slice gap, field of view $=230 \times 180 \times 119 \mathrm{~mm}$, matrix $152 \times 120$, voxel size $=1.5 \times 1.5 \times 4 \mathrm{~mm}$ ) with parallel acquisition (sensitivity encoding, SENSE $=2$ ), scan duration $=5: 45$ minutes $(27)$.

\section{Analyses}

\section{Preprocessing}

For each subject, the $T_{1}$ images were registered to the first echo image of the GRASE scans using the statistical parametric mapping (SPM12) toolkit (28). A singular value decomposition filter was used to reduce noise in the multiecho 
data, (29) and a Gaussian kernel of $2.4 \mathrm{~mm}$ full width at half maximum was used to spatially smooth the GRASE images. Furthermore, all images were visually checked for motion artifacts. Some slices with severe motion artifacts were removed from subsequent analyses.

\section{ROIs}

The white matter was parcellated into five lobes: the frontal, temporal, parietal, occipital, and insular lobes (Figure 1). First, the white matter was parcellated using the T1-weighted images employing Freesurfer (version 5.1) 30 based on the 68 cortical regions in the Desikan-Killiany atlas 31 by assigning each white matter voxel to the most proximal cortical region. Finally, the ROIs were eroded slightly to cope with potential partial-volume errors occurring during the co-registration. The volumes of the segmented white matter lobes are shown in Table 1.

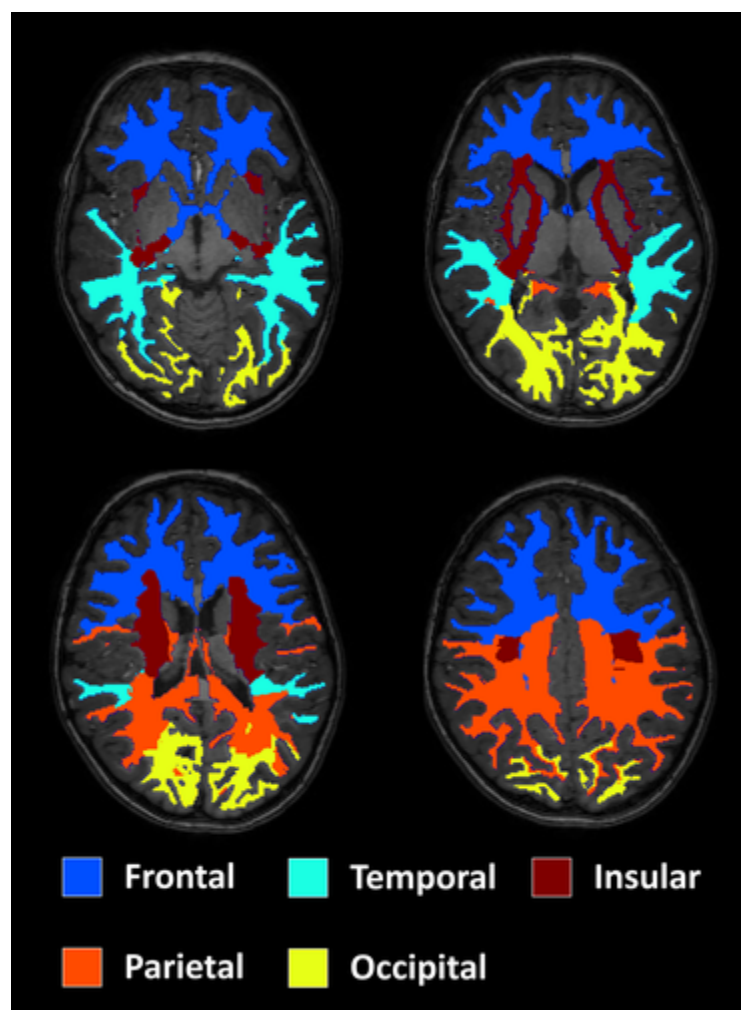

Figure 1 The five white matter (WM) regions of interest (ROls) used in this study, representing the frontal, parietal, temporal, occipital, and insular lobes 
Table 1. White matter volumes of the five lobes

\begin{tabular}{lccc}
\hline & \multicolumn{3}{c}{ WM volume } \\
\cline { 2 - 4 } & $\mathrm{CAE}\left(\mathrm{cm}^{3}\right)$ & Controls $\left(\mathrm{cm}^{3}\right)$ & $\mathrm{p}$-value \\
\hline Frontal & $165 \pm 29$ & $165 \pm 22$ & 0.97 \\
Parietal & $119 \pm 19$ & $121 \pm 16$ & 0.78 \\
Occipital & $41 \pm 7$ & $41 \pm 4$ & 0.90 \\
Temporal & $64 \pm 12$ & $63 \pm 8$ & 0.86 \\
Insular & $32 \pm 6$ & $31 \pm 4$ & 0.60 \\
Whole brain & $421 \pm 51$ & $422 \pm 70$ & 0.99 \\
\hline
\end{tabular}

Abbreviations: CAE, childhood absence epilepsy; WM, white matter.

\section{Multiexponential analysis}

Multiexponential analysis of the multiecho signal decay data was performed using the nonnegative least squares (NNLS) algorithm (32). To solve the NNLS, a basis set of 120 logarithmically spaced relaxation functions ( $\mathrm{T}_{2}$ range 15 to $2000 \mathrm{msec}$ ) was used. The algorithm was regularized using an additional minimal energy constraint that allows an increased misfit between $2 \%$ and $2.5 \%$ $\left(1.020 \leq \chi_{\text {reg }} / \chi_{\min } \leq 1.025\right)$.

The extended phase graph (EPG) algorithm (33) along with the Fourier transform of the slice-selective excitation pulse (34) was used to account for possible stimulated echoes caused by B1 inhomogeneities, and imperfect slice profiles due to slice-selective excitation (27).

The NNLS results in a T2 spectrum, indicating which T2 components are present in the signal. The water trapped between the bilayers of the myelin is known to decay with a relatively fast $\mathrm{T}_{2}$ time of 15 to $40 \mathrm{msec}$. Therefore, the MWF was calculated as the ratio of myelin-water-associated T2 components (15-40 $\mathrm{msec}$ ) to all T2 components $(15-2000 \mathrm{msec})(21,33,35)$. Because the MWF distribution in a region of interest (ROI) is (right-)skewed, we applied the median to represent the MWF in the ROIs. 


\section{Statistical analysis}

Differences between children with CAE and controls in age, general intelligence, processing speed, and the speed and accuracy of the Bourdon-Vos test were assessed using the Student's $t$ test for independent samples. Differences in sex and handedness were assessed with the chi-square test of independence.

To investigate whether lobar myelin-water content differed between groups a multivariate analysis of covariance (MANCOVA) was performed, where the MWF of the five lobes were used as dependent variables. Because myelin varies with age (36) and was shown previously to differ between males and females (37) age and sex are added as covariates in the MANCOVA model. Subsequently, post hoc linear multivariable regression analysis was performed for each lobe to assess differences between groups, correcting for age and sex.

The impact of the duration of CAE and the duration of antiepileptic drug (AED) use on the frontal myelin-water content was evaluated using a linear multivariable regression model for the CAE group, correcting for age and sex. Furthermore, to explore the relation of frontal myelin-water content with neurocognitive performance, a linear multivariable regression model was used for both groups combined, correcting for age and sex. This multivariable regression model was used for each of the neurocognitive performance variables, general intelligence, and processing speed from the WISC-III, as well as the speed and accuracy of the Bourdon-Vos. Statistical significance was inferred when $P<0.05$.

\section{Results}

\section{Subject characteristics}

The population consisted of 17 children with CAE and 15 controls. The subject characteristics are shown in Table 2. The two groups did not differ significantly regarding age, sex, and handedness. All included children were following regular education, except one child included in the CAE group. Nine were taking ethosuximide (range 14.7-27.2 mg/kg), three were taking valproic acid (range 13.3$30.8 \mathrm{mg} / \mathrm{kg}$ ), two were taking ethosuximide + valproic acid (1. $31.8 \mathrm{mg} / \mathrm{kg}$ and 
22.7 mg/kg, respectively; 2. $25.7 \mathrm{mg} / \mathrm{kg}$ and $14.12 \mathrm{mg} / \mathrm{kg}$, respectively) and one was taking lamotrigine + clobazam $(1.4+0.42 \mathrm{mg} / \mathrm{kg})$. At the time of the MRI, two children were still drug-naive, whereas 15 were receiving AED treatment. Processing speed index was significantly lower for children with CAE compared to controls, although both groups were still within normal clinical range. Mean performance on the WISC subtests and Bourdon-Vos did not differ significantly between groups. A trend toward worse performance in CAE was present in the WISC subtests and speed for sustained attention in the Bourdon-Vos compared to controls.

Table 2. Subject characteristics of children with CAE and controls

\begin{tabular}{|c|c|c|c|}
\hline Demographics & CAE & Controls & $\mathrm{p}$-value \\
\hline No & 17 & 15 & - \\
\hline Age (years, mean \pm SD) & $9.2 \pm 2.1$ & $9.8 \pm 1.8$ & 0.37 \\
\hline $\operatorname{Sex}(M / F)$ & $12 / 5$ & $11 / 4$ & 0.86 \\
\hline Handedness (R/L) & $16 / 1$ & $11 / 4$ & 0.11 \\
\hline Age of onset (years, mean \pm SD) & $8.0 \pm 2.0$ & - & - \\
\hline Duration of epilepsy (years, mean \pm SD) & $1.2 \pm 0.7$ & - & - \\
\hline Schooling (regular/special) & $16 / 1$ & $15 / 0$ & 0.34 \\
\hline Family history of epilepsy (Yes/No) & $2 / 15$ & $1 / 14$ & 0.62 \\
\hline \multicolumn{4}{|l|}{ Neurocognitive performance } \\
\hline \multicolumn{4}{|l|}{ WISC } \\
\hline Subtests (mean \pm SD) & $9.6 \pm 1.9$ & $10.9 \pm 2.3$ & 0.09 \\
\hline Processing speed index (mean \pm SD) & $95 \pm 15$ & $108 \pm 14$ & 0.03 \\
\hline \multicolumn{4}{|l|}{ Bourdon-Vos } \\
\hline Speed (mean z-score \pm SD) & $-0.9 \pm 0.8$ & $-0.3 \pm 1.2$ & 0.09 \\
\hline Speed (z-score $\leq-1 /$-score $>-1)$ & $12 / 17$ & $7 / 15$ & \\
\hline Accuracy (mean z-score \pm SD) & $0.0 \pm 0.9$ & $-0.3 \pm 0.7$ & 0.38 \\
\hline Accuracy $(z$-score $\leq-1 / z$-score $>-1)$ & $5 / 17$ & $4 / 15$ & \\
\hline
\end{tabular}

Abbreviations: AED, antiepileptic drug; CAE, childhood absence epilepsy; F, female; L, left; M, male; No, number; R, right; SD, standard deviation; WISC, Wechsler Intelligence Scale for Children. 


\section{Chapter 4}

\section{Myelin content}

A T1-weighted scan with the corresponding MWF map of a child with CAE and a control is shown in Figure 2.

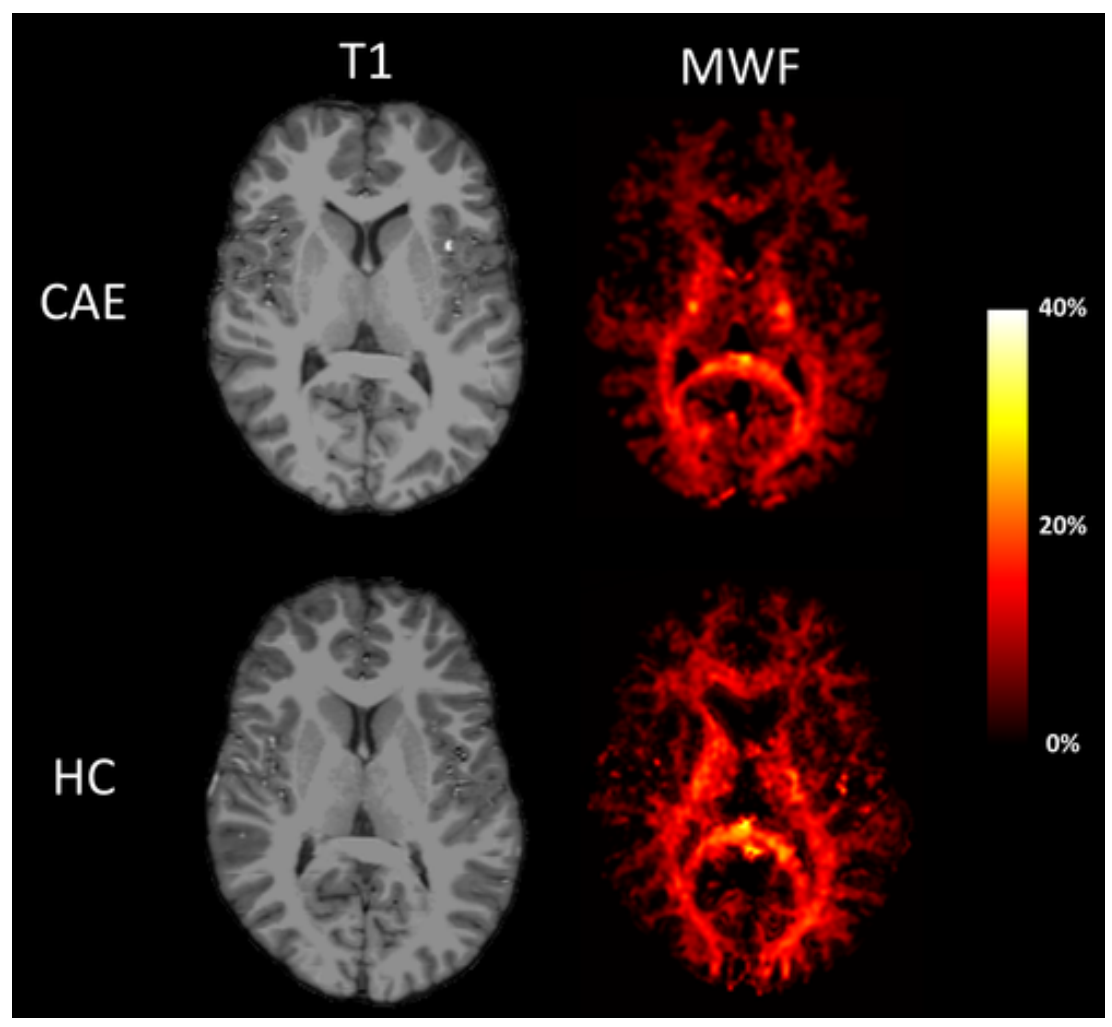

Figure 2

An axial slice of a T1-weighted image and myelin - water fraction map for a 10 year-old boy with childhood absence epilepsy (CAE) and a 10 - year- old male healthy control $(\mathrm{HC})$, positioned through the splenium and genu of the corpus callosum 
The MANCOVA revealed that the lobar myelin-water content is significantly different between children with CAE and controls, while controlling for effects of age and sex $(P<0.05)$. Post hoc regression analysis showed a significantly lower frontal myelin-water content in children with CAE compared to controls. For any of the other four lobes, no significant differences were found (Table 3). A scatterplot of the frontal MWF values as a function of age is shown in Figure 3. Least-square lines for CAE (solid) and controls (dashed) are added for visualization, qualitatively revealing that the frontal myelin-water content increases with age. Moreover, the difference between children with CAE and controls does not vary over age.

Table 3. MWF values in the five lobes of children with CAE and controls

\begin{tabular}{lccc}
\hline MWF Lobes & CAE (\%) & Controls (\%) & p-value \\
\hline Frontal & $5.7 \pm 1.0$ & $6.6 \pm 1.1$ & $\mathbf{0 . 0 2}$ \\
Parietal & $7.2 \pm 1.2$ & $7.5 \pm 1.3$ & 0.51 \\
Occipital & $7.4 \pm 1.2$ & $7.9 \pm 1.1$ & 0.30 \\
Temporal & $4.6 \pm 0.8$ & $5.0 \pm 0.7$ & 0.18 \\
Insular & $8.6 \pm 1.7$ & $9.4 \pm 1.7$ & 0.28 \\
\hline
\end{tabular}

Note The raw MWF values are shown, and that the effects of age and sex are not included. The $P$ value denotes the significance level of the group difference obtained with the regression model. Bold values denote statistical significance. Abbreviations: CAE, childhood absence epilepsy; MWF, myelin-water fraction.

The deepest white matter regions (insular lobe) show the highest myelin-water content, while the myelin-water content in the frontal and temporal lobes is lower compared to the parietal and occipital lobes. These findings are consistent with the known patterns of myelin development, moving from posterior to anterior areas, and outward from the central to the peripheral regions (38). 


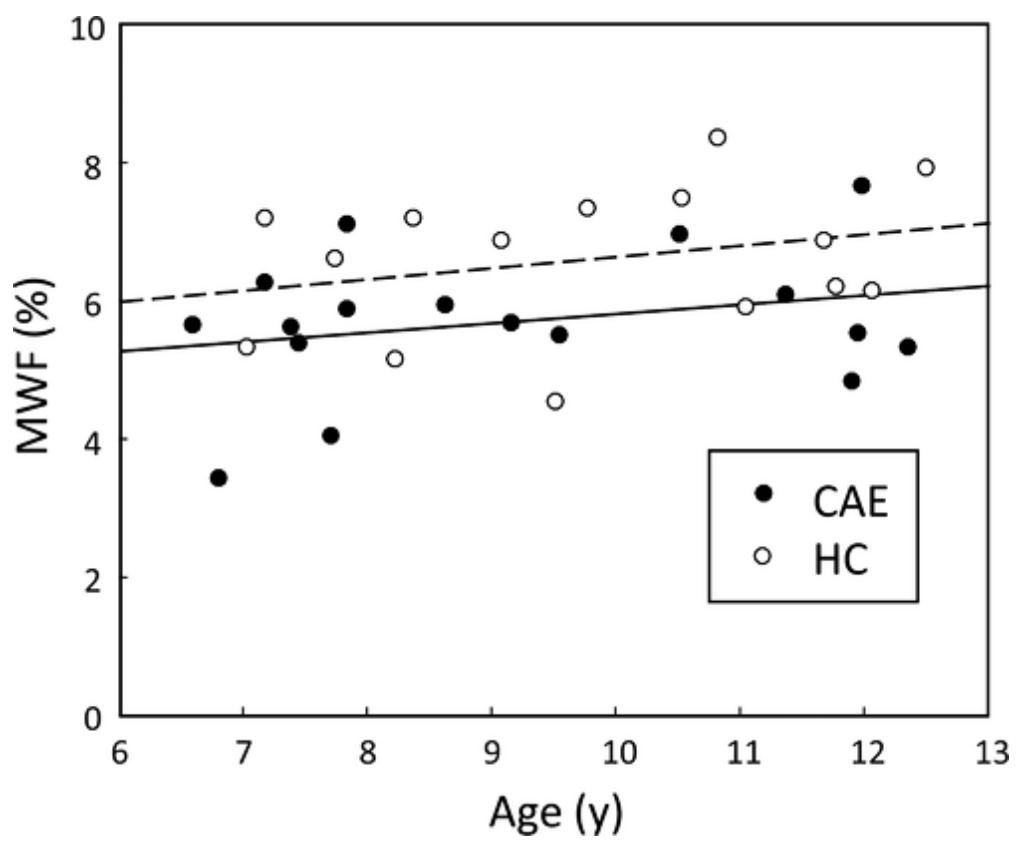

Figure 3 Frontal myelin-water fraction as a function of age. Least-square lines for childhood absence epilepsy (solid) and controls (dashed) are added for visualization, qualitatively revealing that the frontal myelin-water content increases with age. Abbreviations: CAE, childhood absence epilepsy; HC, healthy control; MWF, myelin-water fraction; $y$, years

Using regression, signification relations were not found between frontal myelinwater content and the duration of CAE ( $\beta=0.13, P=0.65$ ) or the duration of AED use $(\beta=-0.13, P=0.54)$. In the whole sample, no significant relations were found between frontal myelin-water content and general intelligence $(\beta=0.22, P=0.19)$, the processing speed index $(\beta=0.22, P=0.18)$, and the speed $(\beta=0.24, P=0.15)$ and accuracy $(\beta=-0.09, P=0.61)$ of the Bourdon-Vos. 


\section{Discussion}

In the current study, the cerebral myelin-water content of children with early onset CAE was investigated and compared with age- and sex-matched controls. A lower myelin-water content was found in the frontal lobe of children with CAE compared to controls, whereas myelin-water content did not differ in any of the other lobes. Neurocognitive performance and sustained attention in our cohort of children with CAE did not relate significantly to the myelin-water content, although the results were indicative of a better performance for increased myelinwater content.

Previously, CAE studies using diffusion-weighted MRI reported lower fractional anisotropy (FA) values in the genu, an important part of the corpus callosum in the frontal lobe $(6,39)$. However, although diffusion-weighted MRI measures are valuable in white matter research, they fail to provide more specific information on the myelin content and cannot discriminate between axonal damage, alterations in myelin content, or topographic deviations (40). Previously, Spader et al (41) showed the feasibility of identifying in vivo myelin abnormalities using MRI and reported a reduced MWF in three children with epilepsy. However, it has not been previously employed in a group with generalized epilepsy.

The main function of myelin is accelerating information processing due to the propagation of electrical signals (ie, action potentials) using saltatory conduction. However, the precise mechanisms are yet to be completely understood.

The observed lower frontal myelin-water content might occur in an early stage of the neurodevelopment (ie, related to a genetic component), or might be acquired during or after epilepsy onset (ie, related to epileptiform activity during the vulnerable years of childhood). Although no definite association for the duration of epilepsy was found in this study, the observed abnormality can be interpreted as a neurodevelopmental aspect of the disorder because the maturation of the frontal lobe is still ongoing (42). Human and animal studies have suggested frontal involvement during the generation or propagation of generalized GSWDs, although the exact brain regions involved are of ongoing debate $(1,2)$. EEGfunctional MRI (fMRI) studies have found different patterns of activation (2) and animal studies point to the somatosensory cortex in the generation of GSWDs. On 
the other hand, deactivation of frontal areas during GSWDs (43) and/or differences in resting state networks involved in attention have also been reported (2) and might be related to changes in myelin content as well. From this relatively small cross-sectional sample we cannot affirm whether the reduced myelin-water content predates the onset of absence epilepsy, or whether the difference in myelin-water content worsens or improves with a longer follow-up. These aspects need to be elucidated in longitudinal studies.

We observed a lower performance for processing speed index and a trend toward lower general intelligence and speed for sustained attention in children with CAE. This is in agreement with previous studies on neurocognition in CAE $(9,12,44)$ Although no definite association between neurocognition and myelinwater was found in the current study, it has been suggested that myelin may be important in optimizing the timing of information through neural circuits (20). Evidence also suggests that myelin may be influenced by seizures, as has been shown in preclinical studies where epilepsy induced rats show a reduced myelin content (45-47). Moreover, histopathological studies in focal epilepsy have shown abnormalities in white matter myelination, axonal integrity, and cellular composition, $(48,49)$ although limited data exist in generalized epilepsy as it is more difficult to collect tissue samples. Therefore, the used methods and findings of this study are promising for epilepsy research, as it may help to better understand the relationship between epileptiform activity and neurocognitive comorbidities.

\section{Study considerations}

Our study has several important strengths. The study used well-defined inclusion criteria for children with CAE in agreement with current ILAE standards. Moreover, the age- and sex-matched controls enabled us to make reliable grouplevel comparisons. Furthermore, to minimize the influence of subject motion, which is an inherent problem when scanning young children, we employed a $2 \mathrm{D}$ multislice acquisition instead of the more commonly applied $3 \mathrm{D}$ acquisition.27 Although 2D imaging does not prevent subject motion artifacts completely, it does allow for removal of corrupted slices, whereas subject motion in $3 \mathrm{D}$ acquisition affects the entire volume. In this study, less than $4 \%$ of the total slices were corrupted and subsequently removed. The main limitation of this 
study is the sample size, which limits the power for more in-depth correlation analysis with clinical/epilepsy variables, for which we did not find a relation. Furthermore, it cannot be excluded that the use of AEDs has had a bearing on the results of this study, as ethosuximide and valproic acid have been associated with neurocognitive side effects $(9,50)$. Nonetheless, because current guidelines prescribe the use of these AEDs, the results in this study reflect children with CAE at this point in time. Furthermore, no relation was found between the duration of AED use and the frontal myelin-water content in this study, indicating that our results are not driven by medication use. Future studies, preferably, larger populations followed over time, are necessary to elucidate the relationship between AED use and the myelination process.

\section{Conclusion}

This study, for the first time, found a lower myelin-water content in the frontal lobe in children with CAE compared with age- and sex-matched controls, probably implicating an altered neurodevelopmental aspect in CAE. Whether the altered myelin-water content predates the onset of absence epilepsy, or whether the myelin-water content worsens over time cannot be concluded from this study. Therefore, more myelin-specific studies with longitudinal designs are warranted to further investigate the relation of (frontal) myelin content and CAE. 
Chapter 4

\section{Funding information}

Stichting Vooruit

\section{Acknowledgments}

The authors thank Remco Berting, Henri Saes, Paul Hofman, and other staff of Kempenhaeghe for their valuable contributions or support. We thank all the subjects who agreed to participate in the study. The authors are grateful for the guidance of Prof. J.H.S. Vles in the early stages of the project. The authors gratefully acknowledge Stichting Vooruit for funding this research.

\section{Conflict of interest}

None of the authors has any conflict of interest to disclose. We confirm that we have read the Journal's position on issues involved in ethical publication and 


\section{References}

1. Carney PW, Masterton RAJ, Flanagan D, Berkovic SF, Jackson GD. The frontal lobe in absence epilepsy. Neurology. 2012;78:1157-65.

2. Moeller F, LeVan P, Muhle H, Stephani U, Dubeau F, Siniatchkin M, et al. Absence seizures: individual patterns revealed by EEG-fMRI. Epilepsia. 2010;51:2000-10.

3. Verrotti A, Matricardi S, Rinaldi VE, Prezioso G, Coppola G. Neuropsychological impairment in childhood absence epilepsy: review of the literature. J Neurol Sci. 2015;359:59-66.

4. Caplan R, Levitt J, Siddarth P, Wu KN, Gurbani S, Sankar R, et al. Frontal and temporal volumes in Childhood Absence Epilepsy. Epilepsia. 2009;50:2466-72.

5. Wang G, Dai ZY, Song W, Wang S, Shi H, Pan P, et al. Grey matter anomalies in drug-naïve childhood absence epilepsy: a voxel-based morphometry study with MRI at 3.o T. Epilepsy Res. 2016;124:63-6.

6. Liang JS, Lee SP, Pulli B, Chen JW, Kao SC, Tsang YM, et al. Microstructural Changes in Absence Seizure Children: a Diffusion Tensor Magnetic Resonance Imaging Study. Pediatr. Neonatol.2016;57:318-25.

7. Xue K, Luo C, Zhang D, Yang T, Li J, Gong D, et al. Diffusion tensor tractography reveals disrupted structural connectivity in childhood absence epilepsy. Epilepsy Res. 2014;108:125-38.

8. Cheng D, Yan X, Gao Z, Xu K, Zhou X, Chen Q. Common and Distinctive Patterns of Cognitive Dysfunction in Children With Benign Epilepsy Syndromes. Pediatr Neurol. 2017;72:36-41.

9. Masur D, Shinnar S, Cnaan A, Shinnar RC, Clark P, Wang J, et al. Pretreatment cognitive deficits and treatment effects on attention in childhood absence epilepsy. Neurology. 2013;81:1572-80.

1o. Kernan CL, Asarnow R, Siddarth P, Gurbani S, Lanphier EK, Sankar R, et al. Neurocognitive profiles in children with epilepsy. Epilepsia. 2012;53:2156-63.

11. Cerminara C, D'Agati E, Casarelli L, Kaunzinger I, Lange KW, Pitzianti M, et al. Attention impairment in childhood absence epilepsy: an impulsivity problem? Epilepsy Behav. 2013;27:337-41.

12. D'Agati E, Cerminara C, Casarelli L, Pitzianti M, Curatolo P. Attention and executive functions profile in childhood absence epilepsy. Brain Dev. 2012;34:812-7.

13. Levav M, Mirsky AF, Herault J, Xiong L, Amir N, Andermann E. Familial Association of Neuropsychological Traits in Patients With Generalized and Partial Seizure Disorders. J Clin Exp Neuropsychol. 2002;24:311-26.

14. Berg AT, Levy SR, Testa FM, Blumenfeld H. Long-term seizure remission in childhood absence epilepsy: might initial treatment matter? Epilepsia. 2014;55:551-7.

15. Oostrom KJ, Smeets-Schouten A, Kruitwagen CLJJ, Peters ACB, Jennekens-Schinkel A. Not Only a Matter of Epilepsy: early Problems of Cognition and Behavior in Children With "Epilepsy Only"-A Prospective, Longitudinal, Controlled Study Starting at Diagnosis. Pediatrics. 2003;112:1338-44.

16. Covanis A, Skiadas K, Loli N, Lada C, Theodorou V. Absence epilepsy: early prognostic signs. Seizure Eur. J. Epilepsy. 1992;1:281-9.

17. Qiu W, Gao Y, Yu C, Miao A, Tang L, Huang S, et al. Structural Abnormalities in Childhood Absence Epilepsy: voxel-Based Analysis Using Diffusion Tensor Imaging. Front Hum Neurosci. 2016;10:1-7. 


\section{Chapter 4}

18. Laule C, Vavasour IM, Kolind SH, Li DKB, Traboulsee TL, Moore GRW, et al. Magnetic resonance imaging of myelin. Neurotherapeutics. 2007;4:460-84.

19. Baraban M, Mensch S, Lyons DA. Adaptive myelination from fish to man. Brain Res. 2016;1641:149-61.

20. Fields RD. A new mechanism of nervous system plasticity: activity-dependent myelination. Nat Rev Neurosci. 2015;16:756-67.

21. Alonso-Ortiz E, Levesque IR, Pike GB. MRI-based myelin water imaging: a technical review. Magn Reson Med. 2015;73:70-81.

22. Berg AT, Berkovic SF, Brodie MJ, Buchhalter J, Cross JH, van Emde BW, et al. Revised terminology and concepts for organization of seizures and epilepsies: report of the ILAE Commission on Classification And Terminology, 2005-2009. Epilepsia. 2010;51:676-85.

23. Fisher RS, Cross JH, French JA, Higurashi N, Hirsch E, Jansen FE, et al. Operational classification of seizure types by the International League Against Epilepsy: position Paper of the ILAE Commission

for Classification and Terminology. Epilepsia. 2017;58:522-30.

24. Wechsler D. Manual for the Wechsler Intelligence Scale for Children, 3rd edn. San Antonio, TX: The Psychological Corporation; 1991.

25. Kort W, Schittekatte M, Dekker PH, Verhaeghe P, Compaan EL, Vermeir G. WISC-III NL. Handleiding en verantwoording. Londen: The Psychological Corporation; 2005.

26. Vos PG. Bourdon-Vos test handleiding. Swets test. Services. 1988.

27. Drenthen GS, Backes WH, Aldenkamp AP, Jansen JFA. Applicability and reproducibility of 2D multi-slice GRASE myelin water fraction with varying acquisition acceleration. NeuroImage. 2019;195:333-9.

28. Friston KJ, Ashburner J, Kiebel S (eds). Statistical Parametric Mapping. Elsevier; 2007.

29. Bydder M, Du J. Noise reduction in multiple-echo data sets using singular value decomposition. Magn Reson Imaging. 2006;24:849-56.

30. Fischl B, Dale AM. Measuring the thickness of the human cerebral cortex from magnetic resonance images. Proc Natl Acad Sci. 2000;97:11050-5.

31. Desikan RS, Ségonne F, Fischl B, Quinn BT, Dickerson BC, Blacker D, et al. An automated labeling system for subdividing the human cerebral cortex on MRI scans into gyral based regions of interest. NeuroImage. 2006;31:968-80.

32. Whittall KP, Mackay AL, Graeb DA, Nugent RA, Li DK, Paty DW. In vivo measurement of T2 distributions and water contents in normal human brain. Magn Reson Med. 1997;37:34-43.

33. Prasloski T, Mädler B, Xiang QS, MacKay A, Jones C. Applications of stimulated echo correction to multicomponent T2 analysis. Magn Reson Med. 2012;67:1803-14.

34. Lebel RM, Wilman AH. Transverse relaxometry with stimulated echo compensation. Magn Reson Med. 2010;64:1005-14.

35. Whittall KP, MacKay AL. Quantitative interpretation of NMR relaxation data. J Magn Reson. 1989;84:134-52.

36. Kavroulakis E, Simos PG, Kalaitzakis G, Maris TG, Karageorgou D, Zaganas I, et al. Myelin content changes in probable Alzheimer's disease and mild cognitive impairment: associations with age and severity of neuropsychiatric impairment. J Magn Reson Imaging. 2018;47:1359-72. 
37. Arshad M, Stanley JA, Raz N. Adult age differences in subcortical myelin content are consistent with protracted myelination and unrelated to diffusion tensor imaging indices. NeuroImage. 2016;143:26-39.

38. Welker KM, Patton A. Assessment of Normal Myelination with Magnetic Resonance Imaging. Semin Neurol. 2012;32:15-28.

39. Corrêa DG, Ventura N, Zimmermann N, Doring TM, Tukamoto G, Leme J, et al. Evaluation of deep gray matter volume, cortical thickness and white matter integrity in patients with typical absence epilepsy: a study using voxelwise-based techniques. Neuroradiology. 2017;59:237-45.

40. Chahboune H, Mishra AM, DeSalvo MN, Staib L, Purcaro M, Scheinost D, et al. DTI abnormalities in anterior corpus callosum of rats with spike-wave epilepsy. NeuroImage. 2009;47:459-66.

41. Spader HS, Ellermeier A, O'Muircheartaigh J, Dean DC, Dirks H, Boxerman JL, et al. Advances in myelin imaging with potential clinical application to pediatric imaging. Neurosurg Focus. 2013;34:E9.

42. Määttä S, Säisänen L, Kallioniemi E, Lakka TA, Lintu N, Haapala EA, et al. Maturation changes the excitability and effective connectivity of the frontal lobe : a developmental TMS - EEG study. HumBrain Mapp. 2019;40:2320-35.

43. Moeller F, Stephani U, Siniatchkin M. Simultaneous EEG and fMRI recordings (EEG-fMRI) in children with epilepsy. Epilepsia. 2013;54:971-82.

44. Lopes AF, Simões MR, Monteiro JP, Fonseca MJ, Martins C, Ventosa L, et al. Intellectual functioning in children with epilepsy: frontal lobe epilepsy, childhood absence epilepsy and benign epilepsy with centro-temporal spikes. Seizure. 2013;22:886-92.

45. Luo Y, Hu Q, Zhang Q, Hong S, Tang X, Li C, et al. Alterations in hippocampal myelin and oligodendrocyte precursor cells during epileptogenesis. Brain Res. 2015;1627:154-64.

46. You Y, Bai H, Wang C, Chen L-W, Liu B, Zhang H, et al. Myelin damage of hippocampus and cerebral cortex in rat pentylenetetrazol model. Brain Res. 2011;1381:208-16.

47. Ye Y, Xiong J, Hu J, Kong M, Li C, Chen H, et al. Altered hippocampal myelinated fiber integrity in a lithium-pilocarpine model of temporal lobe epilepsy: a histopathological and stereological investigation. Brain Res. 2013;1522:76-87.

48. Hu X, Wang J-Y, Gu R, Qu H, Li M, Chen L, et al. The relationship between the occurrence of intractable epilepsy with glial cells and myelin sheath - an experimental study. Eur Rev Med Pharmacol Sci. 2016;20:4516-24.

49. Deleo F, Thom M, Concha L, Bernasconi A, Bernhardt BC, Bernasconi N. Histological and MRI markers of white matter damage in focal epilepsy. Epilepsy Res. 2018;140:29-38.

50. Ijff DM, van Veenendaal TM, Debeij-van Hall MH, Jansen JF, de Louw AJ, Majoie MH, et al. The Cognitive Profile of Ethosuximide in Children. Pediatr. Drugs. 2016;18:379-85. 


$$
5
$$




\title{
Neurocognitive and behavioral profile in Panayiotopoulos Syndrome
}

\author{
Eric L.A. Fonseca Wald \\ Mariette H.J.A. Debeij-van Hall \\ Eline de Jong \\ Albert P. Aldenkamp \\ R. Jeroen Vermeulen \\ Johan S.H. Vles \\ Sylvia Klinkenberg \\ Jos G.M. Hendriksen
}

Developmental Medicine E Child Neurology 2019. Doi:10.1111/dmcn.14417 


\section{Abstract}

Panayiotopoulos Syndrome (PS) is characterized by seizures with autonomic symptoms and is regarded to have a good clinical prognosis. Nevertheless, data on neurocognitive performance and behavioral problems are limited. This study aims to determine neurocognitive performance and behavioral problems in children with PS.

All eighteen children diagnosed with PS in Kempenhaeghe Epilepsy Centre between 2010-2017 were retrospectively analyzed. All had undergone a neuropsychological/behavioral assessment, an academic assessment and a $24 \mathrm{~h}$ EEG.

Mean full-scale IQ (93.5; 76-123; $\mathrm{p}=0.04)$ and performance IQ (93.2; 76-126; $\mathrm{p}=\mathrm{o.04}$ ) were within the normal range, although significantly lower compared to the normative mean. Verbal IQ (96.3; 76-118) and processing speed (96.1; 74-114) were not significantly lower. Simple auditory/visual reaction times, visual attention, visual-motor-integration, and verbal memory were significantly lower compared to normative values. On average, PS patients were 8 months behind in arithmetic speed and 11 months in reading speed for the number of months in school. Behavioral questionnaires revealed significantly higher scores on reported internalizing behavioral problems.

Children with PS demonstrated diffuse cognitive dysfunction in full-scale IQ, performance-IQ, attention, visual-motor-integration, and verbal memory. A high prevalence of internalizing behavioral problems was reported. This strongly suggests neuropsychological and behavioral co-morbidity in children with PS. 


\section{Introduction}

In Panayiotopoulos Syndrome (PS) autonomic seizures occur in an otherwise typically developing child (1-3). Incidence has been estimated at 0.8 per 100.000 children aged $<16$ years old (4). Seizures are often long in duration, infrequent (in some, limited to one episode) and occur frequently during sleep $(1,5,6)$. Autonomic status epilepticus may present in up to $20 \%$ of children $(1,3,7,8)$. While PS has been considered a type of occipital epilepsy the inter-ictal electroencephalogram (EEG) is characterized by multifocal (high amplitude) spikes or sharp and slow-waves, with often but not necessarily an occipital/posterior location $(1,6,9,10)$. In the majority of children with PS, remission occurs 1 to 2 years after onset (11).

PS has been considered a benign epilepsy syndrome due to a good clinical prognosis; nevertheless, a few studies have observed (mild) neurocognitive deficits, such as lower performance in (subtests) of intelligence, visual(perceptual) functioning, attention, semantic processing, arithmetic, language, and memory $(6,12-19)$.

Neurocognitive findings have raised subsequent hypotheses to which brain areas may be involved in PS. In particular deficits in visual functioning have been postulated due to the frequent occipital location of epileptic activity. Nevertheless, results have been conflicting so far. Rose et al. reported visual(perceptual) abnormalities in 7 out of 28 children with PS (15) and Lopes et al. found lower mean performance in the copy task of the Rey-Osterrieth Complex Figure in a case-control study ( $\mathrm{n}=19)$ (14). Furthermore, Lopes et al. and Specchio et al. $(\mathrm{n}=17)$ found low average scores in subtests of the WISC-III partly dependent on visual function $(6,14)$. Lopes et al. subsequently proposed a dysfunction in the parietal lobe due to impairments in visual-perceptual functioning and semantic processing (14). Hodges et al. showed similar results for visual-(perceptual) dysfunction in a case-series of three children (12). Whereas, Bedoin et al. suggested frontal lobe disturbance based on a reduction in the ability to diffuse inhibition outside the attentional focus, which might be explained by the posterior-to-frontal propagation of interictal activity (16). Hence, current evidence is inconclusive; although cognitive functions or networks associated with the location of epileptiform activity in PS are potentially at risk. 
Additional information on neuropsychological functioning in PS will contribute to the understanding of the impact of this allegedly benign epilepsy syndrome on neurocognition. Furthermore, since reports on potential behavioral problems are lacking, we were interested in the occurrence of behavioral problems in PS. The aim of the current study was to report on the neurocognitive functioning and behavior in children diagnosed with PS.

\section{Methods}

\section{Inclusion}

Patient files of children referred between 2010 and 2017 to Kempenhaeghe Epilepsy Centre, a tertiary epilepsy centre, were searched for potential cases of PS and evaluated based on clinical information and EEG records. Patients were included based on the following criteria: 1) seizures coinciding with autonomic symptoms in children; 2) an EEG with (multi)focal spikes or sharp and slowwaves, not necessarily in the occipital regions, compatible with PS according to ILAE statements (20-22).

All children had a multidisciplinary assessement as part of routine interdisciplinary care, which included a medical assessment by a neurologist specialized in pediatric epilepsy, a $24 \mathrm{~h}-\mathrm{EEG}$, a neuropsychological/ behavioral assessment by a trained neuropsychologist and an academic assessment by a school expert.

The medical charts of all children with PS were carefully inspected and clinical data such as age of onset, semiology, drug-history, (24h)-EEG findings and school performance were collected in an online data management system (Castor Electronic Data Capture, CIWIT bv, The Netherlands). All included children and/or parents gave permission for use of medical charts for research purposes. This research protocol was approved by the local medical ethics committee. 


\section{Neuropsychological, achievement and behavioral assessment}

A description of the neuropsychological, achievement and behavioral tests used is presented in Table 1 . Neuropsychological test results were selected assessed using Baron's distinction of different neurocognitive domains in child neuropsychology (23). The following neurocognitive domains were assessed: intelligence, attention, visual-perceptual function, and learning/memory. In addition, achievement tests and by proxy parental/teacher questionnaires on behavior were used. Based on the assessments of a trained psychologist and academic evaluations by a trained school-specialist, the presence of academic underachievement was scored as normal, mild-, moderate- or severe. For this, we used the definition described by Massa et al. 2001 (Table 2) (24).

Table 1 Description of neurocognitive, educational achievement and behavioral tests

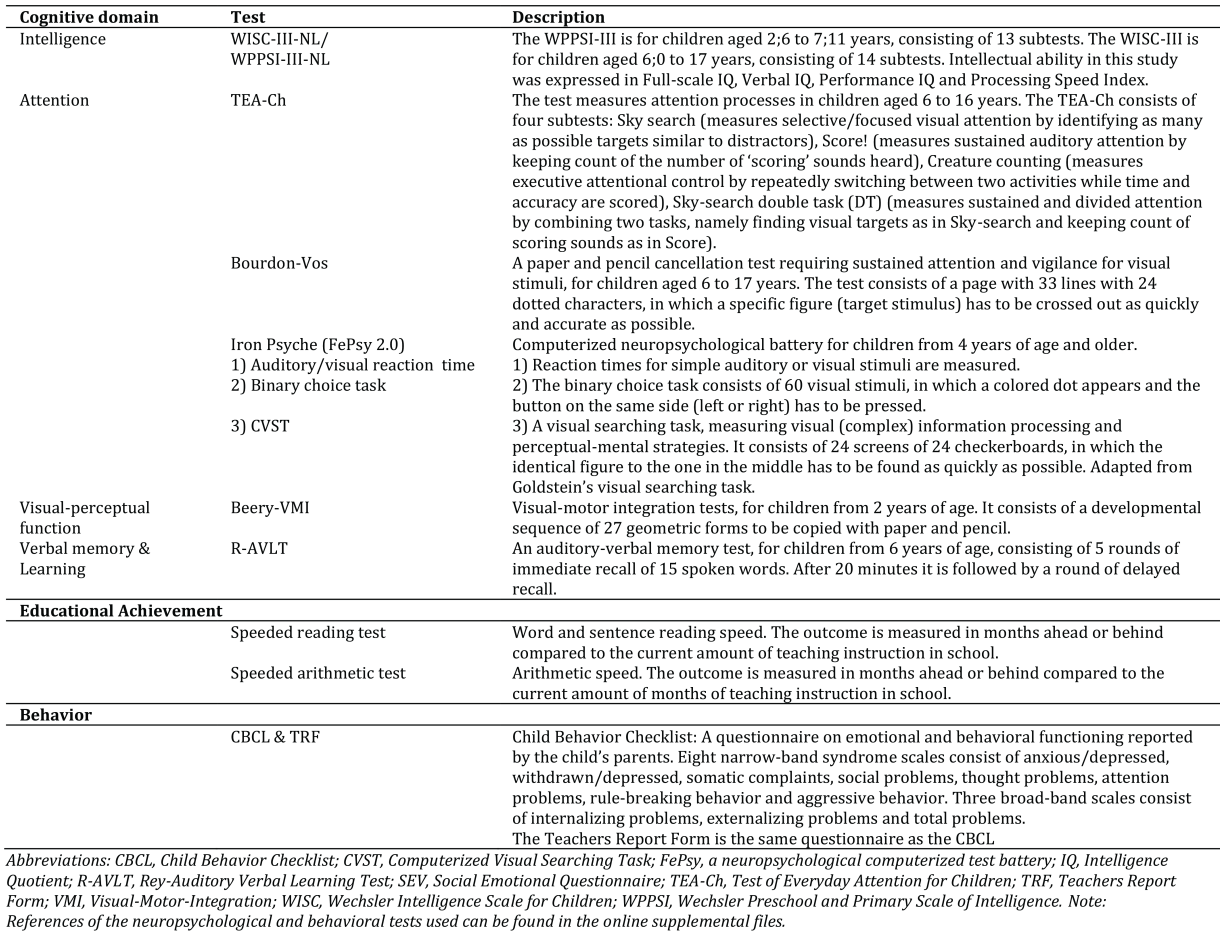

\section{Statistical Analysis}

Raw scores of neuropsychological tests were converted into age-corrected standardized scores and transformed into Z-scores (mean $=0$; standard 
deviation=1) or a T-score ( mean $=50$; standard deviation $=10$ ) based on normative data from the corresponding neuropsychological test manuals. A one-sample ttest was used to test whether the sample mean was different to the normative mean (i.e., a Z-score of o or a T-score of 5o). The Wilcoxon-signed rank test was used to test whether the sample median was statistically different from the normative median (available from the corresponding neuropsychological test manuals) in those tests reporting in decile scores. All analyses were done with SPSS (SPSS Inc, Chicago, Illinois, USA). A p-value of $<0.05$ indicated statistical significance.

\section{Results}

\section{Population}

In total 18 children met our inclusion criteria for PS. The patient characteristics are presented in Table 2. All children were born after an uneventful pregnancy and did not have a history of abnormal cognitive or motor development prior to epilepsy onset. Two patients had a first-degree relative with epilepsy and two had a first-degree relative with a learning disorder. The median clinical follow-up time was 4.9 (1.4-11) years. The most common clinical features during seizures are listed in Figure 1. Nine children experienced nocturnal seizures and three children had early morning seizures. The median seizure duration was 45 minutes (range minutes-6.5 hours). Two children presented with a status epilepticus at seizure onset. Total seizure frequency was low. Furthermore, the location of inter-ictal epileptiform discharges on EEG also varied widely between patients and in 13 out of 18 focus migration was observed during follow-up. Focal migration between EEGs has been described in the literature and is a common observation in PS (1, 3). The average time from seizure onset till seizure freedom was $2.5 \pm 2.2$ years, defined as no seizures for at least 1 year. At the time of data collection, initial monotherapy failed in six patients and had to be switched into another monotherapy. Two children received two AED's simultaneous. In four children AED treatment was not initiated and seven children were still using AED's. Sixteen patients were seizure free. In nine children the last EEG was free of epileptiform discharges. 


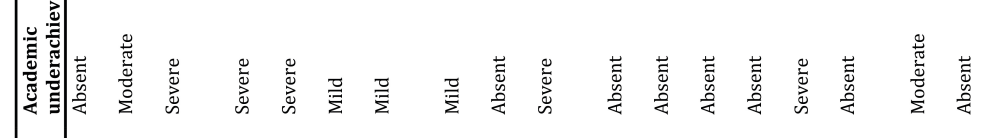
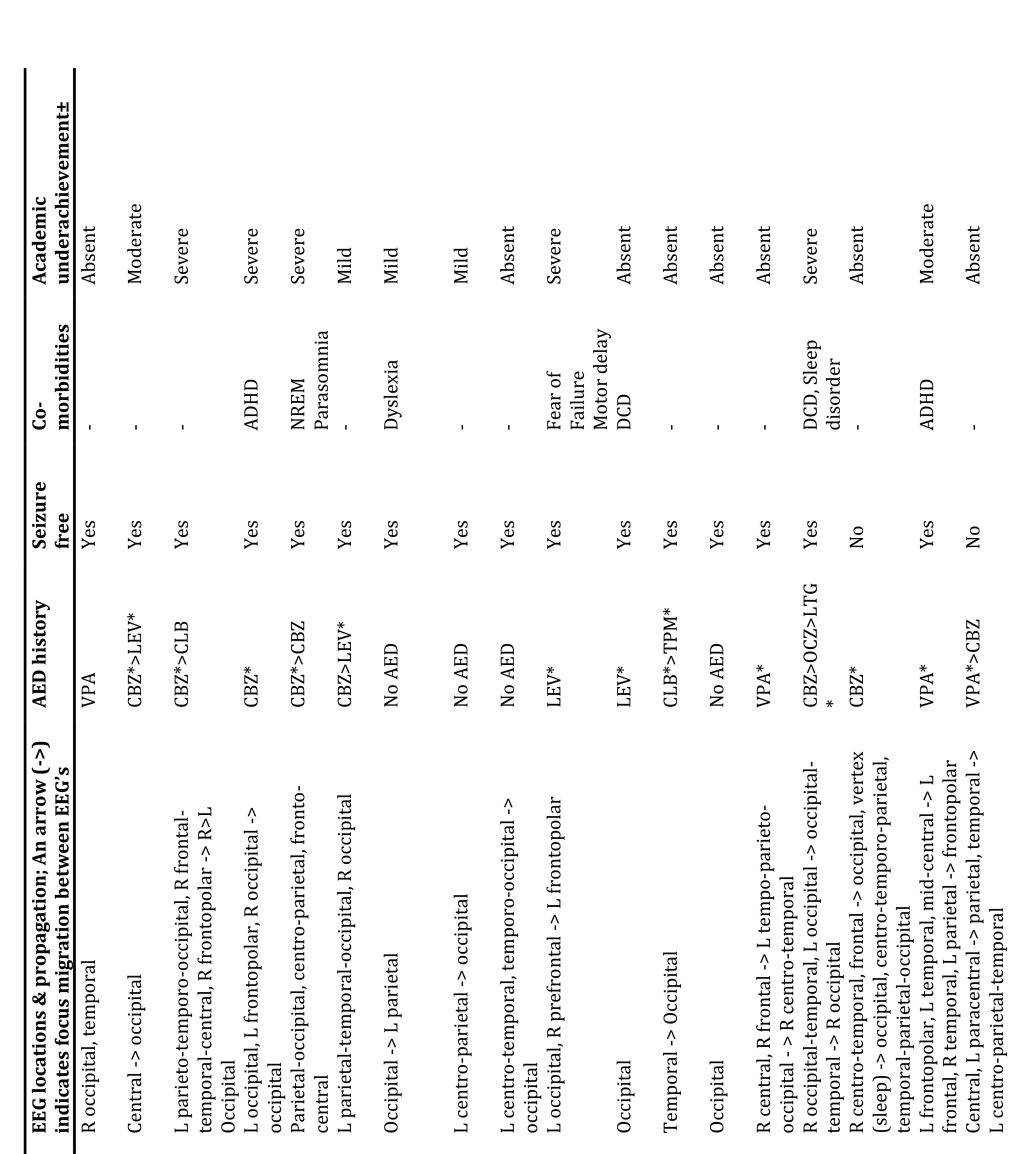

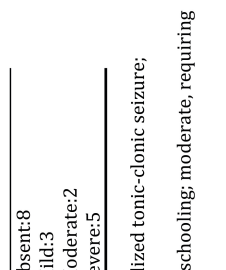
恶

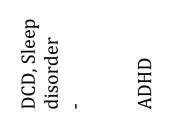

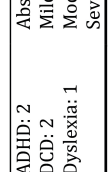

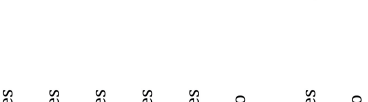

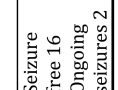

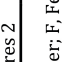

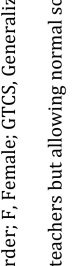




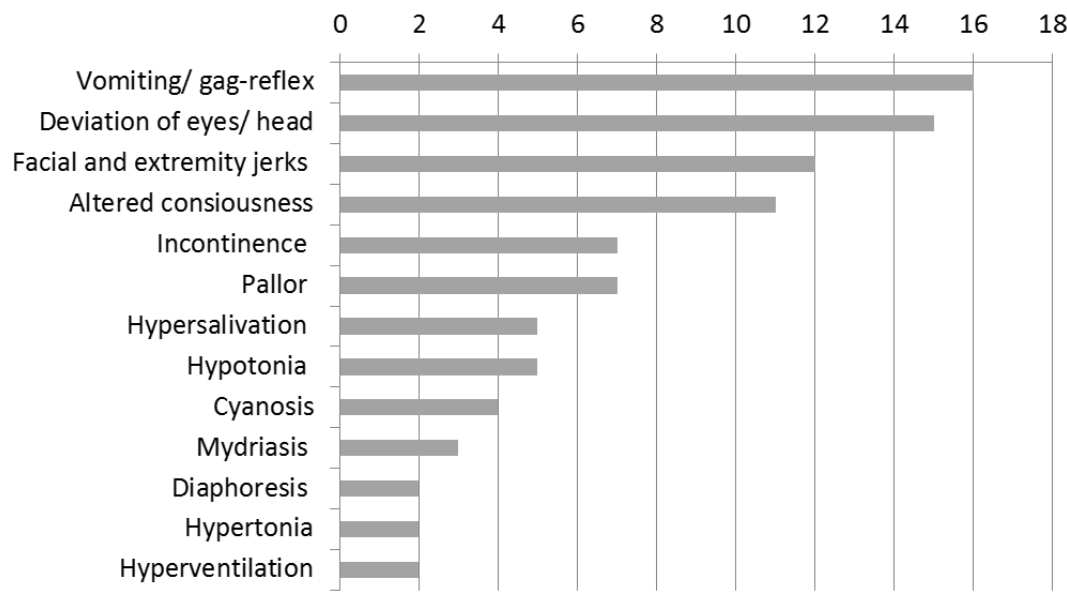

Figure 1 Frequency of patients with the most common semiological features in our study population $(n=18)$.

\section{Neurocognitive performance}

Results on neurocognitive performance are presented in Table 3 and Figure 2 (subtests of the WISC and neurocognitive tests performed in a small subset of patients are available in the Supplemental files). The average time from onset to neuropsychological testing was $2.8 \pm 2.5$ years. Mean intelligence scores were within the average clinical range, although on the lower end of the average range: full-scale IQ (93.5; 76-123), performance IQ (93.2; 76-126), verbal IQ (96.3; 72-118) and processing speed $(96.1 ; 74-113)$. Furthermore, full-scale IQ ( $\mathrm{p}=0.04)$ and performance IQ ( $\mathrm{p}=\mathrm{o.04}$ ) were significantly lower than the normative mean. Since intelligence was assessed with the WPPSI-III in three children, analyses were also performed without these children which yielded similar results.

Mean attention scores were significantly lower using the Bourdon-Vos speed of visual processing $(\mathrm{p}=<0.001)$ and in the TEA-Ch (skysearch) test for visual selective attention $(\mathrm{p}=\mathrm{o.006})$ compared to the normative mean. Sustained auditory attention measured with the TEA-Ch Score! subtest did not differ significantly from the normative mean. The attention scores remained significantly lower after excluding two patients with Attention Deficit/Hyperactivity Disorder from the analysis. Simple reaction times were significantly lower compared to the normative median for auditory $(\mathrm{p}=\mathrm{0.007}$ for 
the right side and $\mathrm{p}=0.01$ for the left side) and visual stimuli ( $\mathrm{p}=0.002$ for the right side and $\mathrm{p}=\mathbf{0 . 0 0 1}$ for the left side). Visual reaction time had a median decile score of 1 for both hands. The binary choice reaction time (focused attention) and the computerized visual searching task did not differ significantly from the normative median.

The Beery-Buktenica tests showed significantly lower scores $(\mathrm{p}=0.006)$ on visualmotor-integration compared to the normative mean. The results of the BeeryBuktenica test remained significant after excluding two patients with developmental coordination disorder from the analysis. The Rey-Auditory Verbal Learning Test, revealed significantly lower scores on the immediate $(p=0.007)$ and delayed recall tasks $(\mathrm{p}=0.03)$. Age of onset or AED use did not correlate with neuropsychological test results. Neurocognitive results did not change when children who were not seizure free were excluded.

Table 3 Neurocognitive performance, educational achievement and behavioral problems

\begin{tabular}{|c|c|c|c|c|c|}
\hline Cognitive Domain & Test & Subscore & $\mathbf{N}$ & $\begin{array}{l}\text { Mean score }(95 \% \mathrm{CI}) \text { or } \\
\text { Median decile score (range) }\end{array}$ & p-value \\
\hline \multirow[t]{4}{*}{ Intelligence } & WPPSI/WISC-III & Full Scale-IQ & 18 & $-0.43(-0.85--0.02) \dagger$ & $0.04^{*}$ \\
\hline & & Verbal IQ & & $-0.25(-0.65-0.13) \dagger$ & 0.18 \\
\hline & & Performance IQ & & $-0.45(-0.88--0.03) \dagger$ & $0.04^{*}$ \\
\hline & & Processing Speed Index & & $-0.26(-0.65-0.13) \dagger$ & 0.18 \\
\hline \multirow[t]{11}{*}{ Attention } & Bourdon-Vos & Speed & 12 & $-1.50(-2.01--0.99) \dagger$ & $<0.001^{*}$ \\
\hline & & Accuracy & & $-0.25(-1.11-0.61) \dagger$ & 0.54 \\
\hline & TEA-Ch & Skysearch (attention score) & 14 & $-0.67(-1.10--0.23) \dagger$ & $0.006^{*}$ \\
\hline & & Score (correct) & & $-0.22(-0.72-0.29) \dagger$ & 0.37 \\
\hline & FePsy 2.0 & Auditory Reaction time (right) & 13 & $3.00(1-8) \ddagger$ & $0.007^{*}$ \\
\hline & & Auditory Reaction time (left) & & $2.00(1-10) \ddagger$ & $0.01^{*}$ \\
\hline & & Visual Reaction time (right) & 14 & $1.00(1-9) \ddagger$ & $0.002^{*}$ \\
\hline & & Visual Reaction time (left) & & $1.00(1-7) \ddagger$ & $0.001^{*}$ \\
\hline & & Binary Choice Reaction Time & 12 & $7.50(3-9) \ddagger$ & 0.17 \\
\hline & & Computerized Visual Searching Task (time) & 11 & $4.00(1-10) \ddagger$ & 0.72 \\
\hline & & Computerized Visual Searching Task (faults) & & $3.00(1-10) \ddagger$ & 0.14 \\
\hline $\begin{array}{l}\text { Visual-perceptual- } \\
\text { function }\end{array}$ & Beery & Visual-Motor-Integration & 18 & $-0.66(-1.10--0.21) \dagger$ & $0.006^{*}$ \\
\hline Verbal memory \& & R-AVLT & Immediate recall & 16 & $2.50(1-10) \neq$ & $0.007^{*}$ \\
\hline Learning & & Delayed recall & 15 & $1.00(1-10) \ddagger$ & $0.03^{*}$ \\
\hline \multicolumn{6}{|l|}{ Educational } \\
\hline & Speed reading & Words (Months behind/ahead) & 11 & $-10.55(-16.89--4.20)$ & $0.004^{*}$ \\
\hline & & Sentences (Months behind/ahead) & 10 & $-11.20(-19.10--3.30)$ & $0.01^{*}$ \\
\hline & Speed arithmetic & Arithmetic (Months behind/ahead) & 9 & $-7.78(-14.67--0.89)$ & $0.03^{*}$ \\
\hline \multicolumn{6}{|l|}{$\begin{array}{l}\text { Behavioral } \\
\text { Questionnaires }\end{array}$} \\
\hline & CBCL & Internalizing behavioral problems & 17 & $58.1(52.06-64.06) \pi$ & $0.01^{*}$ \\
\hline & (By parent) & Externalizing behavioral problems & & $53.2(46.65-59.82) \pi$ & 0.31 \\
\hline & & Total behavioral problems & & $58.1(52.19-63.93) \pi$ & $0.01^{*}$ \\
\hline & TRF & Internalizing behavioral problems & 9 & $55.8(48.92-62.64) \pi$ & 0.09 \\
\hline & (By teacher) & Externalizing behavioral problems & & $58.1(49.94-66.29) \pi$ & 0.05 \\
\hline & & Total behavioral problems & & $57.4(49.75-65.14) \pi$ & 0.06 \\
\hline
\end{tabular}




\section{Educational achievement}

Mild-to-severe academic underachievement was observed in 10 patients (Table 2). Severe academic underachievement occurred in children with seizure onset at an early age. Children with PS were on average seven months behind in arithmetic speed based on the level they should be at in school $(\mathrm{p}=0.03)$ (Table 3). Furthermore, regarding reading speed children with PS were on average 11 months behind ( $\mathrm{p}=\mathrm{0.004}$ for words and $\mathrm{p}=\mathrm{O} .01$ for sentences). Results in arithmetic and reading speed did not correlate significantly with results on the processing speed index.

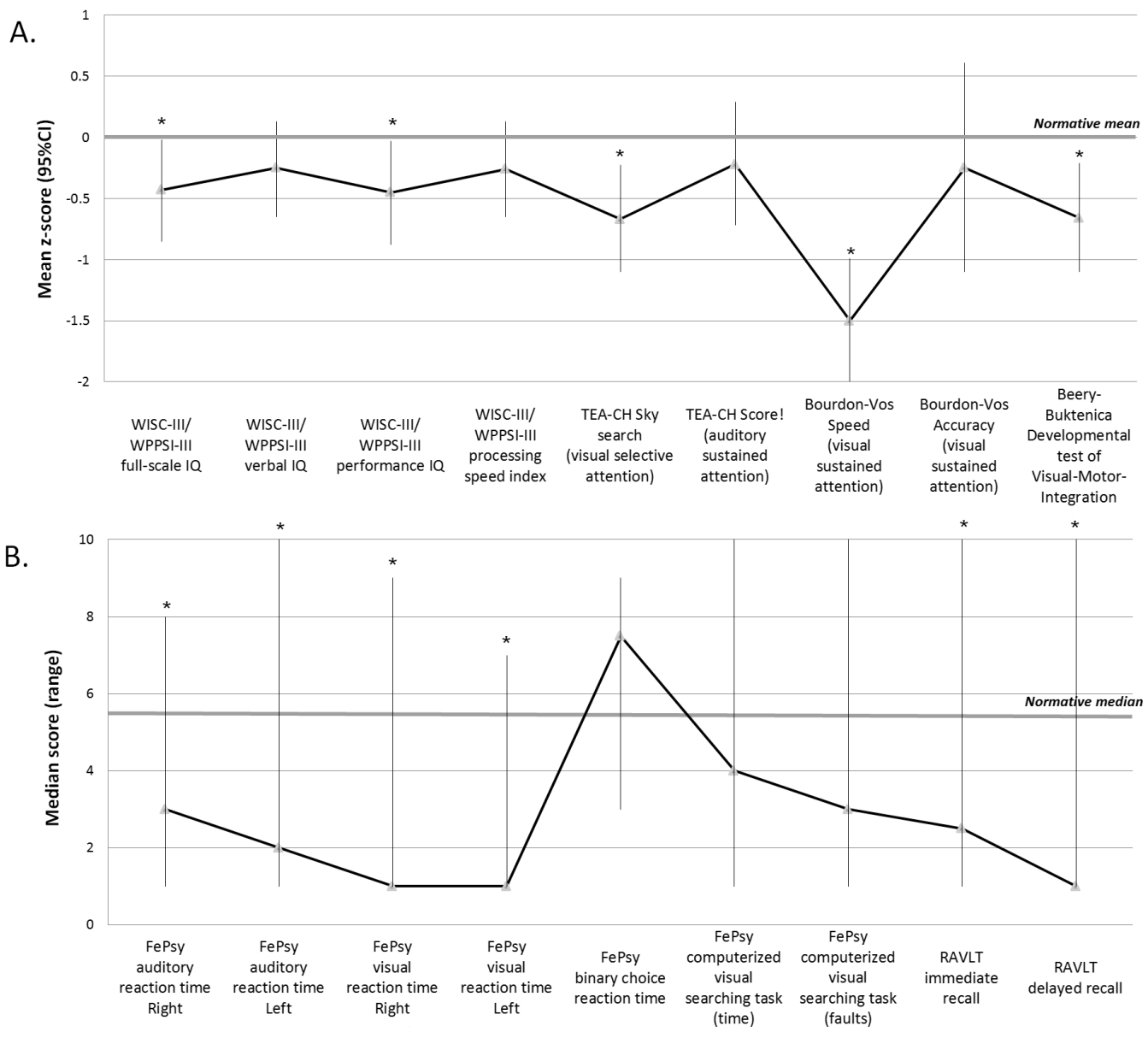

Figure 2 Neuropsychological profile of children with Panayiotopoulos.

A. Z-scores and $95 \%$ confidence interval $(95 \% \mathrm{Cl})$. B. Median scores and range. * Statistically significant differences between mean or median scores compared to the normative median. 


\section{Behavior}

The Childhood Behavior Checklist (CBCL) completed by parents was available for 17 children; a Teacher Report Form (TRF) was available in nine children. Mean total problems and internalizing problems T-scores were significantly higher than the normative mean of 50 in the CBCL reported by parents. Externalizing problems did not differ significantly (Table 3 and Figure 3 ). Teachers did not report significantly higher scores on CBCL indices.

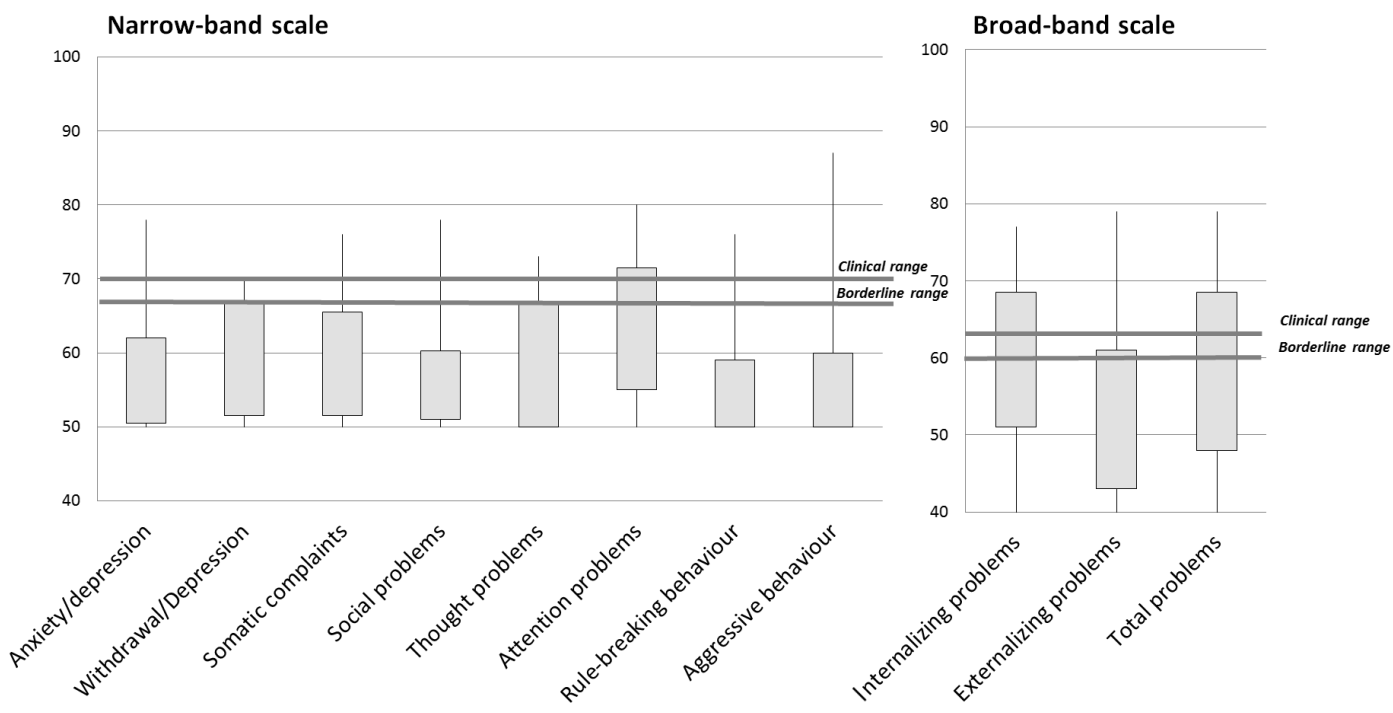

Figure 3

Behavioral profile of children with Panayiotopoulos syndrome based on the Child Behavior Checklist (CBCL) filled by parents. The quartile distribution of T-scores is depicted in boxplots. A narrowband T-score between 67 and 70 is considered borderline; scores above 70 are considered as clinical scores. A broadband T-score between 60 and 63 is considered borderline; scores above 63 as clinical scores. 


\section{Discussion}

This study in children with PS demonstrates that neurocognitive performance was significantly lower compared to the normative mean in several domains. Full-scale IQ and performance IQ were still within the average range, although on the lower end of the average range. Furthermore, our study observed impairments in attention, visual-motor-integration, and verbal memory. Moreover, mild-to-severe academic underachievement was noted in 10 out of the 18 included children with PS. Severe academic underachievement occurred in children with an early age of onset. This was also reflected by a 7 to 11 months delay in the speed of arithmetic and reading. Finally, reports using validated questionnaires on behavior in PS have been lacking. This study found a high prevalence of clinically relevant internalizing behavioral problems, as reported by parents.

The finding that these impairments occur across several different neurocognitive domains, as also observed by others (12, 14-16), probably indicates that multiple brain areas and networks are involved in mediating the neurocognitive dysfunctions observed in PS.

This may be related to the presence of multifocal epileptiform activity; however, this study did not aim to correlate the localization of epileptiform activity or epileptogenesis with cognitive measures. However, since epileptiform activity is often recorded in parietal-temporal-occipital regions in PS the parietal-temporaloccipital cortices or association area may be involved in mediating the observed cognitive dysfunctions (6). Our data suggest that visually demanding tasks are especially affected, for example, tasks involving visual selective attention, visual sustained attention, visual alertness, and visual-motor-integration. This was also reflected in the visually demanding subtests of the WISC-III e.g. object assembly ( $\mathrm{p}=\mathrm{o.003})$, block design $(\mathrm{p}=\mathrm{o.08})$ and picture completion $(\mathrm{p}=\mathrm{o} . \mathrm{o} 8)$, although not all were significantly lower compared to the normative mean (Supplemental files). Interestingly, performance was normal on more complex visual tasks, which may require more activation of frontal areas (25), such as the binary choice reaction time, computerized visual searching task and WISC-III subtests coding and symbol searching. Furthermore, our data suggest that cognitive dysfunctions are not limited to visually demanding tasks, as lower performance was also observed for auditory reaction times and verbal memory. However, slower auditory reaction 
times may contribute to a decreased encoding of the verbal memory task. Germanò et al. also found dysfunctions in the verbal and visual-spatial memory abilities in children with benign childhood epilepsy with occipital paroxysms (18). In a subset of patients lower scores were also observed in the copy and recall tasks of the Rey-Osterrieth Complex Figure Test $(n=9)$ and the Beery-Buktenica motor Coordination task $(\mathrm{n}=9)$ which may suggest dysfunctions in visual perception, memory and/or motor programming (Supplemental files). More sensitive measures are needed to draw definitive conclusions on the specific brain areas or networks mediating cognitive deficits in PS.

A study in six children with PS suggested disruption of prefrontal growth in those children with a status epilepticus, which was also reflected in cognitive and behavioral impairments (13). Indeed, the relatively long duration of seizures in this population, as often seen in Panayiotopoulos syndrome, may have an impact on neurodevelopment, neurocognitive performance, and behaviour. Furthermore, our study found a high incidence of reported internalizing behavioural problems in children with Panayiotopoulos syndrome. In particular, withdrawal/depression, thought problems, attention, and somatic complaints were reported more often. A meta-analysis by Rodenburg et al. on behavioral problems in children with epilepsy also found more internalizing behavioral problems than in the general population (26). They concluded that attention problems, thought and social problems were relatively specific to epilepsy in children in addition to the more general behavioral problems associated with chronic disease.

The neurocognitive and behavioral impairments associated with PS questions the benign nature of this syndrome, as has been questioned in other 'benign' epilepsy syndromes, such as absence epilepsy and benign epilepsy with centro-temporal spikes (BECTS) $(16,27)$. Nevertheless, an effect of AED treatment on cognitive performance cannot be entirely excluded based on this study. Children with PS should be assessed for cognitive deficits, educational underachievement, and behavioral problems to ensure timely intervention. Ideally, this should be managed in an interdisciplinary fashion. If necessary, educational and emotional support programmes should be offered.

This study was performed in a tertiary epilepsy centre. Children with PS were closely monitored regarding the evolution of clinical, cognitive and EEG aspects. 
Limitations include a relatively small sample size, the varying time points of the cognitive assessments and the total follow-up time. From a clinical perspective, patients presented typically for PS and did not seem to have a worse clinical prognosis. Total seizure frequency was low and seizure freedom with monotherapy was attained in the large majority. Use of anti-epileptic drugs (AED's) in a large majority of this population may have had a bearing on the results, although AED use did not correlate with cognitive performance in this study. Specifically, Valproate $(\mathrm{n}=3)$ may have had an impact on attention in some based on an RCT in Childhood Absence Epilepsy (28), but overall it does not seem to impair cognition $(29,30)$. Levetiracetam $(n=4)$ does not seem to impair cognition, whereas there is no consensus as to what extent Carbamazepine ( $\mathrm{n}=5$ ) or Clobazam $(n=2)$ impact cognitive performance $(29-31)$. Topiramate $(n=1)$ has been associated with cognitive impairments in attention, memory, and language function $(29,30)$. Data derived from a single (tertiary) centre, may be biased due to possible referral of more severely affected children. The multitude of cognitive deficits and behavioral problems in this population were larger than could be expected by chance alone. Cautious interpretation of the results is necessary until replicated in future large prospective cohort studies.

\section{Conclusion}

Children with PS demonstrated diffuse cognitive dysfunction in full-scale IQ, performance IQ, attention, visual-motor-integration, and verbal memory. Moreover, a high prevalence of internalizing behavioral problem were present. These findings strongly suggest neuropsychological and behavioral co-morbidity in PS. 


\section{Acknowledgments}

We thank J. Kessels for his contribution to the data collection. We thank our multidisciplinary team in Kempenhaeghe who were involved in the care of these patients.

\section{Disclosure and Funding}

The authors have no interests which that might be perceived as posing a conflict or bias. This research was made possible by collaborative funding by the Maastricht UMC+ and Kempenhaeghe Epilepsy Centre. 


\section{References}

1. Yalcin AD, Ertasoglu Toydemir H. Panayiotopoulos Syndrome with a special emphasis of ictal semiologic features. Epilepsy research. 2017;131:37-43.

2. Caraballo R, Cersosimo R, Fejerman N. Panayiotopoulos syndrome: a prospective study of 192 patients. Epilepsia. 2007;48(6):1054-61.

3. Panayiotopoulos CP. Autonomic seizures and autonomic status epilepticus peculiar to childhood: diagnosis and management. Epilepsy \& behavior : E\&B. 2004;5(3):286-95.

4. Weir E, Gibbs J, Appleton R. Panayiotopoulos syndrome and benign partial epilepsy with centro-temporal spikes: A comparative incidence study. Seizure. 2018;57:66-9.

5. Michael M, Tsatsou K, Ferrie CD. Panayiotopoulos syndrome: an important childhood autonomic epilepsy to be differentiated from occipital epilepsy and acute non-epileptic disorders. Brain \& development. 2010;32(1):4-9.

6. Specchio N, Trivisano M, Di Ciommo V, Cappelletti S, Masciarelli G, Volkov J, et al. Panayiotopoulos syndrome: a clinical, EEG, and neuropsychological study of 93 consecutive patients. Epilepsia. 2010;51(10):2098-107.

7. Specchio N, Trivisano M, Claps D, Battaglia D, Fusco L, Vigevano F. Documentation of autonomic seizures and autonomic status epilepticus with ictal EEG in Panayiotopoulos syndrome. Epilepsy \& behavior : E\&B. 2010;19(3):383-93.

8. Ferrie CD, Caraballo R, Covanis A, Demirbilek V, Dervent A, Fejerman N, et al. Autonomic status epilepticus in Panayiotopoulos syndrome and other childhood and adult epilepsies: a consensus view. Epilepsia. 2007;48(6):1165-72.

9. $\quad$ Ferrie C, Caraballo R, Covanis A, Demirbilek V, Dervent A, Kivity S, et al. Panayiotopoulos syndrome: a consensus view. Developmental medicine and child neurology. 2006;48(3):23640.

10. Iannetti P, Spalice A, Rocchi V, Verrotti A. Diffuse onset of ictal electroencephalography in a typical case of Panayiotopoulos syndrome and review of the literature. J Child Neurol. 2009;24(4):472-6.

11. Covanis A. Panayiotopoulos syndrome: a benign childhood autonomic epilepsy frequently imitating encephalitis, syncope, migraine, sleep disorder, or gastroenteritis. Pediatrics. 2006;118(4):e1237-43.

12. Hodges SL, Gabriel MT, Perry MS. Neuropsychological findings associated with Panayiotopoulos syndrome in three children. Epilepsy \& behavior : E\&B. 2016;54:158-62.

13. Kanemura H, Sano F, Ohyama T, Aoyagi K, Sugita K, Aihara M. Sequential prefrontal lobe volume changes and cognitive dysfunctions in children with Panayiotopoulos syndrome presenting with status epilepticus. Epilepsy research. 2015;112:122-9.

14. Lopes R, Simoes MR, Leal AJ. Neuropsychological abnormalities in children with the Panayiotopoulos syndrome point to parietal lobe dysfunction. Epilepsy \& behavior : E\&B. 2014;31:50-5.

15. De Rose P, Perrino F, Lettori D, Alfieri P, Cesarini L, Battaglia D, et al. Visual and visuoperceptual function in children with Panayiotopoulos syndrome. Epilepsia. 2010;51(7):1205-11.

16. Bedoin N, Ciumas C, Lopez C, Redsand G, Herbillon V, Laurent A, et al. Disengagement and inhibition of visual-spatial attention are differently impaired in children with rolandic epilepsy and Panayiotopoulos syndrome. Epilepsy \& behavior : E\&B. 2012;25(1):81-91.

17. Hirano Y, Oguni H, Funatsuka M, Imai K, Osawa M. Neurobehavioral abnormalities may correlate with increased seizure burden in children with Panayiotopoulos syndrome. Pediatric neurology. 2009;40(6):443-8.

18. Germanò E, Gagliano A, Magazù A, Sferro C, Calarese T, Mannarino E, et al. Benign childhood epilepsy with occipital paroxysms: Neuropsychological findings. Epilepsy research. 2005;64(3):137-50.

19. Gulgonen S, Demirbilek V, Korkmaz B, Dervent A, Townes BD. Neuropsychological functions in idiopathic occipital lobe epilepsy. Epilepsia. 2000;41(4):405-11.

2o. Berg AT, Berkovic SF, Brodie MJ, Buchhalter J, Cross JH, van Emde Boas W, et al. Revised terminology and concepts for organization of seizures and epilepsies: report of the ILAE Commission on Classification and Terminology, 2005-2009. Epilepsia. 2010;51(4):676-85. 
21. Scheffer IE, Berkovic S, Capovilla G, Connolly MB, French J, Guilhoto L, et al. ILAE classification of the epilepsies: Position paper of the ILAE Commission for Classification and Terminology. Epilepsia. 2017;58(4):512-21.

22. Fisher RS, Cross JH, French JA, Higurashi N, Hirsch E, Jansen FE, et al. Operational classification of seizure types by the International League Against Epilepsy: Position Paper of the ILAE Commission for Classification and Terminology. Epilepsia. 2017;58(4):522-30.

23. Baron IS. Neuropsychological evaluation of the child: Oxford University Press; 2004.

24. Massa R, de Saint-Martin A, Carcangiu R, Rudolf G, Seegmuller C, Kleitz C, et al. EEG criteria predictive of complicated evolution in idiopathic rolandic epilepsy. Neurology. 2001;57(6):1071-9.

25. Glascher J, Tranel D, Paul LK, Rudrauf D, Rorden C, Hornaday A, et al. Lesion mapping of cognitive abilities linked to intelligence. Neuron. 2009;61(5):681-91.

26. Rodenburg R, Stams GJ, Meijer AM, Aldenkamp AP, Dekovic M. Psychopathology in children with epilepsy: a meta-analysis. J Pediatr Psychol. 2005;30(6):453-68.

27. Loughman A, Bowden SC, D'Souza W. Cognitive functioning in idiopathic generalised epilepsies: a systematic review and meta-analysis. Neuroscience and biobehavioral reviews. 2014;43:20-34.

28. Glauser TA, Cnaan A, Shinnar S, Hirtz DG, Dlugos D, Masur D, et al. Ethosuximide, valproic acid, and lamotrigine in childhood absence epilepsy. The New England journal of medicine. 2010;362(9):790-9.

29. Ijff DM, Aldenkamp AP. Cognitive side-effects of antiepileptic drugs in children. Handbook of clinical neurology. 2013;111:707-18.

30. Loring DW, Marino S, Meador KJ. Neuropsychological and behavioral effects of antiepilepsy drugs. Neuropsychology review. 2007;17(4):413-25.

31. Eddy CM, Rickards HE, Cavanna AE. The cognitive impact of antiepileptic drugs. Therapeutic advances in neurological disorders. 2011;4(6):385-407. 


\section{Supplemental files}

Table S1 Neurocognitive performance in children with Panayiotopoulos syndrome

\begin{tabular}{|c|c|c|c|c|c|}
\hline Cognitive domain & Test & Subscore & $\mathbf{N}$ & Mean z-score $(95 \% \mathrm{CI})$ & p-value \\
\hline \multirow[t]{12}{*}{ Intelligence } & \multirow[t]{12}{*}{ WISC-III } & Information & 15 & $-0.53(-0.86--0.21)$ & $.003^{*}$ \\
\hline & & Similarities & 15 & $-0.05(-0.58-0.49)$ & .857 \\
\hline & & Arithmetic & 15 & $-0.18(-0.66-0.30)$ & .442 \\
\hline & & Vocabulary & 15 & $-0.20(-0.67-0.27)$ & .377 \\
\hline & & Comprehension & 15 & $-0.27(-0.62-0.09)$ & .131 \\
\hline & & Digit span & 14 & $-0.10(-0.84-0.64)$ & .783 \\
\hline & & Picture completion & 15 & $-0.40(-0.86-0.06)$ & .082 \\
\hline & & Coding & 15 & $-0.16(-0.53-0.22)$ & .388 \\
\hline & & Picture arrangement & 15 & $-0.11(-0.59-0.37)$ & .625 \\
\hline & & Block design & 15 & $-0.44(-0.96-0.07)$ & .083 \\
\hline & & Object assembly & 15 & $-0.73(-1.18--0.29)$ & $.003^{*}$ \\
\hline & & Symbol Search & 15 & $-0.27(-0.77-0.24)$ & .276 \\
\hline Executive function & Stroop & Weighted z-score & 8 & $-0.75(-1.72-0.22)$ & .111 \\
\hline \multirow{3}{*}{ Attention } & \multirow{3}{*}{ TEA-CH } & Creature Counting (correct) & 9 & $-0.30(-0.85-0.25)$ & .249 \\
\hline & & Creature Counting (time) & & $-0.26(-1.40-0.88)$ & .614 \\
\hline & & Score DT & 8 & $-0.71(-1.50-0.09)$ & .073 \\
\hline $\begin{array}{l}\text { Motor and sensory- } \\
\text { perceptual } \\
\text { examinations }\end{array}$ & Beery & Motor & 9 & $-1.17(-1.57--0.76)$ & $<0.001^{*}$ \\
\hline \multirow{2}{*}{$\begin{array}{l}\text { Visuoperceptual, } \\
\text { visiospatial, and } \\
\text { visuoconstructional, } \\
\text { function }\end{array}$} & Beery & Visual & 10 & $-0.40(-1.31--0.51)$ & .348 \\
\hline & RCFT & Copy & 9 & $-2.07(-3.55--0.60)$ & $.012^{*}$ \\
\hline \multirow[t]{3}{*}{ Memory \& Learning } & RCFT & Copy Time & 8 & $-0.86(-1.28--0.44)$ & $.002^{*}$ \\
\hline & & Short delay recall (3 min) & 6 & $-1.55(-2.40--0.70)$ & $.005^{*}$ \\
\hline & & Delayed recall (30 min) & 8 & $-1.32(-1.98--0.65)$ & $.002^{*}$ \\
\hline
\end{tabular}

Cognitive performances per test are compared with the normative mean

Abbreviations: N, Number of patients; TEA-Ch, Test of Everyday Attention for Children; RCFT; Rey Complex Figure Test and recognition trial; WISC, Wechsler Intelligence Scale for Children.

${ }^{*} p<0.05$ 


\title{
Neuropsychological tests used
}

\author{
WISC-III-NL $(1,2)$ \\ WPPSI-III-NL $(3,4)$ \\ TEA-Ch $(5,6)$ \\ Bourdon-Vos (7) \\ Iron Psyche (FePsy 2.0)(8) \\ Beery-VMI (9) \\ R-AVLT (10) \\ Speeded reading test $(11,12)$, \\ Speeded arithmetic test (13) \\ CBCL \& TRF (14)
}

\section{References}

1. Wechsler D. Wechsler Intelligence Scale for Children - Third Edition UK London: The Psychological Corporation. 1992.

2. Kort W, Schittekatte M, Dekker PH, Verhaeghe P, Compaan EL, Bosman M, et al. WISC-III NL. Handleiding en verantwoording. Londen: The Psychological Corporation. 2005.

3. Wechsler D. WPPSI-III administration and scoring manual. Psychological Corporation. 2002.

4. Hendriksen H. WPPSI-III NL. Wechsler Preschool and Primary Scale of Intelligence. Nederlandstalige bewerking. Afname- en scoringshandleiding. 3 ed. Amsterdam: Pearson. 2009.

5. Manly T, Anderson V, Nimmo-Smith I, Turner A, Watson P, Robertson IH. The differential assessment of children's attention: the Test of Everyday Attention for Children (TEA-Ch), normative sample and ADHD performance. Journal of child psychology and psychiatry, and allied disciplines. 2001;42(8):1065-81.

6. Manly T, Roberston I, Anderson V, Nimmo-Smith I. Test of Everyday Attention in Children. Amsterdam: Pearson. 2004.

7. Vos PG. Bourdon-Vos test handleiding. Swets test Services. 1988.

8. Alpherts WCJ, Aldenkamp AP. FePsy: 'The Iron Psyche'. Heemstede: Instituut voor epilepsiebestrijding. 1995 .

9. Beery KE, Beery NA. The Beery-Buktenica development test of visual-motor integration, administration, scoring and teaching manual, $5^{\text {th }}$ ed. Minneapolis: NCS Pearson. 2006.

10. Kalverboer AF, Deelman BG. De 15-woorden tests A en B: een voorlopige handleiding (15WT/VWT). Groningen: Academisch Ziekenhuis Groningen, afd. Neuropsychologie. 1986.

11. De Vos T. Tempo-Test-Lezen (woorden). 2nd ed. Lisse: Swets \& Zeitlinger. 2002.

12. De Vos T. Tempo-Test-Lezen (zinnen). and ed. Lisse: Swets \& Zeitlinger. 2000.

13. De Vos T. Handleiding tempo-test-rekenen. Amsterdam: Harcourt Assessment bv. 2004.

14. Achenbach TM, Edelbrock CS. Manual for the child behavior checklist and revised child behaviour profile. Burlington: University of Vermont Department of Psychiatry. 1983. 
Chapter 5 


\title{
Commentary
}

\section{Rethinking neurobehavioral comorbidity in Panayiotopoulos syndrome}

\author{
By Sarah J. Wilson \\ Developmental Medicine \& Child Neurology 2020 \\ With permission of the publisher Mac Keith Press
}

In 2016, Epilepsy \& Behavior released a Special Issue exploring new ways of thinking about cognition and behavior (1), following the revised approach to classifying the epilepsies published by the International League Against Epilepsy (ILAE) Commission on Classification and Terminology 2005-2009) (2, 3). At its heart, this new approach uses a descriptive or phenomenological taxonomy to classify epilepsy and its syndromes, allowing all of the features of a syndrome to be carefully characterized. The well-crafted paper by Fonseca Wald et al. describing the neurocognitive and behavioral profile of Panayiotopoulos syndrome provides an expert illustration of this new approach (4). In their study, they precisely profile a range of impairments in cognition and behavior in a syndrome that was previously considered neurocognitively and behaviorally 'benign'. In so doing, the researchers link the cognitive and behavioral features of the syndrome to the seizure semiology and its proposed underlying brain network 
dysfunction, allowing the essential neurobehavioral comorbidity of this syndrome to be captured.

This brings to light a striking observation, namely the extent to which the subjective psychological profile of attentional and thinking problems in Panayiotopoulos syndrome maps on to the objectively measured deficits, particularly in psychomotor speed, sustained attention and visuospatial functions. Importantly, this moves us from thinking about cognition and behaviour in terms of the secondary effects of seizures to what may be the more fundamental manifestations of Panayiotopoulos syndrome itself. At the same time Fonseca Wald et al. measure and capture potential secondary effects by carefully documenting the academic underachievement of their patients relative to seizure and drug treatment variables.

In the supplementary material, Fonseca Wald et al. provide an excellent level of individual case detail. This clearly captures the spectrum of impairment in Panayiotopoulos syndrome, showing that individuals with more severe neurological features and neurobehavioral comorbidity tend to have more significant academic difficulties. This provides highly practical information for the treating clinician, who must provide prognostic counselling to patients and their families about the educational and psychosocial impact of the syndrome, including consideration of clinical, behavioral, and educational interventions that might minimize poor outcomes.

Going forward, this type of deeper phenotyping is vital for all epilepsy syndromes if we are to link cognitive and behavioral phenotypes with their corresponding neurological phenotypes in this new approach to classification. This, in turn, will assist the identification of causes, genetic or otherwise, allowing us to better understand and treat the cognitive, behavioral, and seizure expression of the underlying network dysfunction. And by leading to a more exact account of the neurocognitive and behavioral features of Panayiotopoulos syndrome, Fonseca Wald et al. encourage others to profile their own patients more carefully, ultimately improving differential diagnosis and treatment for all patients. 


\section{References}

1. Wilson SJ, Baxendale S. Reprint of: The new approach to classification: Rethinking cognition and behavior in epilepsy. Epilepsy \& behavior : E\&B. 2016;64(Pt B):300-3.

2. Berg AT, Berkovic SF, Brodie MJ, Buchhalter J, Cross JH, van Emde Boas W, et al. Revised terminology and concepts for organization of seizures and epilepsies: report of the ILAE Commission on Classification and Terminology, 2005-2009. Epilepsia. 2010;51(4):676-85.

3. Scheffer IE, Berkovic S, Capovilla G, Connolly MB, French J, Guilhoto L, et al. ILAE classification of the epilepsies: Position paper of the ILAE Commission for Classification and Terminology. Epilepsia. 2017;58(4):512-21.

4. Fonseca Wald ELA, Debeij-Van Hall MHJA, De Jong E, Aldenkamp AP, Vermeulen RJ, Vles JSH, et al. Neurocognitive and behavioural profile in Panayiotopoulos syndrome. Developmental Medicine \& Child Neurology. 


$$
5
$$


General Discussion 
Chapter 6 


\section{General discussion}

Neurocognitive co-morbidities may often accompany childhood epilepsy. However, more subtle neurodevelopmental and neurocognitive co-morbidities in benign epilepsy syndromes, such as absence epilepsy (AE) and Panayiotopoulos syndrome (PS), are far less researched. Therefore, this thesis aimed to gain more knowledge on neurocognition and brain alterations of children with $\mathrm{AE}$ and Panayiotopoulos syndrome (PS).

\section{Neurocognitive functioning in children with AE and PS}

In children with $\mathrm{AE}$, multiple studies have been performed investigating neurocognitive functioning. In chapter 2 we, therefore, present a meta-analysis and systematic review of the literature. Based on this review attention deficits seem the most pronounced neurocognitive weakness in children with AE. Furthermore, significant lower average scores were found for general intelligence and tests on executive function. Less conclusive results were reported for (expressive) language, motor functioning, visuo-spatial functioning, and learning \& memory. Despite observations of statistically lower cognitive performance when compared to normative data, mean scores still fall within the average range as a group and are only clinically relevant in some children. Chapter 3 reports on neurocognitive functioning during follow-up. A significant lower performance was found for sustained attention scores, performance IQ, perceptual organization, processing speed, simple reaction times, and visual-motor-integration in comparison to normative samples. Chapter 4 includes a study focusing on the cerebral myelin content in childhood absence epilepsy (CAE). Similar trends are found for the subtests on intelligence, processing speed and sustained attention.

Studies on the neurocognitive profile of children with PS are still scarce. The neurocognitive performance in children with PS was studied and presented in chapter 5. Children with PS performed significantly lower compared to the normative mean in several domains. Full-scale IQ and performance IQ were significantly lower when compared to normative data, although scores were still on the lower end of the average range. Furthermore, performance in attention, visual-motor-integration, and verbal memory were also lower compared to the 
normative mean. Although we found weaknesses in different cognitive domains, as observed by others (1-4), our data point towards weaknesses in several visual demanding tasks. Such as visual selective attention, visual sustained attention, visual alertness, visual-motor-integration and visually demanding subtests of the WISC-III. Interestingly, the performance was normal on more complex visual tasks, which may require more mediation of frontal areas (5), such as the binary choice reaction time, computerized visual searching task, and WISC-III subtests coding and symbol search. Lower performance was also observed for auditory reaction times and verbal memory, however, performance for auditory sustained attention was normal. Germanò et al. did also find weaknesses in verbal and visual-spatial memory abilities in children with benign childhood epilepsy with occipital paroxysms (6).

\section{Development of neurocognition in children with $A E$ and other types of epilepsy}

In chapter 3 longitudinal data were presented to elaborate on neurocognitive development during follow-up in children with AE. In our study, children with AE improved in sustained attention over time, as reflected by a significant improvement on a group-level and a reliable improvement in up to half of the patients on an individual level based on the reliable change index scores. Interestingly, improvements in attention occurred in both children with and without seizure freedom.

Receptive vocabulary showed a decline over time, although scores were still within the normal range in most children. Receptive vocabulary (PPVT-III) was also studied in the study by Masur et al. and was within the normal range in recently diagnosed drug-naïve children with CAE compared to the normative mean (7), while Jackson et al. reported a lower performance in receptive vocabulary in children with $\mathrm{AE}$ at 8 months follow-up compared to controls (8). Although in the latter study, verbal-IQ was also significantly lower than controls, which is in contrast with our study.

Other results from our longitudinal follow-up of a cohort in children with AE show that some experienced a decrease in cognitive function in auditory-verbal 
delayed recall. Performance IQ and reaction times may worsen in a proportion of children, although the frequency of children with an improvement in these tests was similar. Lower than average scores persisted during follow-up for performance-IQ, perceptual organization, processing speed, attention, simple reaction times, and visual-motor-integration, although some children improved or worsened in specific cognitive domains.

Improvement in sustained attention in this thesis did not coincide with similar improvements in other cognitive domains per se. Nevertheless, cognitive performance in one domain may be related to performance in other domains. For example, Masur et al. reported a direct sequential effect among attention, memory, executive function, and academic achievement (7).

Current literature on cognitive performance and AE is primarily cross-sectional, while longitudinal data are limited. Siren et al. found an improvement in sustained attention over a 10-month period, which was also seen in the control group. However, as their study did not use age-corrected norms, the observed improvement in both groups may be attributable to growing older, i.e. an ageeffect due to normal development. Improvements in attention may, therefore, occur after 12 months of follow-up as seen in our sample. In a large randomized clinical trial, the overall prevalence of attentional deficits from baseline of about one third remained roughly the same throughout one year of follow-up $(7,9,10)$. Contrarily, in the same RCT, modest improvements in attention were reported in a by proxy questionnaire after one year (11). Therefore, this thesis is the first reporting of neurocognitive development in children with $\mathrm{AE}$ using reliable change methodology.

Longitudinal studies on neurocognitive development have been performed in heterogeneous samples of children with epilepsy which included limited numbers of children with AE and none have been conducted in PS to our knowledge. In such an heterogeneous sample of 113 children with epilepsy (consisting of [atypical] idiopathic localization related epilepsy, localization related symptomatic epilepsy, idiopathic generalized epilepsies, symptomatic generalized epilepsies, epilepsy with continuous spikes and waves during slow sleep, and some unknown types) of which only 2 children with CAE, it was found that performance IQ was initially lower than verbal IQ, however, this discrepancy decreased overtime (12). This is in contrast with our study (chapter 3), in which 
performance IQ was lower than verbal IQ, but overall the difference did not decrease over time. Nevertheless, in some children the difference in performance IQ and verbal IQ decreased and in some it increased, which was almost always based on a change in performance IQ for better or worse. A longitudinal study in 42 children with either idiopathic or cryptogenic epilepsy of which 7 children with CAE, noted lower performance in sustained attention, learning, and memory span for words, which remained stable throughout follow up, although instability in individual performances were only present in children with epilepsy and persistence of poor performance in some cognitive abilities was associated with repeating a grade at school (13). In another study consisting of children with a localization related epilepsy or idiopathic generalized epilepsy, lower performance across cognitive domains was highly dependent on the presence of ADHD or academic problems at the time of epilepsy onset and was found to hamper improvements in attention over-time (14). In our study (chapter 3) the presence of academic problems or ADHD could not be related to cognitive performance or the course thereof and improvements in attention were also seen in children with an without co-morbidities such as ADHD, although our sample size may not be large enough to detect more subtle differences. Cognitive development in 69 children with localization-related and idiopathic generalized epilepsy of which 11 with $\mathrm{AE}$ were found to have cognitive abnormalities across several cognitive domains, such as attention, fine motor dexterity, and psychomotor speed, which was detectable at or near the time of diagnosis and largely remained stable over the 5 to 6 years of follow up, although response inhibition with the D-KEFS (Color-Word Interference Test-Inhibition) did tend to improve over time for children with idiopathic generalized epilepsy (15).

\section{Academic performance and neurocognitive maturation in adulthood}

Vulnerabilities in neurocognitive domains may hamper academic careers, especially since based on this thesis and current literature cognitive weaknesses may persist despite seizure freedom. A high prevalence of academic difficulties in our samples of children with either AE or PS was observed. In AE the presence of mild-to-severe academic difficulties was present in 65\% (chapter 3 ) and this is in line with previous studies (chapter 2) (16-20). In PS academic underachievement was noted in 10 out of the 18 included children (chapter 5). Moreover, clinically 
relevant delays in arithmetic and reading speeds were observed in children with PS (chapter 5). In PS severe academic underachievement occurred mostly in children with an early age of onset.

Furthermore, this thesis also reported a high prevalence of internalizing behavioral problems in children with PS (chapter 5). In particular, withdrawn/depression, thought problems, attention problems, and somatic complaints were reported more often. Studies on behavioral problems in PS are scarce. A report of six children with PS suggested disruption of prefrontal growth in children who underwent a status epilepticus, which might reflect both cognitive and behavioral impairments (21). A meta-analysis by Rodenburg et al. on behavioral problems in children with various epilepsy syndromes also found more internalizing behavioral problems than in the general population (22). They concluded that attention, thought and social problems were relatively specific to epilepsy in children in addition to the more general behavioral problems associated with having a chronic disease.

To date, studies on neurocognition in adults with a history of AE are limited. In PS such studies have not been carried out to the best of our knowledge. The few studies that have investigated cognitive function in adults with a history of $\mathrm{AE}$ suggest that lower performance on neuropsychological tests may persist, but current studies are small in sample size. A small study in young adults with CAE in remission ( $\mathrm{n}=10$ ) reported a full-scale IQ of 92 (69-99), a performance IQ of 85 (66-117), with particularly low scores in the picture arrangement, block design and object assembly subtests of the WAIS-R (23). Language and executive function did not differ with a control group. Loughman et al. reported on cognitive function using the Woodcock-Johnson-III test of cognitive abilities in an adult population of genetic generalized epilepsy syndromes, including CAE $(n=10)$ and JAE $(n=21)$ patients (24). This study reported lower scores on brief intellectual ability, crystallized intelligence, new learning/memory and speed of processing. Abarrategui et al. reported lower scores in visual-spatial working memory, processing speed (coding), cognitive flexibility, abstract visual-spatial, verbal reasoning and acquired knowledge in patients with CAE and JAE persisting into adulthood (25). 
Other studies investigated the possible impact of AE on working and academic careers. In a telephone follow-up study, 13 out of 52 retrospectively identified patients aged 11 to 36 years with a history of CAE reported some sort of psychopedagogical help (26). Another study in patients focusing on long-term psychosocial outcome in juvenile myoclonic epilepsy (JME) with a mean age over 60 years used AE patients as an epilepsy matched-control group (27). A significantly lower amount of patients with a history of absence epilepsy accomplished a university degree compared to patients with JME, although a healthy control group was lacking. Nevertheless, the overall psychosocial outcome for the patients in that study was favorable. However, another study compared a group of patients with rheumatoid arthritis to patients with CAE and similar impact of "chronic disease" (28). In that study, young adults with a history of CAE were more prone to working in jobs requiring minimum education, having more behavioral problems and psychiatric consultations, compared to the control group with rheumatoid arthritis.

\section{What factors underlie neurocognitive comorbidities?}

Neurocognitive comorbidities may be related to different factors, which may be difficult to disentangle completely. Such factors may be due to a direct influence of (inter)ictal activity, pharmacological side-effects on cognitive performance or other factors affecting neurodevelopment (genetic/environmental) (29-32). In other studies, clinical factors have been associated with cognitive performance, although these have not been consistent across the literature. Identified risk factors in various studies include an early age of onset, high frequency of seizures, insufficient response to the first well chosen drug, particular ictal and inter-ictal EEG characteristics and a longer duration of epilepsy (33).

In our study on the neurocognitive development of children with AE (chapter 3), the course of neurocognitive performance over time was not associated with seizure freedom, the duration of epilepsy or any specific EEG variables. Admittedly, these were explorative correlations and a larger sample size may be needed. However, these findings are in line with research on cognitive development in heterogeneous samples of children with epilepsy $(13,14)$. In a prospective cohort study of Caplan et al. verbal IQ was associated with the 
duration of epilepsy and AED treatment. Moreover, ADHD was associated with the duration of epilepsy and seizure frequency (20). A seizure duration of more than 20 seconds in drug-naïve children with AE was correlated with attentional dysfunction and errors of omission in a large randomized clinical trial on the efficacy of AED treatment in AE (34). Siren et al. concluded that the improvements in cognition were due to attaining seizure freedom. However, as the majority (10 out of 11) were seizure free, a direct relationship was difficult to proof in that study (35). Furthermore, a longer duration of generalized $3-\mathrm{Hz}$ spikewave discharges and clinical absence seizures only correlated significantly with the performance during the visual memory tasks. Two studies found a higher prevalence of learning and behavioural problems, in children with a frontal onset of generalized spike-and-wave complexes $(36,37)$. However, in our study (chapter 3) children with a similar focal or frontal onset did not seem to have a worse course of cognitive development.

In chapter 3 drug-load was not correlated with neurocognitive development and correlations with specific AED use were not possible due to insufficient power. Nevertheless, AED use may still have an effect on neurocognitive performance. For example, Ethosuximide has been associated with lower performance on simple reaction times but does not seem to affect measures on intelligence, processing speed, sustained attention, visual-motor-integration or verbal memory (38). A previous systematic review concluded that Lamotrigine is not associated with reduced cognitive function (39), but may increase attentional performance slightly. Interestingly, in chapter 3 a reliable improvement in sustained attention was noted in all children in who Lamotrigine $(n=3)$ was added after the first measurement. Despite a baseline occurrence of attentional deficits in up to one third in a large randomized clinical trial, the use of Valproate was associated with higher numbers of attentional deficits during follow-up compared to Ethosuximide or Lamotrigine (7, 9, 34, 40).

In our study on neurocognition in PS (chapter 5), AED use did not correlate with neurocognitive performance. In addition to the possible aforementioned effects of Valproate in this study, it seems that Levetiracetam does not impair cognition, whereas there is no consensus to what extent Carbamazepine or Clobazam impact cognitive performance (41-43). Topiramate has been related to cognitive 
impairments in attention, memory, and language function although only one patient was treated with Topiramate in the PS cohort $(41,42)$.

Based on our findings presented in chapter 3 cognitive performance in most cognitive domains develop at the same rate as normative samples. Cognitive deficits or symptoms related to ADHD have been observed at the time or even prior to seizure onset in children with epilepsy (44). Which may suggest that neurocognitive co-morbidities might be acquired before epilepsy onset, implying that neurodevelopment in these children may be related to alterations in the brain prior to epilepsy onset or coinciding with processes during epileptogenesis.

\section{Do alterations in myelin underlie cognitive comorbidities?}

In chapter 4 we presented a study on cerebral myelin content in children with CAE compared to healthy controls. There are indications that neurodevelopment may ultimately differ in AE. For example, a study found abnormal cortical thickness connectivity in various regions in young adults with a history of CAE (45). Insights into possible underlying mechanisms are starting to be unraveled in recent years. Studies using advanced magnetic resonance imaging (MRI) techniques in $\mathrm{AE}$ have found differences in brain regions or networks which are associated with executive function (45-53), attention (47, 50, 51, 53-55) and expressive language $(45,46,48,52,54,56,57)$. Moreover, MRI studies using diffusion measures reported lower fractional anisotropy (FA) values in the genu, an important part of the corpus callosum in the frontal lobe $(58,59)$. Nevertheless, diffusion measures in MRI are not a measure of myelin content.

In chapter 4 we showed that the frontal lobe in children with CAE was associated with a significantly lower average myelin water fraction compared to controls. Although this suggests a probable neurodevelopmental difference in children with CAE, we don't have data to speculate on the temporal evolution yet. Therefore, it is not clear whether the reduced myelin content predates the onset of $\mathrm{AE}$ or whether the difference in myelin content worsens or improves with a longer duration of follow-up. Especially since the frontal lobe is still maturing during childhood/adolescence and is thought to be important in optimizing the timing of information through neural circuits (6o). Given the involvement of the frontal lobe in attention and executive functions, this may ultimately provide insights into pathophysiological mechanisms underlying the neurocognitive co- 
morbidities in children with epilepsy. Nevertheless, in our study myelin content did not correlate significantly with neurocognitive performance. Studies in epilepsy-induced rats have shown a reduction in myelin content (61-63) and studies in focal epilepsy have shown abnormalities in white matter myelination, axonal integrity, and cellular composition $(64,65)$. Lower myelin content in the frontal lobe may be related to the frontal involvement in the generation and propagation of generalized spike-and-wave studies in children with AE, although other brain areas are also involved. However, in this study (chapter 4), we could not investigate a correlation of the myelin content with epileptiform activity due to insufficient power. The duration of epilepsy did not correlate with myelin content, but a longer follow up time may be needed to ascertain a lack of correlation. Although our study was not meant to investigate the effect of AED's on myelin content, we cannot rule out a potential modulating effect. For example, some animal studies have shown modulating abilities of valproic acid in the myelination process (66).

\section{Limitations of the thesis}

Selection criteria of the children in the presented studies were based on welldefined inclusion criteria in agreement with current ILAE recommendations. Nevertheless, these recommendations may be subject to change as knowledge progresses and epilepsy syndromes may, in fact, be a biological continuum. These studies were performed in a tertiary epilepsy centre, in which children were closely monitored regarding clinical, cognitive, and EEG aspects. Nevertheless, the proportion of children which are difficult to treat or have co-morbidities may be higher, and may not reflect the overall population. In chapter 4 , however, we recruited children with $\mathrm{CAE}$, which would otherwise not be referred to our tertiary epilepsy centre. Another limitation is the retrospective nature of chapters 3 and 5. Furthermore, assigning cognitive domains to neuropsychological tests may be oversimplified, as neuropsychological tests may require multiple cognitive functions. The Flynn effect, which is a tendency of IQ to rise by $\sim 3$ points per decade on average, may have had a bearing on our results (67). Therefore, future studies should also be carried out with updated neuropsychological tests, such as the WISC-V. False-positive findings (type 1 errors), may have occurred in this thesis due to multiple comparisons. On the other hand, false-negative findings 
(type 2 errors) may have occurred due to relatively small sample sizes. Other confounding factors, such as a change in parenting habits after diagnosis, may also affect cognitive outcomes (13). Furthermore, it cannot be excluded that the use of AEDs has had a bearing on the results, as touched upon before. However, the current studies reflect current clinical practice, and possible neurocognitive effects of AEDs should ideally be investigated in randomized clinical trials.

\section{Clinical implications}

The presence and persistence of cognitive weaknesses even after cessation of seizures are in contrast with the allegedly benign nature of these syndromes. Based on this thesis and current literature, this seems to also affect children in their academic careers and psychosocial well-being, even into adulthood. The International League Against Epilepsy (ILAE) has already begun to recognize that neurocognitive co-morbidities in benign epilepsy syndromes may have a profound impact on an individual's life and the term benign may be better replaced by "selflimited" and "pharmacoresponsive" (68). However, these terms do not envy remission without sequelae as the term benign implies. Possible persistence of neurocognitive co-morbidities and its consequences to academic achievement should also be formally recognized. Although epileptic encephalopathy is reserved for very severe epilepsy syndromes, encephalopathic effects to some extent may also occur in other epilepsy syndromes as has been proposed by Berg et al. (69). Recognizing neurocognitive co-morbidities and academic underachievement early on is important to ensure timely intervention and should, therefore, be explored at the time of diagnosis. Managing the expectations of parents and not simply dismissing the epilepsy as benign, "which they will outgrow", may prove useful when a child does not meet this ideal situation.

A broad neuropsychological test battery should be used, especially focusing on attention and executive function, as well as, other cognitive domains. Preferably, children should first be tested before anti-epileptic drugs are initiated, although multiple absence seizures might impact the reliability of the neurocognitive tests administered. To ascertain a preferable cognitive development neuropsychological testing should at least be repeated once. Supportive programs 
may differ per patient, which may be discussed in a multidisciplinary team, consisting of a neurologist, neuropsychologists and a school expert.

\section{Future perspectives}

Future studies should further explore neurocognitive development, preferably by using long-term follow-up studies with multiple measurements, focusing on neurocognition, psychosocial consequences and academic difficulties. Although sustained attention scores improved over time, other studies should seek to replicate these findings and further explore cognitive development of other types of attention. To ensure a sufficiently large sample size, such efforts should ideally be conducted in a multi-center setting or centers should commit to long-term inclusion of patients in ongoing prospective cohorts. Ideally, patients should be followed-up into adulthood. Furthermore, the use of reliably change methodologies allows for monitoring neurocognitive trajectories in individual patients, and should be used in addition to group analyses. Nevertheless, these studies are at risk of significant lost-to-follow-up as in a large proportion of children the epilepsy will remit and some do not have any apparent clinical significant impairment, although development for that child may still be suboptimal. Therefore, future studies should take great care to minimize the overall burden of participation. More research is urgently needed in patients with juvenile absence epilepsy, which overall has a worse clinical prognosis. Most research includes $\mathrm{CAE}$ with or without some children with juvenile absence epilepsy. Studies using advanced imaging techniques are needed to further explore the functional and structural alterations in the brain of children with epilepsy. Perhaps, this will someday enable us to develop new biomarkers and better understand the overlapping pathophysiology of epilepsy and neurocognitive co-morbidities. If possible this will allow us to more specifically intervene early on. 


\section{Conclusions}

Both AE and PS show neurocognitive weaknesses in a wide variety of domains, although as a group average performance mostly falls within the average range. In $\mathrm{AE}$ attentional deficits are the most pronounced cognitive weakness, but up to half show an improvement over time. On the other hand, cognitive weaknesses in other cognitive domains seem to persist. Lower myelin content in the frontal lobe of children with AE may suggest differences in the neurodevelopment of children with epilepsy. 


\section{References}

1. De Rose P, Perrino F, Lettori D, Alfieri P, Cesarini L, Battaglia D, et al. Visual and visuoperceptual function in children with Panayiotopoulos syndrome. Epilepsia. 2010;51(7):1205-11.

2. Lopes R, Simoes MR, Leal AJ. Neuropsychological abnormalities in children with the Panayiotopoulos syndrome point to parietal lobe dysfunction. Epilepsy \& behavior : E\&B. 2014;31:50-5.

3. Hodges SL, Gabriel MT, Perry MS. Neuropsychological findings associated with Panayiotopoulos syndrome in three children. Epilepsy \& behavior : E\&B. 2016;54:158-62. Bedoin N, Ciumas C, Lopez C, Redsand G, Herbillon V, Laurent A, et al. Disengagement and inhibition of visual-spatial attention are differently impaired in children with rolandic epilepsy and Panayiotopoulos syndrome. Epilepsy \& behavior : E\&B. 2012;25(1):81-91.

5. Glascher J, Tranel D, Paul LK, Rudrauf D, Rorden C, Hornaday A, et al. Lesion mapping of cognitive abilities linked to intelligence. Neuron. 2009;61(5):681-91.

6. Germanò E, Gagliano A, Magazù A, Sferro C, Calarese T, Mannarino E, et al. Benign childhood epilepsy with occipital paroxysms: Neuropsychological findings. Epilepsy research. 2005;64(3):137-50.

7. Masur D, Shinnar S, Cnaan A, Shinnar RC, Clark P, Wang J, et al. Pretreatment cognitive deficits and treatment effects on attention in childhood absence epilepsy. Neurology. 2013;81(18):1572-80.

8. Jackson DC, Jones JE, Hsu DA, Stafstrom CE, Lin JJ, Almane D, et al. Language function in childhood idiopathic epilepsy syndromes. Brain and language. 2018.

9. Cnaan A, Shinnar S, Arya R, Adamson PC, Clark PO, Dlugos D, et al. Second monotherapy in childhood absence epilepsy. Neurology. 2017;88(2):182-90.

10. Glauser TA, Cnaan A, Shinnar S, Hirtz DG, Dlugos D, Masur D, et al. Ethosuximide, valproic acid, and lamotrigine in childhood absence epilepsy: initial monotherapy outcomes at 12 months. Epilepsia. 2013;54(1):141-55.

11. Shinnar RC, Shinnar S, Cnaan A, Clark P, Dlugos D, Hirtz DG, et al. Pretreatment behavior and subsequent medication effects in childhood absence epilepsy. Neurology. 2017.

12. van Iterson L, Zijlstra BJ, Augustijn PB, van der Leij A, de Jong PF. Duration of epilepsy and cognitive development in children: a longitudinal study. Neuropsychology. 2014;28(2):212-21. Oostrom KJ, van Teeseling H, Smeets-Schouten A, Peters ACB, Jennekens-Schinkel A, DuSech. Three to four years after diagnosis: cognition and behaviour in children with 'epilepsy only'. A prospective, controlled study. Brain : a journal of neurology. 2005;128:154655 .

14. Hermann BP, Jones JE, Sheth R, Koehn M, Becker T, Fine J, et al. Growing up with epilepsy: a two-year investigation of cognitive development in children with new onset epilepsy. Epilepsia. 2008;49(11):1847-58. development in children with new onset epilepsy. Developmental medicine and child neurology. 2014;56(7):635-41.

16. Berg AT, Levy SR, Testa FM, Blumenfeld H. Long-term seizure remission in childhood absence epilepsy: might initial treatment matter? Epilepsia. 2014;55(4):551-7.

17. Covanis A, Skiadas K, Loli N, Lada C, Theodorou V. Absence epilepsy: early prognostic signs. Seizure. 1992;1(4):281-9.

18. Oostrom KJ, Smeets-Schouten A, Kruitwagen C, Peters ACB, Jennekens-Schinkel A, DuSech. Not only a matter of epilepsy: Early problems of cognition and behavior in children with "epilepsy only" - A prospective, longitudinal, controlled study starting at diagnosis. Pediatrics. 2003;112(6):1338-44.

19. Urena-Hornos T, Rubio-Rubio R, Gros-Esteban D, Cabrerizo de Diago R, Pena-Segura JL, Lopez-Pison J. [Absence epilepsy. A review of our 14 years' experience]. Revista de neurologia. 2004;39(12):1113-9.

2o. Caplan R, Siddarth P, Stahl L, Lanphier E, Vona P, Gurbani S, et al. Childhood absence epilepsy: behavioral, cognitive, and linguistic comorbidities. Epilepsia. 2008;49(11):1838-46. 
21. Kanemura H, Sano F, Ohyama T, Aoyagi K, Sugita K, Aihara M. Sequential prefrontal lobe volume changes and cognitive dysfunctions in children with Panayiotopoulos syndrome presenting with status epilepticus. Epilepsy research. 2015;112:122-9.

22. Rodenburg R, Stams GJ, Meijer AM, Aldenkamp AP, Dekovic M. Psychopathology in children with epilepsy: a meta-analysis. J Pediatr Psychol. 2005;30(6):453-68.

23. Hommet C, Billard C, Motte J, Passage GD, Perrier D, Gillet P, et al. Cognitive function in adolescents and young adults in complete remission from benign childhood epilepsy with centro-temporal spikes. Epileptic disorders : international epilepsy journal with videotape. 2001;3(4):207-16.

24. Loughman A, Bowden SC, D'Souza WJ. A comprehensive assessment of cognitive function in the common genetic generalized epilepsy syndromes. European journal of neurology : the official journal of the European Federation of Neurological Societies. 2017;24(3):453-6o.

25. Abarrategui B, Parejo-Carbonell B, Garcia Garcia ME, Di Capua D, Garcia-Morales I. The cognitive phenotype of idiopathic generalized epilepsy. Epilepsy \& behavior : E\&B. 2018;89:99-104.

26. Martinez-Ferrandez C, Martinez-Salcedo E, Casas-Fernandez C, Alarcon-Martinez H, Ibanez-Mico S, Domingo-Jimenez R. Long-term prognosis of childhood absence epilepsy. Neurologia (Barcelona, Spain). 2017.

27. Holtkamp M, Senf P, Kirschbaum A, Janz D. Psychosocial long-term outcome in juvenile myoclonic epilepsy. Epilepsia. 2014;55(11):1732-8.

28. Camfield CS, Camfield PR. Long-term social outcomes for children with epilepsy. Epilepsia. 2007;48:3-5.

29. Jafarian M, Karimzadeh F, Alipour F, Attari F, Lotfinia AA, Speckmann EJ, et al. Cognitive impairments and neuronal injury in different brain regions of a genetic rat model of absence epilepsy. Neuroscience. 2015;298:161-70.

30. Lenck-Santini PP, Scott RC. Mechanisms Responsible for Cognitive Impairment in Epilepsy. Cold Spring Harbor perspectives in medicine. 2015;5(10).

31. Nicolai J, Ebus S, Biemans DP, Arends J, Hendriksen J, Vles JS, et al. The cognitive effects of interictal epileptiform EEG discharges and short nonconvulsive epileptic seizures. Epilepsia. 2012;53(6):1051-9.

32. Aldenkamp A, Arends J. The relative influence of epileptic EEG discharges, short nonconvulsive seizures, and type of epilepsy on cognitive function. Epilepsia. 2004;45(1):5463.

33. Verrotti A, Matricardi S, Rinaldi VE, Prezioso G, Coppola G. Neuropsychological impairment in childhood absence epilepsy: Review of the literature. Journal of the neurological sciences. 2015;359(1-2):59-66.

34. Dlugos D, Shinnar S, Cnaan A, Hu F, Moshe S, Mizrahi E, et al. Pretreatment EEG in childhood absence epilepsy: associations with attention and treatment outcome. Neurology. 2013;81(2):150-6.

35. Siren A, Kylliainen A, Tenhunen M, Hirvonen K, Riita T, Koivikko M. Beneficial effects of antiepileptic medication on absence seizures and cognitive functioning in children. Epilepsy \& behavior : E\&B. 2007;11(1):85-91.

36. Jocic-Jakubi B, Jovanovic M, Jankovic DS, Lagae L. Frontal-onset absences in children: associated with worse outcome? A replication study. Seizure. 2009;18(4):275-8.

37. Lagae L, Pauwels J, Monte CP, Verhelle B, Vervisch I. Frontal absences in children. European journal of paediatric neurology : EJPN : official journal of the European Paediatric Neurology Society. 2001;5(6):243-51.

38. IJff DM, van Veenendaal TM, Debeij-van Hall MH, Jansen JF, de Louw AJ, Majoie MH, et al. The Cognitive Profile of Ethosuximide in Children. Paediatric drugs. 2016;18(5):379-85.

39. Aldenkamp AP, Baker G. A Systematic Review of the Effects of Lamotrigine on Cognitive Function and Quality of Life. Epilepsy \& behavior : E\&B. 2001;2(2):85-91.

40. Glauser TA, Cnaan A, Shinnar S, Hirtz DG, Dlugos D, Masur D, et al. Ethosuximide, valproic acid, and lamotrigine in childhood absence epilepsy. The New England journal of medicine. 2010;362(9):790-9.

41. Ijff DM, Aldenkamp AP. Cognitive side-effects of antiepileptic drugs in children. Handbook of clinical neurology. 2013;111:707-18.

42. Loring DW, Marino S, Meador KJ. Neuropsychological and behavioral effects of antiepilepsy drugs. Neuropsychology review. 2007;17(4):413-25. 
43. Eddy CM, Rickards HE, Cavanna AE. The cognitive impact of antiepileptic drugs. Therapeutic advances in neurological disorders. 2011;4(6):385-407.

44. Parisi P, Moavero R, Verrotti A, Curatolo P. Attention deficit hyperactivity disorder in children with epilepsy. Brain \& development. 2010;32(1):10-6.

45. Curwood EK, Pedersen M, Carney PW, Berg AT, Abbott DF, Jackson GD. Abnormal cortical thickness connectivity persists in childhood absence epilepsy. Annals of clinical and translational neurology. 2015;2(5):456-64.

46. Bai X, Guo J, Killory B, Vestal M, Berman R, Negishi M, et al. Resting functional connectivity between the hemispheres in childhood absence epilepsy. Neurology. 2011;76(23):1960-7.

47. Berman R, Negishi M, Vestal M, Spann M, Chung MH, Bai X, et al. Simultaneous EEG, fMRI, and behavior in typical childhood absence seizures. Epilepsia. 2010;51(10):2011-22.

48. Caplan R, Levitt J, Siddarth P, Wu KN, Gurbani S, Sankar R, et al. Frontal and temporal volumes in Childhood Absence Epilepsy. Epilepsia. 2009;50(11):2466-72.

49. Carney PW, Masterton RA, Flanagan D, Berkovic SF, Jackson GD. The frontal lobe in absence epilepsy: EEG-fMRI findings. Neurology. 2012;78(15):1157-65.

50. Li Q, Cao W, Liao X, Chen Z, Yang T, Gong Q, et al. Altered resting state functional network connectivity in children absence epilepsy. Journal of the neurological sciences. 2015;354(12):79-85.

51. Luo C, Yang T, Tu S, Deng J, Liu D, Li Q, et al. Altered intrinsic functional connectivity of the salience network in childhood absence epilepsy. Journal of the neurological sciences. 2014;339(1-2):189-95.

52. Tosun D, Siddarth P, Toga AW, Hermann B, Caplan R. Effects of childhood absence epilepsy on associations between regional cortical morphometry and aging and cognitive abilities. Human brain mapping. 2011;32(4):580-91.

53. Zhang Z, Liao W, Wang Z, Xu Q, Yang F, Mantini D, et al. Epileptic discharges specifically affect intrinsic connectivity networks during absence seizures. Journal of the neurological sciences. 2014;336(1-2):138-45.

54. Luo C, Li Q, Lai Y, Xia Y, Qin Y, Liao W, et al. Altered functional connectivity in default mode network in absence epilepsy: a resting-state fMRI study. Human brain mapping. 2011;32(3):438-49.

55. Killory BD, Bai X, Negishi M, Vega C, Spann MN, Vestal M, et al. Impaired attention and network connectivity in childhood absence epilepsy. NeuroImage. 2011;56(4):2209-17.

56. Holmes MD, Brown M, Tucker DM. Are "generalized" seizures truly generalized? Evidence of localized mesial frontal and frontopolar discharges in absence. Epilepsia. 2004;45(12):156879 .

57. Tucker DM, Brown M, Luu P, Holmes MD. Discharges in ventromedial frontal cortex during absence spells. Epilepsy \& Behavior. 2007;11(4):546-57.

58. Liang JS, Lee SP, Pulli B, Chen JW, Kao SC, Tsang YM, et al. Microstructural Changes in Absence Seizure Children: A Diffusion Tensor Magnetic Resonance Imaging Study. Pediatrics and neonatology. 2016;57(4):318-25.

59. Correa DG, Ventura N, Zimmermann N, Doring TM, Tukamoto G, Leme J, et al. Evaluation of deep gray matter volume, cortical thickness and white matter integrity in patients with typical absence epilepsy: a study using voxelwise-based techniques. Neuroradiology. 2017;59(3):237-45.

6o. Fields RD. A new mechanism of nervous system plasticity: activity-dependent myelination. Nature reviews Neuroscience. 2015;16(12):756-67.

61. Luo Y, Hu Q, Zhang Q, Hong S, Tang X, Cheng L, et al. Alterations in hippocampal myelin and oligodendrocyte precursor cells during epileptogenesis. Brain research. 2015;1627:154-64.

62. You Y, Bai H, Wang C, Chen LW, Liu B, Zhang H, et al. Myelin damage of hippocampus and cerebral cortex in rat pentylenetetrazol model. Brain research. 2011;1381:208-16.

63. Ye Y, Xiong J, Hu J, Kong M, Cheng L, Chen H, et al. Altered hippocampal myelinated fiber integrity in a lithium-pilocarpine model of temporal lobe epilepsy: a histopathological and stereological investigation. Brain research. 2013;1522:76-87.

64. Hu X, Wang JY, Gu R, Qu H, Li M, Chen L, et al. The relationship between the occurrence of intractable epilepsy with glial cells and myelin sheath - an experimental study. European review for medical and pharmacological sciences. 2016;20(21):4516-24.

65. Deleo F, Thom M, Concha L, Bernasconi A, Bernhardt BC, Bernasconi N. Histological and MRI markers of white matter damage in focal epilepsy. Epilepsy research. 2018;140:29-38. 


\section{Chapter 6}

66. Rosenzweig I, Vukadinovic Z, Turner AJ, Catani M. Neuroconnectivity and valproic acid: the myelin hypothesis. Neuroscience and biobehavioral reviews. 2012;36(8):1848-56.

67. Trahan LH, Stuebing KK, Fletcher JM, Hiscock M. The Flynn effect: a meta-analysis. Psychological bulletin. 2014;140(5):1332-60.

68. Scheffer IE, Berkovic S, Capovilla G, Connolly MB, French J, Guilhoto L, et al. ILAE classification of the epilepsies: Position paper of the ILAE Commission for Classification and Terminology. Epilepsia. 2017:58(4):512-21.

69. Berg AT. Epilepsy, cognition, and behavior: The clinical picture. Epilepsia. 2011;52 Suppl 1:712 . 
General discussion 


$$
5
$$


Summary 
Chapter 7 


\section{Summary}

\section{Chapter 1}

Childhood epilepsy has long been associated with neurocognitive co-morbidities. This is reflected by a relatively high prevalence of cognitive deficits, educational underachievement and behavioral problems in children with epilepsy. The intricate relationship between epilepsy and neurocognitive co-morbidities is not fully understood and probably is multifactorial. More subtle neurodevelopmental and neurocognitive co-morbidities in benign epilepsy syndromes, such as childhood absence epilepsy (CAE) and Panayiotopoulos syndrome (PS), are far less researched.

General aim - The aim of this thesis was to investigate neurocognitive development in AE or PS, by studying cognitive abilities and development over time, and exploring potential associated factors. From a neurodevelopment perspective, the myelin content in the brain of children with childhood AE will be assessed.

\section{Chapter 2}

A systematic review and meta-analysis was conducted on studies reporting on cognitive performance in children with absence epilepsy (CAE and JAE). Based on this review attentional deficits seem the most pronounced cognitive weakness in CAE. Furthermore, significant lower average scores were found for intelligence indices and tests on executive function. Less conclusive results were found for (expressive) language, motor function, visuoperceptual functioning, and learning \& memory. Despite observations of statistically lower cognitive performance compared to normative data, average scores mostly fall well within the normal clinical range.

\section{Chapter 3}

A retrospective longitudinal study was conducted focusing on cognitive development using two consecutive cognitive measurements in children with AE (CAE \& JAE). Changes in cognitive performance per test were investigated on a 
group and on an individual level. Reliable change methodology was used to determine a significant change in performance in an individual. Lower performance was noted for sustained attention, performance IQ, perceptual organization, processing speed, simple reaction times, and visual-motorintegration. Performance in sustained attention improved significantly on a group level, as well as in half of the individuals. Cognitive weaknesses in other cognitive domains persisted regardless of seizure freedom, although on an individual basis some children showed an improvement while others showed a decline in performance. A high prevalence of academic underachievement and learning affecting co-morbidities were also noted.

\section{Chapter 4}

A neuroimaging study focusing on cerebral myelin was conducted in children with CAE. This was part of an ongoing prospective longitudinal cohort study on brain development and neurocognitive development in children with CAE. In this study, cerebral myelin in children with CAE was compared to controls by using a novel imaging technique in epilepsy research which is myelin-water-fraction imaging. It was found that the average myelin water fraction in the frontal lobe in children with CAE was significantly lower compared to matched healthy controls. However, we could not show a significant correlation between a lower myelin water fraction and cognitive performance.

\section{Chapter 5}

A retrospective cohort study was conducted on the neurocognitive and behavioral profile of children with a PS. Significantly lower performance was noted in fullscale IQ, performance IQ, attention, visual-motor-integration, and verbal memory. Our data may point towards weaknesses in visual demanding tasks, such as visual selective attention, visual sustained attention, visual alertness, visualmotor-integration and visually demanding subtests of the WISC-III. Nevertheless, lower performance was also observed for auditory reaction times and verbal memory. Auditory sustained attention did not differ compared to normative values. Furthermore, a high prevalence of internalizing behavioral problems in children with PS was also reported and in particular, withdrawn/depression, thought problems, attention, and somatic complaints were reported by parents, with similar trends reported by teachers. 


\section{Chapter 6}

The results presented in this thesis are in contrast with the allegedly benign nature of these syndromes and implies differences in neurodevelopment and neurocognitive development. Cognitive weaknesses were observed in multiple cognitive domains in AE and a PS. Cognitive development of children with AE showed improvement in sustained attention regardless of seizure freedom, although other cognitive weaknesses persisted. CAE was characterized by a lower frontal myelin content, although we were not able to show a significant relation with cognitive measures. 


$$
5
$$


Nederlandse samenvatting 
Chapter 8 


\section{Nederlandse samenvatting}

\section{Hoofdstuk 1}

Epilepsie bij kinderen wordt al enige tijd in verband gebracht met neurocognitieve comorbiditeiten. Dit uit zich door het relatief vaak voorkomen van cognitieve deficiënties, problemen op school en gedragsmatige problemen bij kinderen met epilepsie $(6,39)$. De relatie tussen epilepsie en neurocognitieve comorbiditeiten is op zijn minst ingewikkeld te noemen en wordt gezien het multifactorieel karakter nog niet volledig begrepen. Er is nog altijd onduidelijkheid over de mate van neurocognitieve comorbiditeiten en de mogelijke subtiele veranderingen in het brein bij de zogenaamde goedaardige epilepsiesyndromen. Deze thesis beperkt zich tot onderzoek naar absence epilepsie (AE) en het Panayiotopoulos syndroom (PS) bij kinderen.

Hoofddoel - Het doel van dit proefschrift was om de neurocognitieve ontwikkeling bij kinderen met een AE of PS te onderzoeken. Getracht werd de cognitieve vaardigheden en de ontwikkeling hiervan in de tijd te bestuderen, en exploratief op zoek te gaan naar hieraan gerelateerde parameters. Daarnaast werd de neurologische ontwikkeling onderzocht door te kijken naar het myelinegehalte in de hersenen bij kinderen met een AE op de kinderleeftijd.

\section{Hoofdstuk 2}

Een systematische review en meta-analyse werd uitgevoerd naar studies die rapporteerden over het cognitief functioneren van kinderen met een AE. Aandachts-problemen lijken op basis hiervan het meest uitgesproken. Verder werden significant lagere gemiddelde scores gevonden voor intelligentie parameters en tests die kijken naar executieve functies. Minder eenduidig waren de studies die rapporteerden over (expressieve)taal vaardigheden, motorische functies, visuoperceptueel functioneren en leren \& geheugen. Wel moet hieraan toegevoegd worden dat de gemiddelde scores veelal binnen het normale klinisch bereik vielen. 


\section{Hoofdstuk 3}

Een retrospectief longitudinaal onderzoek werd uitgevoerd dat zich richtte op de cognitieve ontwikkeling bij AE op de kinderleeftijd. Er werd gebruikt gemaakt van twee opeenvolgende metingen. Veranderingen in de cognitieve prestaties per test werden onderzocht op groeps- en op individueel niveau. De reliable change methodiek werd gebruikt om na te gaan of een verandering van een individu in prestatie op een bepaalde test betrouwbaar geacht kan worden. Lagere prestaties werden gevonden voor volgehouden aandacht, performaal IQ, perceptuele organisatie, verwerkingssnelheid, eenvoudige reactietijden en visuele-motorintegratie. Prestaties op volgehouden aandacht verbeterden op groepsniveau, evenals bij de helft van de individuen. Lagere prestaties in andere cognitieve domeinen bleven bestaan, ongeacht of er sprake was van aanvalsvrijheid. Er was ook sprake van een hoge prevalentie van schoolproblemen en relatief veel comorbiditeiten die het leren negatief zouden kunnen beïnvloeden.

\section{Hoofdstuk 4}

Een MRI studie gericht op het bepalen van het myeline-gehalte in het brein werd uitgevoerd bij kinderen met een AE op de kinderleeftijd. Dit maakt deel uit van een prospectieve longitudinale cohortstudie naar de hersenontwikkeling en de neurocognitieve ontwikkeling bij kinderen met een AE op de kinderleeftijd. In deze studie werd de myeline-water-fractie vergeleken met een gezonde controlegroep. Hieruit bleek dat het gemiddelde myeline-gehalte in de frontaal kwab bij AE op de kinderleeftijd lager was dan bij de controles. We konden echter geen significante correlatie aantonen tussen een lagere myeline-gehalte en cognitieve prestaties.

\section{Hoofdstuk 5}

Een retrospectief cohortonderzoek werd uitgevoerd naar het cognitief profiel en gedragsproblemen van kinderen met een PS. Significant lagere gemiddelde prestaties werden opgemerkt voor totaal IQ, performaal IQ, aandacht, visuelemotor-integratie en verbaal geheugen. Onze gegevens kunnen wijzen op zwakke punten in visueel veeleisende cognitieve taken, zoals visueel selectieve aandacht, visueel volgehouden aandacht, visuele alertheid, visuele-motor-integratie en visueel veeleisende subtests van de WISC-III. Desalniettemin waren de prestaties 
ook significant lager voor auditieve reactietijden en verbaal geheugen. Auditief volgehouden aandacht was niet verschillend in vergelijking met de normatieve gemiddelden. Verder werd er een hoge prevalentie van internaliserende gedragsproblemen bij kinderen met PS gemeld door ouders en vergelijkbare trends werden opgemerkt door leraren.

\section{Hoofdstuk 6}

De resultaten in dit proefschrift zijn niet in overeenstemming met het vermeende goedaardige karakter van deze epilepsie syndromen en impliceren dat er wel degelijk een impact is op de neurologische en neurocognitieve ontwikkeling. Verschillende cognitieve domeinen lijken aangedaan in AE en PS. Prestaties op volgehouden aandacht verbeterden bij AE op de kinderleeftijd, ongeacht de aanwezigheid van aanvalsvrijheid. De gemiddeld lagere prestaties op andere cognitieve domeinen hielden echter aan. De hersenontwikkeling van kinderen met een AE op de kinderleeftijd lijkt te verschillen, gezien we een lager myelinegehalte vonden in de frontaal kwab. Een relatie met het cognitief functioneren kon niet worden aangetoond. 


$$
5
$$




\section{Valorisation}


Chapter 9 


\section{Valorisation addendum}

The aim of clinical research is to ultimately improve patient care. Research questions often arise from health care itself. Physicians hope that these patients will benefit the most from new research findings. Nevertheless, clinical research does also benefit others in society. This valorisation addendum will discuss ways to capitalize on the scientific knowledge discussed in this thesis.

Valorisation as defined by the The National Valorisation Committee:

"the process of creating value from knowledge, by making knowledge suitable and/or available for social and/or economic use and by making knowledge suitable for translation into competitive products, services, processes and new activities" (Waardevol - Indicatoren voor Valorisatie 2011(1))

\section{Relevance}

Epilepsy affects about 41-187/100.0oo children per year (2). Being diagnosed with epilepsy is accompanied by many uncertainties, such as, seizure reoccurrence, treatment success and possible therapeutic side effects. In addition, psychosocial and socio-economic factors also play a role. For example, fears regarding the unpredictability of seizures, developing a low self-esteem, the need for special education and problems in family adjustment. Furthermore, in some children, the question arises whether possible effects on cognition and/or behavior may impact academic achievement as cognitive deficits, educational underachievement and behavioral problems are more common among some patients with epilepsy $(3,4)$.

To be able to improve care in patients with epilepsy it is necessary to better understand cognitive abilities and brain development in patients with epilepsy. This thesis focused on two epilepsy syndromes, namely absence epilepsy and Panayiotopoulos syndrome.

\section{Findings}

Neurodevelopment and neurocognitive co-morbidities in allegedly benign epilepsy syndromes, such as absence epilepsy and Panayiotopoulos syndrome, are 
far less researched, but may have an impact on academic, behavioral and overall development. In this thesis we have shown that both AE and PS show neurocognitive weaknesses in a wide variety of domains, although as a group average performance mostly falls within the average range. In $\mathrm{AE}$, attentional deficits are the most pronounced cognitive weakness, but up to half show an improvement over time. On the other hand, cognitive weaknesses in other cognitive domains seem to persist. A lower myelin content in the frontal lobe of children with AE may suggest differences in the neurodevelopment of children with epilepsy. This thesis, contributes to the knowledge on the neurocognitive aspects of epilepsy, which is helpful to improve counseling and treatment strategies.

\section{Target groups}

The results of this thesis are relevant for people involved in the care of children with absence epilepsy or Panayiotopoulos syndrome such as, (child)neurologists, epileptologist, (neuro)psychologists, paediatricians, and general practitioners. Awareness of cognitive problems in children with epilepsy enables health care professionals to watch out for a possible neurocognitive co-morbidity or academic underachievement, so that children can be referred as soon as possible. For neuropsychologists, knowledge on the cognitive functions most likely affected is valuable to be able to perform the necessary neuropsychological tests. Furthermore, this thesis may be relevant to those involved in the academic careers of these children, such as teachers, orthopedagogues or people providing special education for children with epilepsy In the Netherlands educational counsellors of the LWOE (Landelijk Werkverband Onderwijs en Epilepsy) are involved in the guidance of children with epilepsy and their teachers to optimize school achievements.

Next, our findings are useful for people involved in epilepsy research, such as people writing on consensus articles, such as guidelines for epilepsy syndrome classification. The research described in this thesis contradicts that absence epilepsy and Panayiotopoulos syndrome are benign epilepsy syndromes at least partly due to the neurocognitive co-morbidity as discussed throughout this thesis. It has led to a better understanding of the neurocognitive development of 
children with absence epilepsy and Panayiotopoulos syndrome. As discussed in chapter 6, the International League Against Epilepsy (ILAE) has proposed to replace the term benign by "self-limited" and "pharmacoresponsive" (5). However, the impact on cognitive performance and possible consequences on academic achievement should also be formally recognized.

It may be useful for institutions involved in funding scientific research. Additionally, it may help policy makers and health insurances to justify funds for adequate neuropsychological follow-up and academic support programs (such as the LWOE). Parents and patients with absence epilepsy or Panayiotopoulos syndrome may want to know to what extent it may have an impact on cognitive performance. For parents, it is important to not simply dismiss absence epilepsy and Panayiotopoulos as a benign epilepsy type "which they will outgrow", as this may lead to false expectations in at least a proportion of children.

\section{Knowlegde translation}

A prerequisite for the implementation of new scientific knowledge is communicating this knowledge to the scientific community and making it available for the public. Therefore, the chapters in this thesis were published in international peer-reviewed journals. Furthermore, the results were discussed during (poster)presentations and at (inter)national symposia (such as a yearly international symposium at epilepsy centre Kempenhaeghe). Moreover, a case presentation and discussion was published in a Dutch journal (Epilepsie Periodiek voor professionals). In addition, we have given participating children and parents information on the results of the study.

\section{Implementation and future work}

Although the used methods and neuropsychological tests are not routine care for every child with absence epilepsy or Panayiotopoulos syndrome, and a costeffectivness study has not been performed, it does provide necessary insight for further development of follow-up protocols. Therefore, our findings can be used 
to improve clinical practice and neuropsychological follow-up in these children. Other clinical implications have been discussed in chapter 6 .

This thesis may inspire new research and businesses (for example involved in the development of neuropsychological tools) to develop new diagnostic measures and treatments specifically made for children with epilepsy. Myelin imaging may be a used as a prognostic tool in the follow-up of children with epilepsy. As myelin imaging is a very novel imaging technique in epilepsy research, our methodology and findings warrant further imaging studies focusing on myelin and epilepsy. Nevertheless, it is still too early to predict the relevance of these findings on a larger scale such as how this will improve the care of children with epilepsy. In the future, more research on myelinisation patterns of children with epilepsy is needed to explore how this relates to neurodevelopmental problems and if this may be a core pathophysiological process to which treatment could be developed. More recommendations for future research are described in chapter 6 . 


\section{References}

1. Van Drooge L, Vandeberg R, Zuijdam F, Mostert B, van der Meulen B, Bruins E. WaardevolIndicatoren voor Valorisatie. Rathenau Instituut. 2011.

2. Camfield P, Camfield C. Incidence, prevalence and aetiology of seizures and epilepsy in children. Epileptic disorders : international epilepsy journal with videotape. 2015;17(2):117-23.

3. Berg AT. Epilepsy, cognition, and behavior: The clinical picture. Epilepsia. 2011;52 Suppl 1:712.

4. Fastenau PS, Jianzhao S, Dunn DW, Austin JK. Academic underachievement among children with epilepsy: proportion exceeding psychometric criteria for learning disability and associated risk factors. Journal of learning disabilities. 2008;41(3):195-207.

5. Scheffer IE, Berkovic S, Capovilla G, Connolly MB, French J, Guilhoto L, et al. ILAE classification of the epilepsies: Position paper of the ILAE Commission for Classification and Terminology. Epilepsia. 2017;58(4):512-21. 


$$
5
$$


Dankwoord 


\section{Dankwoord}

Met veel dankbaarheid denk ik terug aan...

alle begeleiding die ik heb mogen ontvangen van mijn promotieteam. Zonder jullie toewijding en sturing was dit proefschrift niet tot stand gekomen.

hen die aan de wieg stonden van dit proefschrift, de kansen in mij zagen, en de middelen hebben gevonden, om dit promotietraject op te zetten.

diegene die mij inspireerden en kennis hebben laten maken met de wetenschap.

de beoordelingscommissie voor het toetsen van dit proefschrift.

mijn technische tweeling, voor alle brainstorm sessies, uren bij de scanner, MRIanalyses en de gezellige tijd.

mijn paranimfen, voor de goede vrienden die jullie zijn, de steun die ik aan jullie heb, de gedeelde interesses op wetenschappelijk vlak en in het leven daarnaast.

die enthousiaste student, die op een secure wijze veel werk verzet heeft.

alle co-auteurs van de hoofdstukken voor hun bijdrage en kritische blik.

de twee MRI-laboranten, voor alle verrichte MRI-scans en jullie hulp om alle kinderen zo goed mogelijk de MRI-scanner in te krijgen.

die radioloog die de klinische beoordeling deed van de MRI-beelden.

alle neurologen, neuropsychologen, schooldeskundigen en verpleegkundigen in Kempenhaeghe, of andere betrokkenen in de zorg van de deelnemende kinderen.

alle deelnemende kinderen voor hun enthousiasme en het stil liggen in de scanner.

alle ouders en verwijzers voor hun bereidheid om bij te dragen aan de LEES-studie 
iedereen die het PhD leven zo gezellig maakte op de onderzoekskamer, tijdens de lunch, tijdens de weekendjes, de vele activiteiten en andere mooie momenten die we als collega's hebben gedeeld.

die dierbare vrienden, die ik reeds sinds het begin van de studie geneeskunde ken, en sommige langer, bij wie ik altijd terecht kan en met wie ik nog steeds mooie momenten meemaak.

diegenen die mij vergezeld hebben op de wielrenfiets, waardoor ik weer met een leeg hoofd aan het proefschrift kon werken.

mijn huisarts-opleider voor de zorgzame begeleiding, het vertrouwen in mij en de vrijheid die je me biedt om te groeien binnen het huisartsenvak.

mijn familie en schoonfamilie voor de hechte familieband en gezelligheid.

mijn zusje, want ondanks dat een typische broer-zus rivaliteit ons niet bespaard is gebleven, en je nu in Japan woont, denk ik met veel blijdschap terug aan onze jeugd samen. Je kunt altijd op mij rekenen.

mijn ouders, dat jullie altijd in mij en in mijn keuzes geloofd hebben, voor de vele dingen die ik van jullie geleerd heb, en voor alle liefde en warmte die ik altijd van jullie ontvangen heb.

mijn lieve vriendin, Zsa Zsa, mijn allergrootste steun en toeverlaat, voor alles waarin je mij hebt bijgestaan in deze periode, dat je mijn leven elke dag weer een stukje mooier maakt en voor al je liefde.

en eenieder die op een of andere wijze een bijdrage heeft geleverd aan dit proefschrift, mijn ontwikkeling als medisch professional en als mens. 
Dank jullie wel: $\quad$ Mariette Debeij-van Hall

Sylvia Klinkenberg

Jos Hendriksen

Jeroen Vermeulen

Hans Vles

Bert Aldenkamp

Robert van Oostenbrugge

Gerald Drenthen

Jaap Janssen

Walter Backes

Sveta Zinger

Paul Hofman

Twan Voncken

Sander van Kuijk

Saskia Ebus

Eline de Jong

Jochem Kessels

Marjolein van Dijk

Irene Gijselhart

Remco Berting

Henri Saes

Bram van den Borst

Annemie Schols

Erik Biessen

Bianca de Greef

Mariëlle Pruppers

Renske Uiterwijk

Maurice Sopacua

Sjors van de Weijer

Amir Far

Danielle Kerkhofs
Eefje Cleophas

Eleana Zhang

Isis Joosten

Irene Moll

Ellen van Overbeek

Danique Hellebrekers

Judith Lionarons

Fred Schaper

Tugba Kaley

Robert-Jan Goldhoorn

Wouter Hinsenveld

Anne-France Pirson

Bernard Duvivier

Ruud Verhees

Andreas Aerts

Wim Duhayon

Tom Hermans

Gregory van der Kroft

Fredi Plum

Frederik Vanstraelen

Ivo Eijkenboom

Roel van Rie

Etienne Marell

Maud Sluysmans

Marianne en Jos

Cor en Marieke

Schoonfamilie

Carolina

Elsie en Leonardo

Familie

Zsa Zsa 


$$
5
$$


Curriculum Vitae 


\section{Curriculum Vitae}

Eric was born in Bogotá, Colombia on the $15^{\text {th }}$ of January in 1989 . He attended secondary school at the Sintermeerten college in Heerlen and graduated in 2007. He studied Medicine at Maastricht University where he graduated in 2013. Moreover, he followed the Honours programme 'Scientific Research'.

He conducted his master thesis at the department of Respiratory Medicine at the Maastricht University Medical Centre+, which resulted in a systematic review on nutrition and COPD. In 2010 he was president of the Maastricht Medical Student Research Conference (currently named MOSA conference).

As a medical doctor he has worked at the Internal \& Gastroenterology department at the Viecuri Medical Centre in Venlo and at the Neurology department at the Zuyderland Medical Centre in Sittard.

In 2015 Eric started his $\mathrm{PhD}$ at the Academic Centre for Epileptology (ACE), a collaboration between Maastricht University Medical Centre+ and Kempenhaeghe. During his $\mathrm{PhD}$, Eric has won the clinical scientific poster prize at the Kempenhaeghe Conference in 2017. Moreover, he and his research group have been awarded a grant from Stichting 'Vooruit' for research on Absence Epilepsy.

Currently, Eric is a general practitioner trainee at Maastricht University

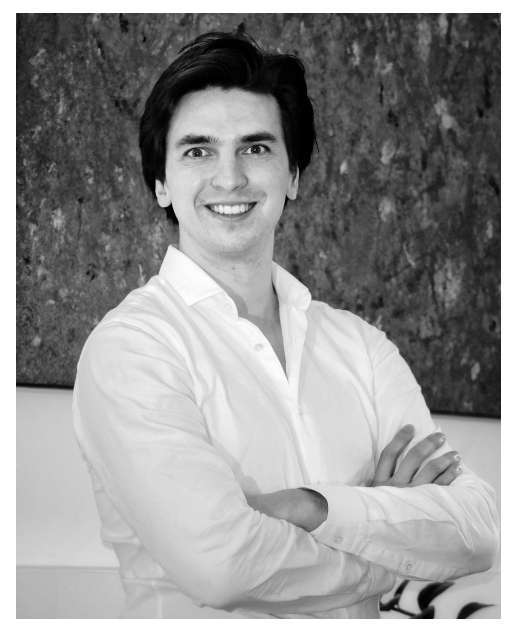




$$
5
$$




\section{List of publications}




\section{List of publications}

\section{This thesis}

Fonseca Wald ELA, Hendriksen JGM, Drenthen GS, v. Kuijk SMJ, Aldenkamp AP, Vles JSH, Vermeulen RJ, Debeij-van Hall MHJA, Klinkenberg S. Towards a better understanding of cognitive deficits in absence epilepsy: a systematic review and meta-analysis. Neuropsychology Review. 2019,29(4):421-499

Fonseca Wald ELA, Klinkenberg S, Voncken TPC, Ebus SCM, Aldenkamp AP, Vles JSH, Vermeulen RJ, Hendriksen JGM*, Debeij-van Hall MHJA*. Cognitive development in absence epilepsy during long-term follow-up. Child neuropsychology. 2019:1-19.

Fonseca Wald ELA*, Drenthen GS*, Backes WH, Debeij-van Hall MHJA, Hendriksen JGM, Aldenkamp AP, Vermeulen RJ, Klinkenberg S, Jansen JFA. Childhood absence epilepsy is characterized by lower frontal myelin-water content. Epilepsia. 2019, 6o(8):1689-1696.

Fonseca Wald ELA, Debeij-van Hall MHJA, de Jong E, Aldenkamp AP, Vermeulen RJ, Johan S.H. Vles, Klinkenberg $S^{*}$, Hendriksen JGM*. Neurocognitive and behavioral profile in Panayiotopoulos Syndrome. Developmental Medicine \& Child Neurology. 2019.

\section{Others}

Fonseca Wald ELA, Klinkenberg S, Vermeulen RJ, Hendriksen JGM, Debeij-van Hall MHJA. Casus: cognitieve problematiek bij kinderen met absence epilepsie. Epilepsie: Periodiek voor professionals. 2017. jaargang 15, nummer 4 
Drenthen GS, Walter H. Backes, Fonseca Wald ELA, Aldenkamp AP, Veremeulen RJ, Debeij-van Hall MHJA, Klinkenberg S. Constructing an axonal-specific myelin developmental atlas and its application to childhood absence epilepsy. Submitted

Drenthen GS*, Fasen $F^{*}$, Fonseca Wald ELA, Backes WH, Aldenkamp AP, Vermeulen RJ, Debeij-van Hall MHJA, Hendriksen JGM, Klinkenberg S, Jansen JFA. Functional brain integrity is related to epilepsy duration in childhood absence epilepsy. Submitted

Fonseca Wald ELA, van den Borst B, Gosker HR, Schols AMWJ. Dietary fiber and fatty acids in COPD risk and progression: a systematic review. Respirology 2014;19(2):176-84.

* Both authors contributed equally 
